\title{
Triapine Analogues and Their Copper(II) Complexes: Synthesis, Characterization, Solution Speciation, Redox Activity, Cytotoxicity, and $\mathrm{mR2}$ RNR Inhibition
}

Iuliana Besleaga, Iryna Stepanenko, Tatsiana V. Petrasheuskaya, Denisa Darvasiova, Martin Breza,
Marta Hammerstad, Małgorzata A. Marć, Alexander Prado-Roller, Gabriella Spengler,
Ana Popović-Bijelić, Eva A. Enyedy,* Peter Rapta,* Anatoly D. Shutalev, ${ }^{*}$ and Vladimir B. Arion*

Cite This: https://doi.org/10.1021/acs.inorgchem.1c01275

ABSTRACT: Three new thiosemicarbazones (TSCs) $\mathbf{H L}^{1}-\mathbf{H L}^{3}$ as triapine analogues bearing a redox-active phenolic moiety at the terminal nitrogen atom were prepared. Reactions of $\mathbf{H L}^{1}-\mathbf{H L}^{3}$ with $\mathrm{CuCl}_{2} \cdot 2 \mathrm{H}_{2} \mathrm{O}$ in anoxic methanol afforded three copper(II) complexes, namely, $\mathbf{C u}\left(\mathbf{H L}^{1}\right) \mathbf{C l}_{2}(\mathbf{1}),\left[\mathbf{C u}\left(\mathbf{L}^{2}\right) \mathbf{C l}\right]\left(\mathbf{2}^{\prime}\right)$, and $\mathbf{C u}\left(\mathrm{HL}^{3}\right) \mathbf{C l}_{2}$ (3), in good yields. Solution speciation studies revealed that the metal-free ligands are stable as $\mathbf{H L}^{1}-\mathbf{H L}^{3}$ at $\mathrm{pH}$ 7.4 , while being air-sensitive in the basic $\mathrm{pH}$ range. In dimethyl sulfoxide they exist as a mixture of $E$ and $Z$ isomers. A mechanism of the $E / Z$ isomerization with an inversion at the nitrogen atom of the Schiff base imine bond is proposed. The monocationic complexes $\left[\mathbf{C u}\left(\mathbf{L}^{1-3}\right)\right]^{+}$are the most abundant species in aqueous solutions at $\mathrm{pH}$ 7.4. Electrochemical and spectroelectrochemical

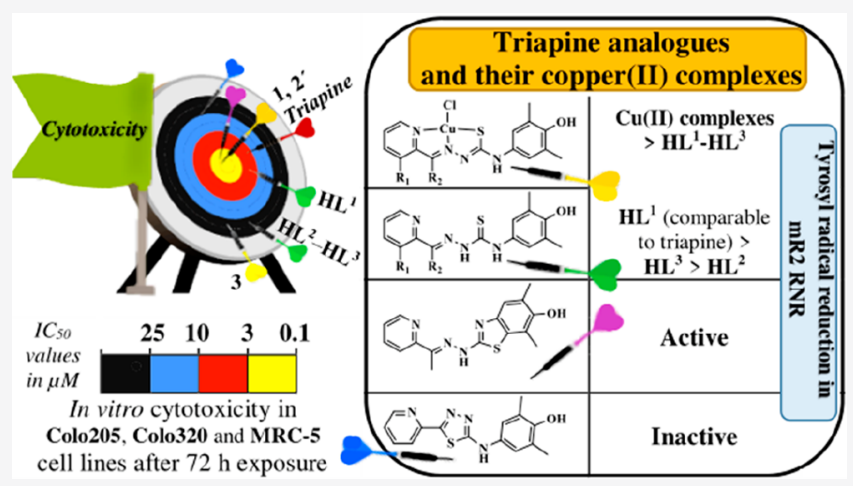
studies of $1, \mathbf{2}^{\prime}$, and 3 confirmed their redox activity in both the cathodic and the anodic region of potentials. The one-electron reduction was identified as metal-centered by electron paramagnetic resonance spectroelectrochemistry. An electrochemical oxidation pointed out the ligand-centered oxidation, while chemical oxidations of $\mathbf{H L}^{\mathbf{1}}$ and $\mathbf{H L}^{2}$ as well as $\mathbf{1}$ and $\mathbf{2}^{\prime}$ afforded several two-electron and four-electron oxidation products, which were isolated and comprehensively characterized. Complexes $\mathbf{1}$ and $\mathbf{2}^{\prime}$ showed an antiproliferative activity in Colo205 and Colo320 cancer cell lines with half-maximal inhibitory concentration values in the low micromolar concentration range, while 3 with the most closely related ligand to triapine displayed the best selectivity for cancer cells versus normal fibroblast cells (MRC-5). HL $^{1}$ and 1 in the presence of 1,4-dithiothreitol are as potent inhibitors of mR2 ribonucleotide reductase as triapine.

\section{INTRODUCTION}

Thiosemicarbazones (TSCs) are known as biologically active compounds with a broad spectrum of pharmacological properties, including anticancer activity. ${ }^{1-4}$ These properties can be modulated by coordination to physiologically relevant metal ions. 5,6 In addition, as versatile ligands, TSCs have tunable electronic and steric properties, which may have a favorable effect on their pharmacological profile. ${ }^{7-10} \alpha-\mathrm{N}$ Heterocyclic TSCs such as 2-formylpyridine TSC (FTSC) and 5-hydroxy-2-formylpyridine TSC were reported to possess anticancer activity several decades ago, ${ }^{1,12}$ and further optimization resulted in the most well-known TSC, 3aminopyridine-2-carboxaldehyde TSC (triapine). Triapine was tested in more than 30 clinical phase I and II trials and currently is involved in a triapine-cisplatin-radiation combination therapy in phase III trial. ${ }^{13}$ Because of the documented side effects (e.g., methemoglobinemia) of triapine and its unfavorable pharmacokinetic profile (e.g., short plasma half- life), ${ }^{14}$ the development of novel TSCs with improved pharmaceutical properties and an established mechanism of action is of high research interest. Notably, two other TSCs, namely, di-2-pyridylketone 4-cyclohexyl-4-methyl-3-thiosemicarbazone $(\mathrm{DpC})$ and 4-(2-pyridinyl)-2-(6,7-dihydro-8 $(5 H)$ quinolinylidene)-hydrazide (COTI-2), are currently undergoing a phase I evaluation as chemotherapeutic agents. ${ }^{8,15}$

The iron-containing ribonucleotide reductase (RNR) is considered as one of the main targets for triapine and related $\alpha$-N-pyridinecarboxaldehyde TSCs. ${ }^{16-19}$ This enzyme catalyzes the reduction of ribonucleotides to deoxyribonucleotides,

Received: April 26, 2021 
and it is particularly important in rapidly dividing cells, such as tumor cells, virally infected cells, and invading bacteria. All these cells share similar properties, such as high proliferation rates, quickly spreading within the host, and aggressive disease progression. ${ }^{20} \mathrm{~A}$ sustained proliferation requires an increased de novo nucleotide synthesis for DNA replication, making RNR targeting a relevant strategy in the treatment of cancer. $^{21,22}$ RNRs are free radical-containing proteins. One way to control and modulate their reactivity is via quenching the catalytically essential tyrosyl radical Y. located in the small RNR subunit (R2 or $\mathrm{NrdB}){ }^{23,24}$ The radical scavengers and iron-chelating ligands, which are able to destroy the diferrictyrosyl radical cofactor, with the aim to inhibit R2 RNR, are widely investigated in anticancer research. ${ }^{25}$ In the case of triapine, it has been suggested that the intracellularly formed, highly potent, redox-active iron complex either leads to reactive oxygen species (ROS) formation, which are then responsible for tyrosyl radical quenching, or that the iron(II) complex itself is able to directly reduce the tyrosyl radical. ${ }^{16}$ Besides triapine, several other R2 RNR inhibitors such as hydroxyurea, 3,4-dihydroxybenzohydroxamic acid (Didox), and 3,4,5-trihydroxybenzamidoxime (Trimidox) have entered clinical trials. ${ }^{26}$ Among other potential tyrosyl radical quenchers, $p$-alkoxyphenols (i.e., $p$-methoxyphenol, $p$-ethoxyphenol, $p$-propoxyphenol, and p-allyloxyphenol) and pyrogallol as well as 4-mercaptophenol were identified. ${ }^{27-29}$ The mechanism of RNR inhibition by the p-alkoxyphenols and pyrogallol was investigated by both experimental techniques (electron paramagnetic resonance (EPR) and UV-visible (UV-vis) spectroscopy) and theoretical tools (molecular docking and molecular dynamics simulations). Among the aminophenols several compounds were tested as anticancer agents, for example, the nonsteroidal anti-inflammatory drug $N$-acetyl-p-aminophenol (acetaminophen), which showed antimelanoma activity to prooxidant glutathione (GSH) depletion by the 3-hydroxy-1,4-quinone-imine-metabolite. ${ }^{29,30}$ Fenretinide (a synthetic retinoid derivative) was introduced in clinical trials for the treatment of breast, bladder, renal, and neuroblastoma malignancies due to its antioxidant activities via scavenging radicals. ${ }^{31}$

It is also worth noting that a coordination to copper(II) may significantly augment the cytotoxic activity of TSCs. ${ }^{6,10}$ Copper(II) as an essential trace element is redox-active, biocompatible, and less toxic than nonendogenous heavy metals. The redox metabolism of cancer cells is different from that of healthy cells and is characterized by increased copper levels in an intracellular environment. ${ }^{32,33}$ Moreover, it was recently suggested that the copper(II) TSC complexes, rather than any metal-free TSCs or their cellular metabolites, are responsible for the biological effects in vitro and in vivo. ${ }^{6}$ One of the reasons for the increased antiproliferative activity of copper(II) complexes of TSCs and the selectivity for cancer cells is considered to be the redox cycling between two oxidation states $\left(\mathrm{Cu}^{2+} \leftrightarrow \mathrm{Cu}^{+}\right)$in a biologically accessible window of potentials (from -0.4 to $+0.8 \mathrm{~V}$ vs normal hydrogen electrode (NHE)) and ROS generation. ${ }^{6,34}$ In this context it is also remarkable that a copper-redox cycle mechanism was found to be responsible for the oxidation of phenolic compounds leading ultimately to reactive oxygendependent DNA damage. ${ }^{35}$ The same authors suggested that singlet oxygen or a singlet oxygen-like entity (e.g., a copperperoxide complex) rather than the free hydroxyl radical plays a role in DNA damage. ${ }^{35}$ At the same time it is worth noting that the idea that an efficient redox cycling of copper(II,I) complexes with thiosemicarbazones can be involved in the anticancer mechanism has been recently challenged ${ }^{36}$ by showing that the most resistant to reduction copper(II) thiosemicarbazonates were the most cytotoxic. In addition, the complexes can also dissociate fast, if the thiosemicarbazone has different affinities to copper(II) and copper(I) and can lose the competition for copper(I) to metallothioneins (MT) and glutathione (GSH).

With this background in mind we aimed at (i) attachment of a phenolic moiety at atom $\mathrm{N} 4$ of thiosemicarbazide, (ii) investigation of solution speciation, complex formation reactions of new TSCs with copper(II) in solution, and synthesis of copper(II) complexes, (iii) investigation of the reduction/oxidation of TSCs containing this potentially redox active group, namely, the 4-aminophenolic unit, and copper(II) complexes thereof by electrochemical and spectroelectrochemical techniques and by using chemical oxidants, for example, $\mathrm{O}_{2}$, p-benzoquinone (PBQ), 2,3-dichloro-5,6-dicyano-1,4-benzoquinone (DDQ), and phenyliodine(III) diacetate (PIDA), as two-electron/two proton acceptors and $\mathrm{Ag}_{2} \mathrm{O}$, along with an analysis of the reversibility of the oxidation process and the number of participating electrons, (iv) identification of the effects of phenolic unit and coordination to copper(II) on the redox activity and cytotoxicity in vitro as well as on the mR2 RNR inhibition and estimation of their potency to act as reductants for a tyrosyl radical with an apparent redox potential of $+1000 \pm 100 \mathrm{mV}$ versus NHE. ${ }^{38}$

In this work we report on the synthesis of new triapine derivatives $\mathbf{H L}^{1}-\mathbf{H L}^{3}$, which contain a potentially redox-active 4-aminophenolic unit, and of copper(II) complexes $\mathbf{C u}\left(\mathbf{H L}^{1}\right)$ $\mathbf{C l}_{2}$ (1), $\left[\mathbf{C u}\left(\mathbf{L}^{2}\right) \mathbf{C l}\right]\left(2^{\prime}\right)$, and $\mathbf{C u}\left(\mathbf{H L}^{3}\right) \mathbf{C l}_{2}$ (3) (Chart 1).

Chart 1. TSCs and Their Copper(II) Complexes Studied in This Work ${ }^{a}$
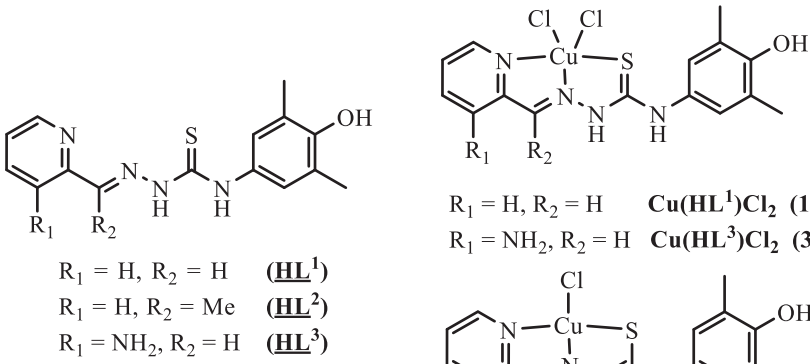

$\mathrm{R}_{1}=\mathrm{H}, \mathrm{R}_{2}=\mathrm{H} \quad \mathrm{Cu}\left(\mathrm{HL}^{1}\right) \mathbf{C l}_{2}(\mathbf{1})$ $\mathrm{R}_{1}=\mathrm{NH}_{2}, \mathrm{R}_{2}=\mathrm{H} \mathbf{C u}\left(\mathbf{H L}^{3}\right) \mathbf{C l}_{2}(3)$<smiles></smiles>

$\mathrm{R}_{1}=\mathrm{H}, \mathrm{R}_{2}=\mathrm{H} \quad\left[\mathbf{C u}\left(\mathbf{L}^{1}\right) \mathbf{C l}\right]\left(\mathbf{1}^{\prime}\right)$ $\mathrm{R}_{1}=\mathrm{H}, \mathrm{R}_{2}=\mathrm{Me} \quad\left[\mathbf{C u}\left(\mathbf{L}^{2}\right) \mathbf{C l}\right]\left(\underline{\mathbf{2}^{\prime}}\right)$ $\mathrm{R}_{1}=\mathrm{NH}_{2}, \mathrm{R}_{2}=\mathrm{H}\left[\mathbf{C u}\left(\mathbf{L}^{3}\right) \mathbf{C l}\right]\left(\underline{\mathbf{3}^{\prime}}\right)$

${ }^{a}$ Underlined labels/numbers indicate compounds studied by SCXRD. The five-coordination of copper(II) in $\mathbf{1}$ and $\mathbf{3}$ has not been confirmed by X-ray crystallography.

The solution behavior of the new TSCs $\left(\mathbf{H L}^{1}-\mathbf{H L}^{3}\right)$, the mechanism typical for TSC $E / Z$ isomerization, and the stability and redox properties of both the metal-free ligands and copper(II) complexes $\left(1,2^{\prime}, 3\right)$ were also investigated by $\mathrm{UV}$-vis spectrophotometry and UV-vis/EPR spectroelectrochemistry and density functional theory (DFT) calculations. In addition, the two- and four-electron oxidation products $\mathbf{H} \mathbf{L}^{\mathbf{1 a}}$ and $H L^{1 \mathbf{1} \prime}$, respectively, were prepared both electrochemically 
Chart 2. Oxidation Products of $\mathrm{HL}^{1}$ and $\mathrm{HL}^{2}$ and Copper(II) Complexes with Oxidized Ligands ${ }^{a}$

1,3,4-Thiadiazole (TDA) core<smiles>Cc1cc(Nc2nnc(-c3ccccn3)s2)cc(C)c1O</smiles>

$\underline{H}^{1 \mathbf{a}^{\prime}}$<smiles>CC1=CC(=Nc2nnc(-c3ccccn3)s2)C=C(C)C1=O</smiles>

$\underline{\mathrm{H}}^{1 \mathbf{a}^{\prime \prime}}$
1,2,4-Triazole-3-thione (TAT) core<smiles>Cc1cc(N2C(=S)N=NC2(C)c2ccccn2)cc(C)c1O</smiles>

$\underline{\mathrm{H}}^{2 \mathrm{~b}}$

Diphenol (DP) species

Benzo $[d]$ thiazol-6-ol/one (BTA) core<smiles>C/C(=N\Nc1[nH]c2cc(C)c(O)c(C)c2c1Nc1cc(C)c(O)c(C)c1)c1ccccn1</smiles>

$\underline{H}^{2 \mathrm{e}}$

Copper(II)-BTA complexes<smiles></smiles>

Copper(II)-TDA complexes<smiles></smiles><smiles></smiles>

$\left[\mathrm{Cu}\left(\mathrm{H} L^{1 \mathrm{~d}}\right)_{2} \mathrm{Cl}_{2}\right](\underline{5})$<smiles>[R2]C(=NNc1nc2cc(C)c(O)c(C)c2s1)c1ncccc1[R]</smiles>

$$
\mathrm{R}_{1}=\mathrm{H}, \mathrm{R}_{2}=\mathrm{H} \quad\left(\mathbf{H} L^{1 \mathbf{c}^{\prime}}\right)
$$

$\underline{\mathrm{H}}{\underline{\underline{2 \mathrm{c}^{\prime \prime}}}}^{\underline{ }}$

$$
\mathrm{R}_{1}=\mathrm{H}, \mathrm{R}_{2}=\mathrm{Me} \quad\left(\mathbf{H} \boldsymbol{L}^{\mathbf{2} \mathbf{c}^{\prime}}\right)
$$


Scheme 1. Oxidation Products of $\mathrm{HL}^{1}$ and $\mathrm{HL}^{2}$ along with Those of Copper(II) Complexes ${ }^{a}$

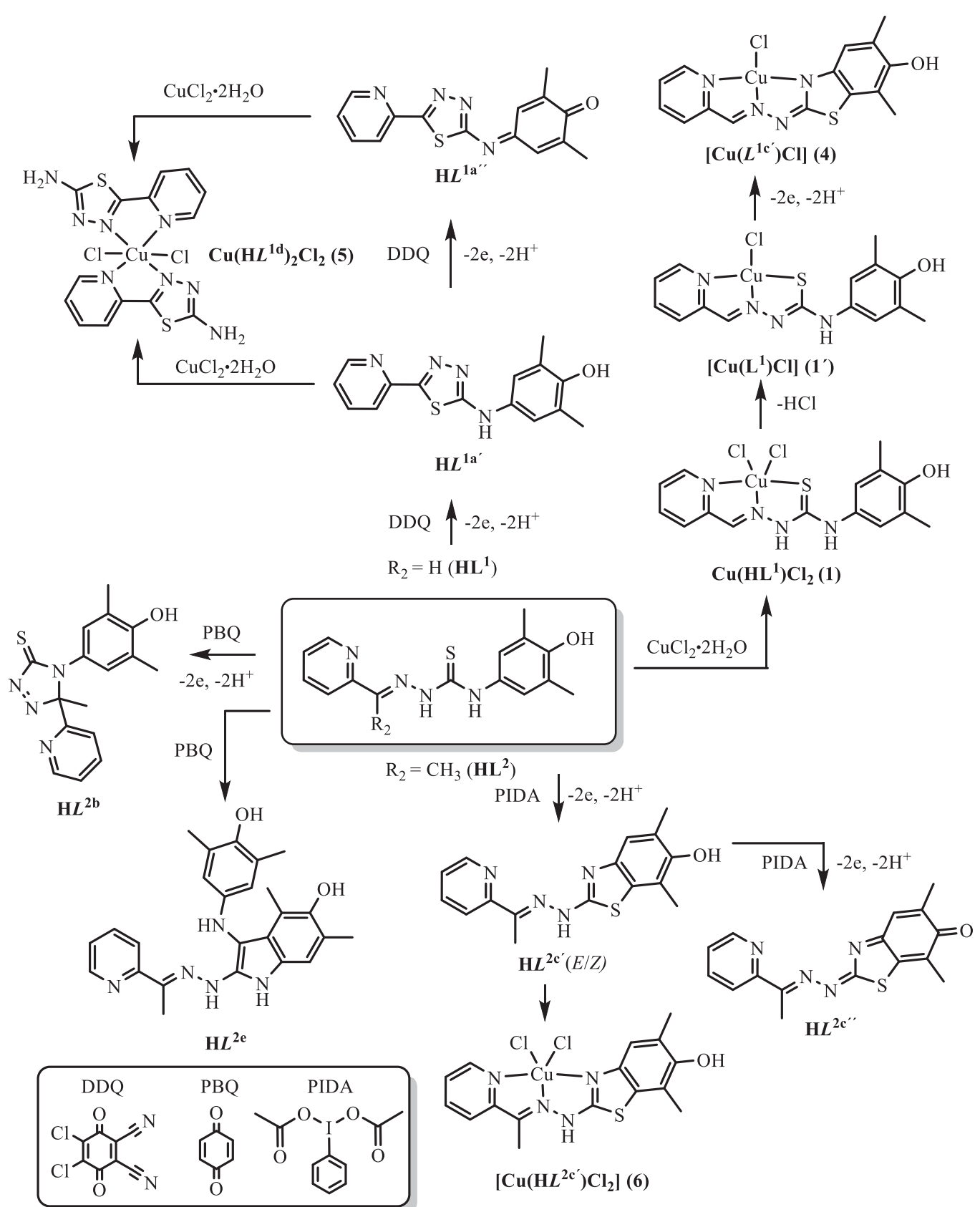

${ }^{a}$ The bottom left panel shows the oxidants used.

yellow solid was filtered off, washed with cold ethanol, and dried in vacuo. Yield: $253 \mathrm{mg}, 86.1 \%$. Anal. Calcd for $\mathrm{C}_{15} \mathrm{H}_{16} \mathrm{~N}_{4} \mathrm{OS} \cdot 0.5 \mathrm{H}_{2} \mathrm{O}$ $\left(M_{\mathrm{r}}=309.39\right)$ : C, 58.23; H, 5.54.; N, 18.11; S, 10.36; Found: C, 57.91; H, 5.45; N, 17.92; S, 10.43\%. Positive ion ESI-MS for $\mathrm{C}_{15} \mathrm{H}_{16} \mathrm{~N}_{4} \mathrm{OS}\left(\mathrm{MeCN} / \mathrm{MeOH}+1 \% \mathrm{H}_{2} \mathrm{O}\right): m / z$ 301.11 $\left[\mathrm{HL}^{1}+\mathrm{H}\right]^{+}$, $323.09\left[\mathrm{HL}^{1}+\mathrm{Na}\right]^{+}, 339.07\left[\mathrm{HL}^{1}+\mathrm{K}\right]^{+}$, negative ion ESI-MS: $\mathrm{m} / z$ $299.10\left[\mathrm{HL}^{1}-\mathrm{H}\right]^{-} .{ }^{1} \mathrm{H}$ NMR (600 MHz, DMSO- $d_{6}, E$ isomer) $\delta$, ppm: $11.86\left(\mathrm{~s}, 1 \mathrm{H}, \mathrm{H}_{9}\right), 10.00\left(\mathrm{~s}, 1 \mathrm{H}, \mathrm{H}_{11}\right), 8.57(\mathrm{~d}, J=4.4 \mathrm{~Hz}, 1 \mathrm{H}$, $\left.\mathrm{H}_{6}\right), 8.43\left(\mathrm{~d}, J=8.0 \mathrm{~Hz}, 1 \mathrm{H}, \mathrm{H}_{3}\right), 8.22\left(\mathrm{~s}, 1 \mathrm{H}, \mathrm{H}_{18}\right), 8.16\left(\mathrm{~s}, 1 \mathrm{H}, \mathrm{H}_{7}\right)$, $7.82\left(\mathrm{td}, J=7.8,1.2 \mathrm{~Hz}, 1 \mathrm{H}, \mathrm{H}_{4}\right), 7.37\left(\mathrm{~m}, 1 \mathrm{H}, \mathrm{H}_{5}\right), 7.02(\mathrm{~s}, 2 \mathrm{H}$, $\left.\mathrm{H}_{13}+\mathrm{H}_{17}\right), 2.17\left(\mathrm{~s}, 6 \mathrm{H}, \mathrm{H}_{19}+\mathrm{H}_{20}\right) \cdot{ }^{13} \mathrm{C}$ NMR (151 MHz, DMSO-d, E isomer) $\delta$, ppm: $176.55\left(\mathrm{C}_{10}\right), 153.31\left(\mathrm{C}_{2}\right), 151.10\left(\mathrm{C}_{15}\right), 149.27$ $\left(\mathrm{C}_{6}\right), 142.51\left(\mathrm{C}_{7}\right), 136.43\left(\mathrm{C}_{4}\right), 130.18\left(\mathrm{C}_{12}\right), 126.26\left(\mathrm{C}_{13}+\mathrm{C}_{17}\right)$, $124.10\left(\mathrm{C}_{5}\right), 123.84\left(\mathrm{C}_{14}+\mathrm{C}_{16}\right), 120.54\left(\mathrm{C}_{3}\right), 16.62\left(\mathrm{C}_{19}+\mathrm{C}_{20}\right) .{ }^{15} \mathrm{~N}$ NMR (61 MHz, DMSO- $d_{6}, E$ isomer) $\delta$, ppm: $325.04\left(\mathrm{~N}_{8}\right), 315.07$ $\left(\mathrm{N}_{1}\right), 174.22\left(\mathrm{~N}_{9}\right), 128.93\left(\mathrm{~N}_{11}\right)$. IR (attenuated total reflectance
(ATR), selected bands, $\left.\tilde{v}_{\text {max }}\right): 3107.39,2950.74,1531.05,1477.88$, $1428.74,1201.82,1105.17,926.54,862.73,761.37,682.25 \mathrm{~cm}^{-1}$. UV-vis $(\mathrm{MeOH}), \lambda_{\max } \mathrm{nm}\left(\varepsilon, \mathrm{M}^{-1} \mathrm{~cm}^{-1}\right): 243 \mathrm{sh}, 328$ (3516). Single crystals of $\mathbf{H L}^{1} \cdot \mathbf{C}_{2} \mathbf{H}_{5} \mathbf{O H}$ suitable for X-ray data collection were obtained from the mother liquor.

2-Acetylpyridine 4-(4-hydroxy-3,5-dimethylphenyl)thiosemicarbazone $\left(\mathrm{HL}^{2} \cdot 0.2 \mathrm{H}_{2} \mathrm{O}\right)$. 2-Acetylpyridine $(0.21 \mathrm{~mL}$, $1.91 \mathrm{mmol})$ was added to 4-(4-hydroxy-3,5-dimethylphenyl)thiosemicarbazide $(269 \mathrm{mg} ; 1.27 \mathrm{mmol})$ in ethanol $(8 \mathrm{~mL})$, heated at $85{ }^{\circ} \mathrm{C}$ overnight, concentrated, and left for crystallization at $4{ }^{\circ} \mathrm{C}$. The obtained light yellow precipitate was filtered off, washed with cold ethanol, and dried in vacuo. Yield: $271 \mathrm{mg}, 67.0 \%$. Anal. Calcd for $\mathrm{C}_{16} \mathrm{H}_{18} \mathrm{~N}_{4} \mathrm{OS} \cdot 0.2 \mathrm{H}_{2} \mathrm{O}\left(M_{\mathrm{r}}=318.01\right)$ : C, 60.43; $\mathrm{H}, 5.83$; N, 17.62; S, 10.08. Found: C, $60.47 ; \mathrm{H}, 5.8 ; \mathrm{N}, 17.55 ; \mathrm{S}, 10.13 \%$. Positive ion ESI-MS for $\mathrm{C}_{16} \mathrm{H}_{18} \mathrm{~N}_{4} \mathrm{OS}\left(M_{\mathrm{r}}=314.41\right)\left(\mathrm{MeCN} / \mathrm{MeOH}+1 \% \mathrm{H}_{2} \mathrm{O}\right)$ : $m / z 315.13\left[\mathrm{HL}^{2}+\mathrm{H}\right]^{+}, 337.11\left[\mathrm{HL}^{2}+\mathrm{Na}\right]^{+}$, negative ion ESI-MS: $m /$ 
$z$ 313.11 $\left[\mathrm{HL}^{2}-\mathrm{H}\right]^{-} .{ }^{1} \mathrm{H}$ NMR (600 MHz, DMSO- $d_{6}, E$ isomer) $\delta$, ppm: $10.46\left(\mathrm{~s}, 1 \mathrm{H}, \mathrm{H}_{9}\right), 9.94\left(\mathrm{~s}, 1 \mathrm{H}, \mathrm{H}_{11}\right), 8.59(\mathrm{~d}, J=4.7 \mathrm{~Hz}, 1 \mathrm{H}$, $\left.\mathrm{H}_{6}\right), 8.54\left(\mathrm{~d}, J=8.1 \mathrm{~Hz}, 1 \mathrm{H}, \mathrm{H}_{3}\right), 8.22\left(\mathrm{~s}, 1 \mathrm{H}, \mathrm{H}_{18}\right), 7.79(\mathrm{td}, J=7.8$, $\left.1.7 \mathrm{~Hz}, 1 \mathrm{H}, \mathrm{H}_{4}\right), 7.39$ (dd, $\left.J=7.2,4.9 \mathrm{~Hz}, 1 \mathrm{H}, \mathrm{H}_{5}\right), 7.02(\mathrm{~s}, 2 \mathrm{H}$, $\left.\mathrm{H}_{13}+\mathrm{H}_{17}\right), 2.44\left(\mathrm{~s}, 3 \mathrm{H}, \mathrm{H}_{7^{\prime}}\right), 2.17\left(\mathrm{~s}, 6 \mathrm{H}, \mathrm{H}_{19}+\mathrm{H}_{20}\right) .{ }^{13} \mathrm{C}$ NMR $(151$ MHz, DMSO- $d_{6}, E$ isomer $) \delta$, ppm: $177.36\left(\mathrm{C}_{10}\right), 154.59\left(\mathrm{C}_{2}\right)$, $151.12\left(\mathrm{C}_{15}\right), 148.54\left(\mathrm{C}_{7}\right), 148.43\left(\mathrm{C}_{6}\right), 136.34\left(\mathrm{C}_{4}\right), 130.36\left(\mathrm{C}_{12}\right)$, $126.33\left(\mathrm{C}_{13}+\mathrm{C}_{17}\right), 124.00\left(\mathrm{C}_{5}\right), 123.83\left(\mathrm{C}_{14}+\mathrm{C}_{16}\right), 121.18\left(\mathrm{C}_{3}\right)$, $16.63\left(\mathrm{C}_{19}+\mathrm{C}_{20}\right), 12.31\left(\mathrm{C}_{7^{\prime}}\right) \cdot{ }^{15} \mathrm{~N}$ NMR $\left(61 \mathrm{MHz}\right.$, DMSO-d $d_{6}, E$ isomer) $\delta$, ppm: $312.94\left(\mathrm{~N}_{8}\right), 310.61\left(\mathrm{~N}_{1}\right), 168.53\left(\mathrm{~N}_{9}\right), 129.34$ $\left(\mathrm{N}_{11}\right)$. IR (ATR, selected bands, $\left.\tilde{v}_{\max }\right): 3386.87,3187.76,1531.57$, $1478.45,1309.19,1182.40,1032.57,942.48,778.97,652.93 \mathrm{~cm}^{-1}$. UV-vis $(\mathrm{MeOH}), \lambda_{\text {max }}, \mathrm{nm}\left(\varepsilon, \mathrm{M}^{-1} \mathrm{~cm}^{-1}\right): 316$ (2842), $407 \mathrm{sh}$. Single crystals of $\mathbf{H L}^{2}$ suitable for X-ray data collection were obtained from the mother liquor.

3-Amino-2-formylpyridine 4-(4-hydroxy-3,5dimethylphenyl)thiosemicarbazone $\left(\mathrm{HL}^{3} \cdot 0.25 \mathrm{H}_{2} \mathrm{O}\right)$. To a solution of 3-(tert-butoxycarbonyl)amino-2-formylpyridine (210 mg, $0.95 \mathrm{mmol}$ ) and 4-(4-hydroxy-3,5-dimethylphenyl)thiosemicarbazide $(200 \mathrm{mg}, 0.95 \mathrm{mmol})$ in a mixture of ethanol/water $3: 1(8 \mathrm{~mL})$ was added dropwise $12 \mathrm{M} \mathrm{HCl}(0.19 \mathrm{~mL}, 2.28 \mathrm{mmol})$. This solution was stirred at room temperature for $1 \mathrm{~h}$ to give $\mathbf{B o c}-\mathbf{H L}^{3} \cdot \mathbf{H C l}$ $\left(\mathrm{C}_{20} \mathrm{H}_{25} \mathrm{~N}_{5} \mathrm{O}_{3} \mathrm{~S} \cdot \mathrm{HCl}\right.$, positive ion ESI-MS for $\mathrm{C}_{20} \mathrm{H}_{25} \mathrm{~N}_{5} \mathrm{O}_{3} \mathrm{~S}\left(M_{\mathrm{r}}=\right.$ 415.51) (MeCN/MeOH+1\% $\left.\mathrm{H}_{2} \mathrm{O}\right): m / z \quad 416.18$ [Boc- $\left.\mathrm{HL}^{3}+\mathrm{H}\right]^{+}$, negative ion ESI-MS: $m / z$ 414.02 $\left.\left[\text { Boc- } \mathrm{HL}^{3}-\mathrm{H}\right]^{-}\right)$. The Bocdeprotection of $\mathrm{HL}^{3}$ was completed at $85{ }^{\circ} \mathrm{C}$ for $7 \mathrm{~h}$ with monitoring by ESI-MS (positive ion ESI-MS for $\mathrm{C}_{15} \mathrm{H}_{17} \mathrm{~N}_{5} \mathrm{OS}\left(M_{\mathrm{r}}=315.39\right)$ $\left(\mathrm{MeCN} / \mathrm{MeOH}+1 \% \mathrm{H}_{2} \mathrm{O}\right): m / z \quad 316.12\left[\mathrm{HL}^{3}+\mathrm{H}\right]^{+}, 338.11$ $\left[\mathrm{HL}^{3}+\mathrm{Na}\right]^{+}$, negative ion ESI-MS: $\left.m / z 314.11\left[\mathrm{HL}^{3}-\mathrm{H}\right]^{-}\right)$. After ethanol evaporation, the solution was neutralized with a saturated solution of $\mathrm{NaHCO}_{3}(\mathrm{pH}=8)$. The precipitate was collected and dried in vacuo. Yield: $267 \mathrm{mg}, 87.9 \%$. Anal. Calcd for $\mathrm{C}_{15} \mathrm{H}_{17} \mathrm{~N}_{5} \mathrm{OS}$. $0.25 \mathrm{H}_{2} \mathrm{O}\left(M_{\mathrm{r}}=319.90\right): \mathrm{C}, 56.31 ; \mathrm{H}, 5.51 ; \mathrm{N}, 21.89 ; \mathrm{S}, 10.02$. Found: C, 56.33; H, 5.34; N, 21.68; S, 10.29\%. ${ }^{1} \mathrm{H}$ NMR $(600 \mathrm{MHz}$, DMSO- $d_{6}, E$ isomer $) \delta$, ppm: $11.47\left(\mathrm{~s}, 1 \mathrm{H}, \mathrm{H}_{9}\right), 9.70\left(\mathrm{~s}, 1 \mathrm{H}, \mathrm{H}_{11}\right)$, $8.39\left(\mathrm{~s}, 1 \mathrm{H}, \mathrm{H}_{7}\right), 8.21\left(\mathrm{~s}, 1 \mathrm{H}, \mathrm{H}_{18}\right), 7.85\left(\mathrm{dd}, J=4.3,1.4 \mathrm{~Hz}, 1 \mathrm{H}, \mathrm{H}_{6}\right)$, $7.15\left(\mathrm{dd}, J=8.3,1.2 \mathrm{~Hz}, 1 \mathrm{H}, \mathrm{H}_{4}\right), 7.08\left(\mathrm{dd}, J=8.3,4.3 \mathrm{~Hz}, 1 \mathrm{H}, \mathrm{H}_{5}\right)$, $6.92\left(\mathrm{~s}, 2 \mathrm{H}, \mathrm{H}_{13}+\mathrm{H}_{17}\right), 6.49\left(\mathrm{~s}, 2 \mathrm{H}, \mathrm{H}_{3^{\prime}}\right), 2.16\left(\mathrm{~s}, 6 \mathrm{H}, \mathrm{H}_{19}+\mathrm{H}_{20}\right) .{ }^{13} \mathrm{C}$ NMR (151 MHz, DMSO- $d_{6}, E$ isomer $) \delta$, ppm: $176.13\left(\mathrm{C}_{10}\right), 151.17$ $\left(\mathrm{C}_{15}\right), 149.23\left(\mathrm{C}_{7}\right), 143.99\left(\mathrm{C}_{3}\right), 137.25\left(\mathrm{C}_{6}\right), 132.97\left(\mathrm{C}_{2}\right), 130.59$ $\left(\mathrm{C}_{12}\right), 126.88\left(\mathrm{C}_{13}+\mathrm{C}_{17}\right), 124.52\left(\mathrm{C}_{5}\right), 123.83\left(\mathrm{C}_{14}+\mathrm{C}_{16}\right), 122.34$ $\left(\mathrm{C}_{4}\right), 16.63\left(\mathrm{C}_{19}+\mathrm{C}_{20}\right) .{ }^{15} \mathrm{~N}$ NMR (61 MHz, DMSO-d 6 , $E$ isomer $) \delta$, ppm: $321.53\left(\mathrm{~N}_{1}\right), 312.8\left(\mathrm{~N}_{8}\right), 174.57\left(\mathrm{~N}_{9}\right), 126.69\left(\mathrm{~N}_{11}\right), 71.10$ $\left(\mathrm{N}_{3^{\prime}}\right)$. IR (ATR, selected bands, $\left.\tilde{v}_{\max }\right): 3456.59,3347.73,3142.99$, 3002.80, 1615.50, 1547.68, 1512.07, 1299.63, 1248.47, 1189.77, $1143.84,861.56,796.22,685.36 \mathrm{~cm}^{-1}$. UV-vis $(\mathrm{MeOH}), \lambda_{\max } \mathrm{nm}(\varepsilon$, $\left.\mathrm{M}^{-1} \mathrm{~cm}^{-1}\right): 299$ (1374), 375 (2220), 448 sh. Single crystals of $\mathbf{H L}^{3}$ suitable for X-ray data collection were obtained from the mother liquor.

\section{SYNTHESIS OF THE COPPER(II) COMPLEXES}

$\mathrm{Cu}\left(\mathrm{HL}^{1}\right) \mathrm{Cl}_{2} \cdot 0.5 \mathrm{H}_{2} \mathrm{O}\left(\mathbf{1} \cdot 0.5 \mathrm{H}_{2} \mathrm{O}\right) \cdot \mathrm{CuCl}_{2} \cdot 2 \mathrm{H}_{2} \mathrm{O}(128 \mathrm{mg}$, $0.75 \mathrm{mmol}$ ) was added to $\mathrm{HL}^{1}(225 \mathrm{mg}, 0.75 \mathrm{mmol})$ in anoxic methanol $(10 \mathrm{~mL})$ in a Schlenk tube and stirred at room temperature under argon for $10 \mathrm{~min}$. The reaction mixture was allowed to stand at $4{ }^{\circ} \mathrm{C}$ overnight. The dark green precipitate was filtered off under argon, washed with anoxic methanol, and dried in vacuo. Yield: $294 \mathrm{mg}, 88.4 \%$. Anal. Calcd for $\mathrm{C}_{15} \mathrm{H}_{16} \mathrm{~N}_{4} \mathrm{OSCuCl} \cdot 0.5 \mathrm{H}_{2} \mathrm{O} \quad\left(M_{\mathrm{r}}=443.84\right): \mathrm{C}, 40.59 ; \mathrm{H}$, 3.86; N, 12.62; S, 7.22. Found: C, 40.73; H, 3.59; N, 12.63; S, 7.19\%. Positive ion ESI-MS for $\mathrm{C}_{15} \mathrm{H}_{16} \mathrm{~N}_{4} \mathrm{OSCuCl} 2(\mathrm{MeCN} /$ $\left.\mathrm{MeOH}+1 \% \mathrm{H}_{2} \mathrm{O}\right): m / z 362.03\left[\mathrm{Cu}\left(\mathrm{HL}^{1}\right)^{2+}-\mathrm{H}\right]^{+}$, negative ion ESI-MS: $m / z 395.99\left[\mathrm{Cu}\left(\mathrm{HL}^{1}\right) \mathrm{Cl}^{+}-2 \mathrm{H}\right]^{-}$. IR (ATR, selected bands, $\left.\tilde{v}_{\max }\right): 3480.77,2989.07,1610.63,1479.59,1269.25$, $1229.98,1189.75,1025.69,774.69,665.85 \mathrm{~cm}^{-1}$. UV-vis $(\mathrm{MeOH}), \lambda_{\max } \mathrm{nm}\left(\varepsilon, \mathrm{M}^{-1} \mathrm{~cm}^{-1}\right): 280$ (16 800), $376 \mathrm{sh}, 422$ $\left(18\right.$ 160). Crystals of $\left[\mathbf{C u}\left(\mathrm{L}^{1}\right) \mathbf{C l}\right] \cdot \mathbf{C H}_{3} \mathbf{O H}\left(\mathbf{1}^{\prime} \cdot \mathbf{C H}_{3} \mathrm{OH}\right)\left(M_{\mathrm{r}}=\right.$ 398.37) suitable for X-ray diffraction study were grown from an $\sim 20$-fold-diluted reaction mixture in a Schlenk tube under argon upon standing at $4{ }^{\circ} \mathrm{C}$. A recrystallization of $\left[\mathrm{Cu}\left(\mathrm{HL}^{1}\right)\right.$ $\mathrm{Cl}_{2}$ ] (1) in methanol in air afforded a minor amount of X-ray diffraction-quality crystals of $\left[\mathrm{Cu}\left(L^{1 \mathrm{c} \prime}\right) \mathrm{Cl}\right]$ (4).

$\left[\mathrm{Cu}\left(\mathrm{L}^{2}\right) \mathrm{Cl}\right] \cdot 0.5 \mathrm{H}_{2} \mathrm{O}\left(2^{\prime} \cdot 0.5 \mathrm{H}_{2} \mathrm{O}\right) . \mathrm{CuCl}_{2} \cdot 2 \mathrm{H}_{2} \mathrm{O} \quad(129 \mathrm{mg}$, $0.76 \mathrm{mmol})$ was added to a solution of $\mathbf{H L}^{2}(238 \mathrm{mg}, 0.76$ $\mathrm{mmol})$ in anoxic methanol $(10 \mathrm{~mL})$ in a Schlenk tube. The reaction mixture was stirred at room temperature under argon for $10 \mathrm{~min}$ and then allowed to stand at $4{ }^{\circ} \mathrm{C}$ overnight. The greenish-brown precipitate was filtered off under argon, washed with anoxic methanol, and dried in vacuo. Yield: 316 mg, 98.8\%. Anal. Calcd for $\mathrm{C}_{16} \mathrm{H}_{17} \mathrm{~N}_{4} \mathrm{OSCuCl} \cdot 0.5 \mathrm{H}_{2} \mathrm{O}\left(M_{\mathrm{r}}=\right.$ 421.40): C, 45.60; H, 4.31; N, 13.30; S, 7.61. Found: C, 45.74; $\mathrm{H}, 4.03 ; \mathrm{N}, 13.42 ; \mathrm{S}, 7.56 \%$. Positive ion ESI-MS for $\mathrm{C}_{16} \mathrm{H}_{17} \mathrm{~N}_{4} \mathrm{OSCuCl}\left(\mathrm{MeCN} / \mathrm{MeOH}+1 \% \mathrm{H}_{2} \mathrm{O}\right): \mathrm{m} / z 376.04$ $\left[\mathrm{Cu}\left(\mathrm{L}^{2}\right)\right]^{+}$, negative ion ESI-MS: $m / z 410.00\left[\mathrm{Cu}\left(\mathrm{L}^{2}\right) \mathrm{Cl}-\mathrm{H}\right]^{-}$. IR (ATR, selected bands, $\left.\tilde{v}_{\max }\right): 3341.84,3223.12,1609.18$, 1547.35, 1483.22, 1452.56, 1303.41, 1202.82, 1019.61, 846.14, $701.29 \mathrm{~cm}^{-1}$. UV-vis $(\mathrm{MeOH}), \lambda_{\max }, \mathrm{nm}\left(\varepsilon, \mathrm{M}^{-1} \mathrm{~cm}^{-1}\right): 277$ (11 835), $316 \mathrm{sh}, 421$ (12 953). Crystals of $\left[\mathbf{C u}\left(\mathbf{L}^{2}\right) \mathbf{C l}\right]\left(2^{\prime}\right)$ suitable for X-ray diffraction study were obtained from an $\sim 20$ fold-diluted reaction mixture under argon in a Schlenk tube at $4{ }^{\circ} \mathrm{C}$.

$\mathrm{Cu}\left(\mathrm{HL}^{3}\right) \mathrm{Cl}_{2} \cdot 0.25 \mathrm{H}_{2} \mathrm{O}\left(3 \cdot 0.25 \mathrm{H}_{2} \mathrm{O}\right) . \mathrm{CuCl}_{2} \cdot 2 \mathrm{H}_{2} \mathrm{O}(114 \mathrm{mg}$, $0.67 \mathrm{mmol})$ was added to $\mathrm{HL}^{3}(210 \mathrm{mg}, 0.67 \mathrm{mmol})$ in anoxic methanol $(10 \mathrm{~mL})$ in a Schlenk tube and stirred at room temperature under argon for $10 \mathrm{~min}$. The reaction mixture was allowed to stand at $4{ }^{\circ} \mathrm{C}$ overnight. The green precipitate was filtered off under argon, washed with anoxic methanol, and dried in vacuo. Yield: $285 \mathrm{mg}$, 93.6\%. Anal. Calcd for $\mathrm{C}_{15} \mathrm{H}_{17} \mathrm{~N}_{5} \mathrm{OSCuCl}_{2} \cdot 0.25 \mathrm{H}_{2} \mathrm{O} \quad\left(M_{\mathrm{r}}=454.35\right): \mathrm{C}, 39.65 ; \mathrm{H}$, 3.88; N, 15.41; S, 7.06. Found: C, 39.58; H, 3.79; N, 15.21; S, 6.98\%. Positive ion ESI-MS for $\mathrm{C}_{15} \mathrm{H}_{17} \mathrm{~N}_{5} \mathrm{OSCuCl} 2(\mathrm{MeCN} /$ $\left.\mathrm{MeOH}+1 \% \mathrm{H}_{2} \mathrm{O}\right): m / z 377.04\left[\mathrm{Cu}\left(\mathrm{HL}^{3}\right)^{2+}-\mathrm{H}\right]^{+}$, negative ion ESI-MS: $m / z 411.00\left[\mathrm{Cu}\left(\mathrm{HL}^{3}\right) \mathrm{Cl}^{+}-2 \mathrm{H}\right]^{-}$. IR (ATR, selected bands, $\left.\tilde{v}_{\max }\right): 3422.07,3340.63,1647.85,1569.29,1480.67$, 1223.63, 1185.74, 1023.07, 718.76, $660.61 \mathrm{~cm}^{-1}$. UV-vis $(\mathrm{MeOH}), \lambda_{\max }, \mathrm{nm}\left(\varepsilon, \mathrm{M}^{-1} \mathrm{~cm}^{-1}\right): 262$ (19564), 288 (17 425), 462 (23 514). Crystals of $\left[\mathrm{Cu}\left(\mathrm{L}^{3}\right) \mathbf{C l}\right] \cdot \mathrm{CH}_{3} \mathbf{O H}$, $\left(3^{\prime} \cdot \mathrm{CH}_{3} \mathrm{OH}\right)\left(M_{\mathrm{r}}=413.38\right)$ suitable for X-ray diffraction study were grown from an $\sim 20$-fold-diluted reaction mixture in a Schlenk tube under argon at $4{ }^{\circ} \mathrm{C}$.

Details about the synthesis and characterization of oxidized thiosemicarbazones and their copper(II) complexes, X-ray data collection and refinement (Tables S1-S3), elemental analysis, UV-vis titrations, kinetic measurements, lipophilicity determination, spectroelectrochemical studies, in vitro cell studies, 3-(4,5-dimethylthiazol-2-yl)-2,5-diphenyl-tetrazolium bromide (MTT) assays, and tyrosyl radical reduction in mouse R2 RNR protein as well as computational details are given in the Supporting Information (Sections 1 and 2).

\section{RESULTS AND DISCUSSION}

Synthesis and Characterization of $\mathrm{HL}^{1}-\mathrm{HL}^{3}$. The new TSCs $\mathbf{H L}^{1}-\mathbf{H L}^{3}$ were obtained by Schiff base condensation reactions of 4-(4-hydroxy-3,5-dimethylphenyl)thiosemicarbazide $^{40}$ with the corresponding aldehyde $\left(\mathbf{H L}^{\mathbf{1}}\right.$, $\left.\mathbf{H L}^{3}\right)$ or ketone $\left(\mathbf{H L}^{2}\right)$ in boiling ethanol $\left(\mathbf{H L}^{\mathbf{1}}, \mathbf{H L}^{2}\right)$ or ethanol/water $\left(3: 1, \mathbf{H L}^{3}\right)$ in the absence $\left(\mathbf{H L}^{1}\right.$ and $\left.\mathbf{H L}^{2}\right)$ or in the presence of $12 \mathrm{M} \mathrm{HCl}\left(\mathbf{H L}^{3}\right)$. The hydrochloric acid in this latter case was used for Boc-deprotection of the intermediate $\mathbf{B o c}-\mathbf{H L}^{3}$. This deprotection reaction was monitored by ESI-MS (disappearance of peaks attributed to 


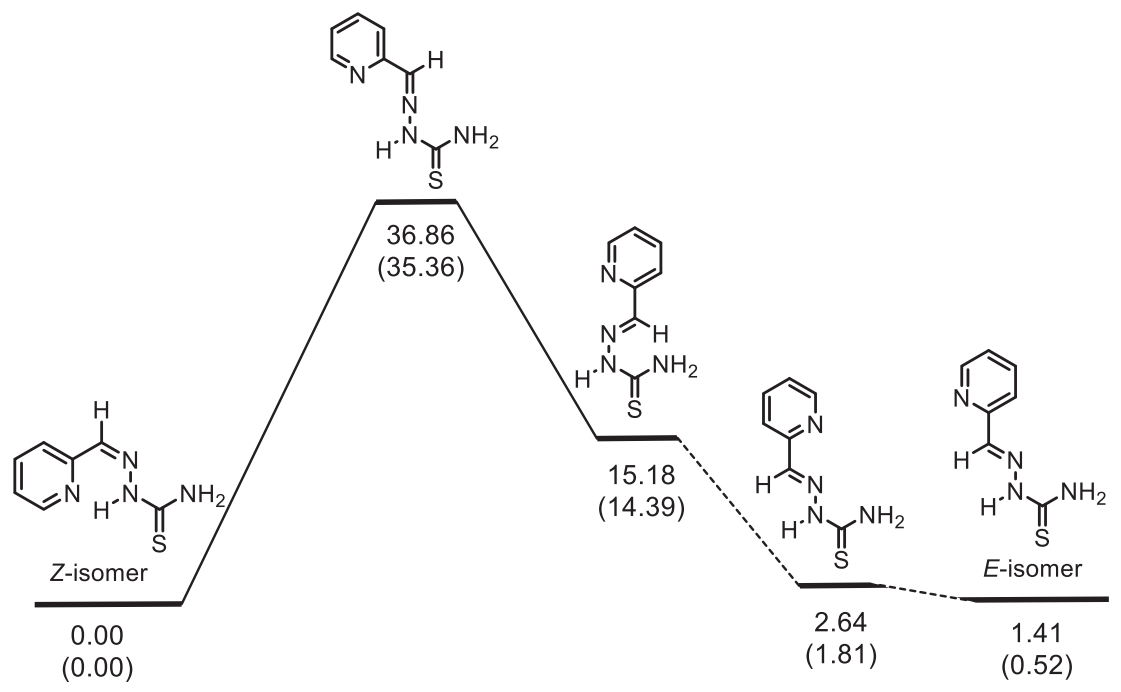

Figure 1. Electronic energy and Gibbs free energy profiles (in $\mathrm{kcal} / \mathrm{mol}$ ) for the transformation of the most stable conformer of ( $Z$ )-2formylpyridine thiosemicarbazone into the most stable conformer of $(E)$-2-formylpyridine thiosemicarbazone in DMSO solution. Free energies (in parentheses) at $298 \mathrm{~K}$ and $1 \mathrm{~atm}$.

$\left[\text { Boc- } \mathrm{HL}^{3}+\mathrm{H}\right]^{+}$and $\left[\text {Boc- } \mathrm{HL}^{3}-\mathrm{H}\right]^{-}$ions) and completed at 85 ${ }^{\circ} \mathrm{C}$ after $7 \mathrm{~h}$, with yields ranging from 67 to $88 \%$. The formation of $\mathrm{HL}^{1}-\mathrm{HL}^{3}$ was confirmed by ESI mass spectra, which showed peaks assigned to ions $\left[\mathrm{HL}^{1-3}+\mathrm{H}\right]^{+}$, $\left[\mathrm{HL}^{1-3}+\mathrm{Na}\right]^{+}$, and $\left[\mathrm{HL}^{1-3}-\mathrm{H}\right]^{-}$. One- and two-dimensional NMR spectra were in agreement with the expected structures for $\mathbf{H L}^{1}-\mathbf{H L}^{3}$ of $C_{1}$ molecular symmetry. In addition, the spectra indicated the presence of $E$ and $Z$ isomers in DMSO$d_{6}$, which is typical for thiosemicarbazones, ${ }^{41-43}$ with a significant predominance of $E$ isomers $(E / Z=23: 1,17: 1$, and $31: 1$ for $\mathbf{H L}^{1}-\mathbf{H L}^{3}$, respectively). The assignment of $E$ and $Z$ isomers was based on NMR spectra, including ${ }^{1} \mathrm{H},{ }^{1} \mathrm{H}$ nuclear Overhauser effect spectroscopy (NOESY), which are presented in more detail in the Supporting Information (see also Schemes S1 and S2 and Tables S4-S6). It is noteworthy that, in contrast to the $E$ isomers of $\mathbf{H L}^{1}-\mathbf{H L}^{3}$, their $Z$ isomers can form an intramolecular hydrogen bond between the pyridine nitrogen and the NH-N group hydrogen, resulting in an increase in the relative stability of these conformers. Indeed, the DFT B3LYP/6-311++G (d,p) calculations for $E$ - and Z$\mathrm{HL}^{1}$ in a DMSO solution (the polarizable continuum model (PCM) solvation model) showed that the most stable conformer of $Z-\mathrm{HL}^{1}$ lies lower in energy than the most stable conformer of $E-\mathrm{HL}^{1}(\Delta E=1.45 \mathrm{kcal} / \mathrm{mol} ; \Delta G=0.76 \mathrm{kcal} /$ $\mathrm{mol}$ at $298 \mathrm{~K}$ and $1 \mathrm{~atm})$. The calculations also demonstrate that $E$ - and $Z-\mathrm{HL}^{2}$ are very close in thermodynamic stability $\left(\Delta E=0.90 \mathrm{kcal} / \mathrm{mol}\right.$ in favor of $\left.Z-\mathrm{HL}^{2}, \Delta G=0.00 \mathrm{kcal} / \mathrm{mol}\right)$, and $E-\mathrm{HL}^{3}$ is slightly more stable than $Z-\mathrm{HL}^{3}(\Delta E=0.84 \mathrm{kcal} /$ mol, $\Delta G=0.86 \mathrm{kcal} / \mathrm{mol}$ ), which can be explained by the presence of an intramolecular hydrogen bond between the 3$\mathrm{NH}_{2}$ group and the aldimine nitrogen in $E-\mathrm{HL}^{3}$. Thus, the formation of $\mathrm{HL}^{1}-\mathrm{HL}^{3}$ with a large predominance of the $E$ isomers indicates that the reactions proceed under a kinetic control. By using DFT B3LYP/6-311++G(d,p) calculations to understand the interconversion between $E$ and $Z$ isomers of 2formylpyridine and thiosemicarbazones as model compounds we found out that an isomerization involving a tautomeric shift of the thioamide $\mathrm{N} 2 \mathrm{H}$ proton to the pyridine nitrogen followed by a rotation around the formed $\mathrm{C}-\mathrm{N} 1$ bond, as proposed previously, ${ }^{44}$ is not favored energetically (see the Supporting Information for details). We believe that the most plausible $Z / E$ isomerization pathway in thiosemicarbazones and semicarbazones involves an inversion at the imine nitrogen. ${ }^{45}$ The intrinsic reaction coordinate (IRC) analysis for one of the aforementioned model compounds revealed that the found transition state connects the desired minima. However, the calculation data obtained show (for more details see the Supporting Information) that the Gibbs free energy barrier for the conversion of the most stable conformer of the $Z$ isomer into the $E$ isomer is relatively high $(\Delta G=35.2 \mathrm{kcal} /$ $\mathrm{mol}$ in the gas phase, $35.4 \mathrm{kcal} / \mathrm{mol}$ in DMSO solution) (Figure 1), which rejects the possibility of an interconversion between the isomers at room temperature.

The redox activity of $\mathbf{H L}^{1}-\mathbf{H L}^{3}$ in the anodic region was validated by cyclic voltammetry (vide infra). Their behavior as reductants is also relevant for quenching the tyrosyl radical in the $\mathrm{mR} 2$-protein. Therefore, attempts to perform an oxidation of $\mathbf{H L}^{1}$ and $\mathbf{H L}^{2}$ by electrolysis and by chemical oxidation were undertaken.

Oxidation of TSCs. The oxidation of different organic molecules with $p$-benzoquinone derivatives is well-documented in the literature. ${ }^{46}$ The reaction of $\mathrm{HL}^{1}$ with $\mathrm{DDQ}\left(2 \mathrm{e}^{-} / 2 \mathrm{H}^{+}\right.$ $E^{\circ}=+0.887 \mathrm{~V}$ vs NHE in an acidic $0.1 \mathrm{M}$ aqueous solution of $p$ - $\mathrm{TsOH})^{47}$ in a $1: 1$ molar ratio resulted in two-electron and four-electron oxidative cyclizations with the major formation of $\mathbf{H} \mathbf{L}^{\mathbf{1 a} \mathbf{a}^{\prime}}(60.9 \%)$ accompanied by a minor generation of $\mathbf{H} \mathbf{L}^{\mathbf{1 \mathbf { a }}}$ $(<5 \%)$, both containing a 1,3,4-thiadiazole ring (Chart 2, Scheme 1). The formation of the 1,3,4-thiadiazole ring occurs via a nucleophilic attack of the sulfur atom to the carbon atom of the aldimine bond of $\mathbf{H L}^{\mathbf{1}}$ as evidenced by frontier molecular orbitals with the highest occupied molecular orbital (HOMO) and lowest unoccupied molecular orbital (LUMO) located at opposite sides of the molecule (Figure 2).

The use of a double amount of DDQ led to the formation of the four-electron oxidation product $\mathrm{HL}^{1 \mathrm{a} \prime \prime}$ in $71.6 \%$ yield. The electrolysis of $\mathrm{HL}^{1}$ at $1000 \mathrm{mV}$ in $\mathrm{CH}_{3} \mathrm{CN}$ versus $\mathrm{Ag} / \mathrm{AgCl}$ resulted in the same oxidation products (vide infra). Both compounds were characterized by ESI mass spectra, which showed peaks at $m / z$ 299.17 $\left[\mathrm{HL}^{1 \mathrm{a} \prime}+\mathrm{H}\right]^{+}, 321.16$ $\left[\mathrm{H} L^{1 \mathrm{a} \prime}+\mathrm{Na}\right]^{+}, 297.18\left[\mathrm{HL}^{1 \mathrm{a} \prime \prime}+\mathrm{H}\right]^{+}, 319.20\left[\mathrm{H} L^{1 \mathrm{a} \prime \prime}+\mathrm{Na}\right]^{+}$, and $296.94\left[\mathrm{HL}^{1 \mathrm{a} \prime}-\mathrm{H}\right]^{-}$. The more sterically hindered ketimine carbon atom in $\mathbf{H L}^{2}$ was expected to reduce the likelihood of 
a)

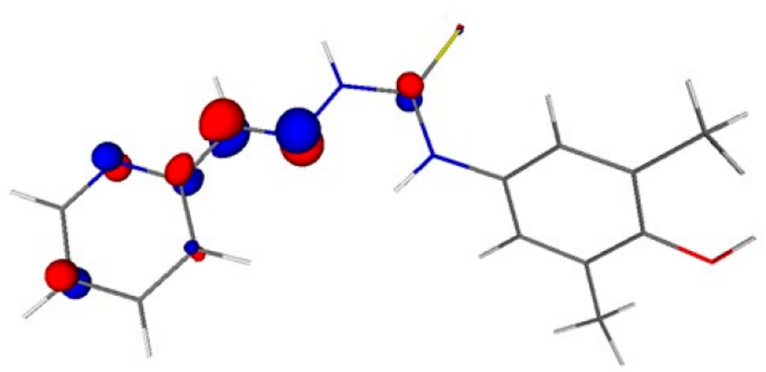

b)

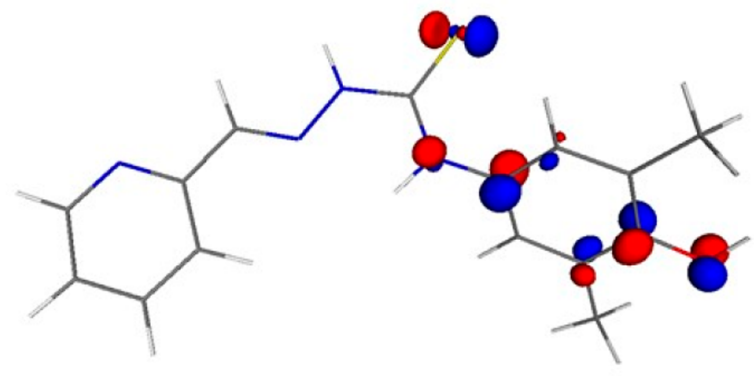

Figure 2. Frontier orbitals in $\mathbf{H L}^{1}$ : (a) LUMO and (b) HOMO drawn at 0.1 au isosurface.

the 1,3,4-thiadiazole ring formation. The reaction of $\mathrm{HL}^{2}$ with DDQ in a 1:1 molar ratio in methanol led to decomposition of the TSC with formation of an unidentified species. When PBQ a weaker oxidant $\left(2 \mathrm{e}^{-} / 2 \mathrm{H}^{+} E^{\circ}=0.643 \mathrm{~V}\right.$ vs NHE in an acidic $0.1 \mathrm{M}$ aqueous solution of $p$-TsOH) than DDQ, was used, ${ }^{47}$ a two-electron oxidative cyclization with the formation of a 1,2,4-triazole-3-thione ring (TAT group, $\mathbf{H} L^{2 \mathbf{b}}$ ) occurred, accompanied by desulfurization of $\mathbf{H L}^{2}$ and conversion into diphenolic species $\mathbf{H} \mathbf{L}^{2 \mathrm{e}}$ (DP group). ${ }^{48}$ The formation of $\mathbf{H} \mathbf{L}^{\mathbf{2 b}}$ was confirmed by ESI mass spectra, where peaks corresponding to $\left[\mathrm{HL}^{2 \mathrm{~b}}+\mathrm{H}\right]^{+}(m / z 313.25),\left[\mathrm{HL}^{2 \mathrm{~b}}+\mathrm{Na}\right]^{+}(m / z$ 335.14 $)$, and $\left[\mathrm{HL}^{2 \mathrm{~b}}-\mathrm{H}\right]^{-}(m / z 310.99)$ were present. We suppose that the initial step of the reaction of $\mathrm{HL}^{2}$ with $\mathrm{PBQ}$ involves a oneelectron oxidation of $\mathrm{HL}^{2}$ favored by the character of the HOMO of $\mathbf{H L}^{2}$ (see Figure S1) along with a $\mathrm{NH}$ deprotonation to give a highly conjugated N/S-centered free radical (see Scheme S8 in Supporting Information). This radical intermediate transforms into triazole $\mathbf{H L}^{2 \mathbf{b}}$ in two steps or undergoes a fragmentation affording 4-isothiocyanato-2,6dimethylphenol. The phenol reacts with $\mathbf{H L}^{2}$ via an $\mathrm{S}_{\mathrm{E}} 2$ mechanism to form the corresponding thioamide followed by a radical-promoted intermolecular transformation into indole $\mathrm{HL}^{2 \mathrm{e}}$ according to a Fukuyama-like indole synthesis ${ }^{49}$ (for a more detailed discussion of the oxidation of $\mathbf{H L}^{2}$ with $\mathrm{PBQ}$ see the Supporting Information).

Other oxidation agents (lead tetraacetate, phenyliodine(III) diacetate (PIDA) with $E^{\circ}=+1.70 \mathrm{~V}$ vs $\mathrm{Fc} / \mathrm{Fc}^{+}$in $\mathrm{ACN},{ }^{50}$ and silver(I) oxide) for $\mathrm{N}$-alkyl(aryl)-aminocarbonyl-4-aminophenols,${ }^{51}$ were also used in an attempt to obtain the desired oxidation products with a 1,4-benzoquinone imine moiety (see also Scheme S3, its accompanying explanation, and Figure S2 in the Supporting Information). The exposure of $\mathbf{H L}^{2}$ to 1 equiv of PIDA furnished the two-electron oxidized product $\mathbf{H} \mathbf{L}^{2 \mathrm{c} \prime}$ and traces of the four-electron oxidized species $\mathbf{H} \mathbf{L}^{2 \mathrm{c \prime}}$. As for $\mathbf{H L}^{1 \mathbf{a} \prime}$ and $\mathbf{H L}^{1 \mathrm{la} \prime}$, the use of a double amount of oxidant resulted in $\mathbf{H L}^{2 \mathrm{c} \prime \prime}$ as the main oxidation product. ESI mass spectra showed peaks at $\mathrm{m} / z$ 313.21, 310.98 attributed to $\left[\mathrm{HL}^{2 \mathrm{Cl}^{\prime}}+\mathrm{H}\right]^{+},\left[\mathrm{HL}^{2 \mathrm{C \prime}}-\mathrm{H}\right]^{-}$as well as $311.12,309.01$ assigned to $\left.\left[\mathrm{HL}^{2 \mathrm{c} \prime \prime}+\mathrm{H}\right]^{+}, \mathrm{HL}^{2 \mathrm{c} \prime \prime}-\mathrm{H}\right]^{-}$in line with the loss of two $\left(\mathrm{HL}^{2 \mathrm{c} \prime}\right)$ or four $\left(\mathbf{H} \mathbf{L}^{2 \mathrm{c} \prime \prime}\right)$ protons when compared to original TSC $\mathbf{H L}^{2}$ $\left(315.13\left[\mathrm{HL}^{2}+\mathrm{H}\right]^{+}, 313.11\left[\mathrm{HL}^{2}-\mathrm{H}\right]^{-}\right)$.

Characterization of Oxidized Organic Compounds by NMR Spectroscopy. The formation of a 1,3,4-thiadiazolering in $\mathbf{H} L^{1 \mathbf{a} \prime}$ and $\mathbf{H} L^{1 \mathbf{a} \prime \prime}$ by an oxidation of $\mathbf{H L}^{1}$ resulted in the disappearance of peaks of the aldimine $\mathrm{CH}$ proton $\left(\mathrm{H}_{7}\right)$ and $\mathrm{NH}\left(\mathrm{H}_{9}\right)$ in $\mathbf{H} \mathbf{L}^{\mathbf{1 a} \prime}$ and $\mathbf{H} \mathbf{L}^{\mathbf{1 a} \prime \prime}$ as well as of the signal of $\mathbf{N H}$ $\left(\mathrm{H}_{11}\right)$ in $\mathbf{H} L^{1 \mathbf{1 a}}$. The formation of a 1,4-benzoquinone imine moiety in $\mathbf{H L}^{1 \mathrm{la} \text { " }}$ was confirmed also by the absence of the $\mathrm{OH}$ signal, which resonates at $8.08-8.22 \mathrm{ppm}$ in $\mathrm{HL}^{1}-\mathrm{HL}^{3}, \mathbf{H L}^{\mathbf{1 a}}$ (see Scheme S4 and Tables S4-S6 in the Supporting Information). The ring-closure reaction resulted in a downfield shift of the resonance signal of carbon $\mathrm{C}_{7}$, which was directly involved in the 1,3,4-thiadiazole ring formation. The quaternary carbon $\mathrm{C}_{7}$ in $\mathbf{H} \mathbf{L}^{\mathbf{1 a}}$ and $\mathbf{H} \mathbf{L}^{\mathbf{1 a}}{ }^{\prime \prime}$ resonates at 158.40 and $169.98 \mathrm{ppm}$, respectively, whereas the aldimine $\mathrm{CH}$ carbon atom $\mathrm{C}_{7}$ in $\mathrm{HL}^{1}$ resonates at $142.51 \mathrm{ppm}$. Analogously, the involvement of the sulfur atom in the 1,3,4-thiadiazole ring led to a downfield shift of the signal of the carbon atom $\mathrm{C}_{10}$ $(C=S)$ to $166.77 \mathrm{ppm}$ in $\mathbf{H} \mathbf{L}^{\mathbf{1 a} \mathbf{a}^{\prime}}$ and to $171.58 \mathrm{ppm}$ in $\mathbf{H} \mathbf{L}^{1 \mathbf{a}^{\prime \prime}}$ when compared to $176.55 \mathrm{ppm}$ in $\mathrm{HL}^{1}$.

The four-electron oxidation of $\mathbf{H L}^{\mathrm{i}}$ to $\mathbf{H} \mathbf{L}^{\mathrm{la} \text { " }}$ with the formation of the imine $\mathrm{N}(11)=\mathrm{C}(12)$ bond resulted in strong downfield shift of the resonance signal of carbon $\mathrm{C}_{12}$ of 1,4benzoquinone moiety of $\mathbf{H L}^{1 \mathrm{la}}$ (162.21 ppm) when compared to that of carbon $\mathrm{C}_{12}$ of phenolic moiety in $\mathbf{H L}^{1}-\mathrm{HL}^{3}, \mathbf{H L}^{\mathbf{1 a}}$ (130.18-132.53 ppm). In addition, the formation of the carbonyl $\mathrm{C}(15)=\mathrm{O}(18)$ bond in $\mathbf{H} \mathbf{L}^{\mathbf{1 a}}$ has a strong effect on the resonance of carbon atom $\mathrm{C}_{15}$, which is strongly downfieldshifted to $187.14 \mathrm{ppm}$ when compared to that in $\mathbf{H L}^{1}-\mathrm{HL}^{3}$ and $\mathrm{HL}^{1 \mathrm{a} \prime}$ at 148.97-151.17 ppm. Remarkable shifts of resonance signals for other atoms of the 1,4-benzoquinone moiety in $\mathbf{H L}^{1 \mathbf{1} \text { " }}$ in comparison to the phenolic moiety in $\mathbf{H L}^{1}-\mathrm{HL}^{3}$ and $\mathrm{HL}^{1 \mathbf{a}^{\prime}}$ were also noticed (see the Supporting Information and Scheme S5 therein).

The formation of the benzothiazole ring in $\mathbf{H L}^{2 \mathbf{c} \prime}$ is evidenced by the presence in the ${ }^{1} \mathrm{H}$ NMR spectrum of one singlet of the $\mathrm{CH}$ group and two singlets of methyl groups of an unsymmetrical phenolic moiety with the intensity ratio of 1:3:3 as well as by one $\mathrm{NH}$ signal at $11.76 \mathrm{ppm}$ in comparison with a number of signals in the spectrum of $\mathbf{H L}^{2}(1(\mathrm{NH}) /$ $\left.1(\mathrm{NH}) / 2(\mathrm{CH}) / 6\left(\mathrm{CH}_{3}\right)\right)$. Of the two proposed tautomers for $\mathbf{H L}^{2 \mathbf{c}^{\prime}}(\mathbf{A}(\mathrm{N}(11) H)$ and $\mathbf{B}(\mathrm{N}(9) H)$; see Scheme S6 in the Supporting Information) the formation of the $E$ isomer of form B in DMSO- $d_{6}$ was evidenced by the cross-peak between protons of methyl $\left(\mathrm{H}_{7^{\prime}}\right)$ and $\mathrm{NH}\left(\mathrm{H}_{9}\right)$ groups in the ${ }^{1} \mathrm{H},{ }^{1} \mathrm{H}$ NOESY spectrum. The DFT B3LYP/6-311++G(d,p) calculations showed that the $E$ isomer of tautomer $\mathbf{A}$ is less stable than the $E$ isomer of tautomer $\mathbf{B}$ in a DMSO solution $(\Delta E=$ $1.58 \mathrm{kcal} / \mathrm{mol} ; \Delta G=1.01 \mathrm{kcal} / \mathrm{mol}$ at $298 \mathrm{~K}$ and $1 \mathrm{~atm})$. We found that, in contrast to $\mathrm{HL}^{1}-\mathrm{HL}^{3}$, the $E / Z$ isomerization was observed for $\mathbf{H L}^{2 \mathrm{c} \prime}$. As expected in case of $\mathbf{H L}^{2 \mathrm{c} \prime}$. $\mathrm{CH}_{3} \mathrm{COOH}$, where nitrogen atom $\mathrm{N}_{1}$ of the pyridine ring is protonated and prevents the hydrogen-bond formation between $\mathrm{H}_{9}$ and $\mathrm{N}_{1}$, which is present in the $Z$ isomer of $\mathbf{H L}^{2 \mathrm{c \prime}}$, only one set of signals attributed to the $E$ isomer was found. The neutral species $\mathrm{HL}^{2 \mathrm{c} \prime}$ in DMSO- $d_{6}$ and $\mathrm{MeOH}-d_{4}$ is present as the $E$ isomer, which converts slowly into the $Z$ isomer. The process is solvent-dependent. The $E / Z$ equilibrium was reached in $6 \mathrm{~d}$ with a molar ratio of $E / Z$ isomers of 7.2:1 (DMSO- $\left.d_{6}\right)$ and 3:1 $\left(\mathrm{MeOH}-d_{4}\right)$ (see Figure S3 in the Supporting Information). The $Z$ isomer of $\mathbf{H L}^{2 \mathbf{c}^{\prime}}$ in DMSO- $d_{6}$ is characterized by the downfield-shifted proton $\mathrm{NH}(9)$ due to 
the hydrogen bond to the pyridine nitrogen atom and resonates at $15.00 \mathrm{ppm}$ (the same proton of the $E$ isomer of $\mathbf{H} L^{2 c^{\prime}}$ is seen at $\left.11.58 \mathrm{ppm}\right)$. The $Z / E$ isomerization of $\mathbf{H} L^{2 c^{\prime}}$ was also studied in $\mathrm{MeOH}-d_{4}$ and methanol by ${ }^{1} \mathrm{H}$ NMR and UV-vis spectroscopy reaching 1:3.6 molar ratio in $14 \mathrm{~d}$ according to NMR spectra (for optical spectra difference see Figure S4). The carbon atom of the methyl group $\left(\mathrm{C}_{7^{\prime}}\right)$ in the $E$ isomers of $\mathrm{HL}^{2 \mathrm{c}^{\prime}} \cdot \mathrm{CH}_{3} \mathrm{COOH}$ and $\mathrm{HL}^{2 \mathrm{c} \prime}$ resonates at 12.55 and $12.56 \mathrm{ppm}$, respectively, whereas in the $Z$ isomer of $\mathbf{H L}^{2 \mathrm{c} \prime}$ it resonates at $21.72 \mathrm{ppm}$. Note that these chemical shifts are consistent with those calculated for $E$ - and $Z-H L^{2 c^{\prime}}$ (8.29 and $23.26 \mathrm{ppm}$, respectively) by the gauge-independent atomic orbital (GIAO) method at the WC04/6-311+G(2d,p) level of theory using the DFT B3LYP/6-311++G(d,p) optimized geometries (DMSO solution, the PCM solvation model). A similar difference in chemical shifts of the $\mathrm{CH}_{3}$ group was also observed for the $E(12.31 \mathrm{ppm})$ and $Z$ isomers $(21.73 \mathrm{ppm})$ of $\mathbf{H L}^{2}$. The DFT calculation also demonstrated that $E$ and $Z$ isomers of $\mathrm{HL}^{2 \mathrm{c} \prime}$ have a quite similar stability in a DMSO solution $(\Delta G=0.11 \mathrm{kcal} / \mathrm{mol}$ in favor of the $E$ isomer; $298 \mathrm{~K}$, $1 \mathrm{~atm})$. As expected, the pyridine ring carbon atom $\mathrm{C}_{3}$ is also sensitive to the hydrogen-bond formation between $\mathrm{H}_{9}$ and $\mathrm{N}_{1}$ in the $Z$ isomer of $\mathbf{H L}^{2 \mathrm{c} \prime}$. The $\mathrm{C}_{3}$ signal in the latter is markedly shifted (124.08 ppm) in comparison to $C_{3}$ in the $E$ isomer (119.65 ppm). A full assignment of resonances was possible only for $\mathrm{HL}^{2 \mathrm{c}^{\prime}} \cdot \mathrm{CH}_{3} \mathrm{COOH}$ (the three quaternary carbons $\mathrm{C}_{12}, \mathrm{C}_{7}$, and $\mathrm{C}_{17}$ were identified according to ${ }^{1} \mathrm{H},{ }^{13} \mathrm{C}$ HMBC; see Figure S5 in the Supporting Information).

The two-electron oxidation of $\mathbf{H} L^{2 c^{\prime}}$ to $H L^{2 \mathrm{c} \prime}$ with the formation of the quinone moiety is accompanied by the downfield shift of the resonance signal of carbon $\mathrm{C}_{15}$ at 184.43 ppm in comparison to that of $\mathrm{C}_{15}$ in $\mathrm{HL}^{2 \mathrm{c}^{\prime}} \cdot \mathrm{CH}_{3} \mathrm{COOH}$ at $148.14 \mathrm{ppm}$, in $E-H L^{2 c^{\prime}}$ at $148.15 \mathrm{ppm}$, and in $Z-H L^{2 \mathrm{c} \prime}$ at $148.39 \mathrm{ppm}$. The lack of the $\mathrm{NH}$ signal confirms the formation of the imine $\mathrm{N}(9)=\mathrm{C}(10)$ bond (see Scheme S7 and Tables S4 and S5 in the Supporting Information).

Synthesis and Characterization of Copper(II) Complexes. The reaction of $\mathrm{HL}^{1}-\mathrm{HL}^{3}$ with $\mathrm{CuCl}_{2} \cdot 2 \mathrm{H}_{2} \mathrm{O}$ in anoxic methanol under an argon atmosphere to preclude an eventual oxidation of the ligands by air oxygen in a 1:1 molar ratio at room temperature afforded green-brown solids of the formulas $\mathrm{Cu}\left(\mathrm{HL}^{1}\right) \mathrm{Cl}_{2}(\mathbf{1}),\left[\mathrm{Cu}\left(\mathrm{L}^{2}\right) \mathrm{Cl}\right]\left(2^{\prime}\right)$, and $\mathrm{Cu}\left(\mathrm{HL}^{3}\right) \mathrm{Cl}_{2}$ (3) in almost quantitative yields. The formation of these copper(II) complexes was confirmed by elemental analyses and ESI mass spectra. The latter showed peaks attributed to $\left[\mathrm{Cu}\left(\mathrm{L}^{1,3}\right)-\mathrm{H}^{+},\left[\mathrm{Cu}\left(\mathrm{L}^{1,3}\right) \mathrm{Cl}-\mathrm{H}\right]^{-}\right.$, or $\left[\mathrm{Cu}\left(\mathrm{L}^{2}\right)\right]^{+}$and $[\mathrm{Cu}-$ $\left.\left(\mathrm{L}^{2}\right) \mathrm{Cl}-\mathrm{H}\right]^{-}$. XRD-quality single crystals of $\left[\mathbf{C u}\left(\mathbf{L}^{1-3}\right) \mathbf{C l}\right]$ $\left(1^{\prime}-3^{\prime}\right)$ were grown from diluted by a factor of ca. 20 reaction mixtures under argon upon standing at $4{ }^{\circ} \mathrm{C}$. Under these conditions the deprotonation of ligands $\mathbf{H L}^{1}$ and $\mathbf{H L}^{3}$ occurred. Attempts to crystallize 1, 2', and 3 in air failed, most likely because of an occurring oxidation of complexes by $\mathrm{O}_{2}$.

Synthesis of the Copper(II) Complexes with Oxidized Ligands. Upon a prolonged standing of a methanolic solution of $\mathbf{C u}\left(\mathrm{HL}^{1}\right) \mathrm{Cl}_{2}$ (1) in air, a minor amount of crystals of $\left[\mathbf{C u}\left(L^{1 \mathbf{c}^{\prime}}\right) \mathbf{C l}\right]$ (4) formed, in which the ligand underwent an oxidative dehydrogenation along with the intramolecular cyclization via a $\mathrm{C}-\mathrm{S}$ coupling reaction between phenolic carbon and thione group into a five-membered thiazole ring, as confirmed by SC-XRD (vide infra). Some rare examples of thiosemicarbazone cyclization with the benzothiazole ring formation due to a coordination to copper(II) were recently reported. ${ }^{52,53}$ A direct complex formation reaction between the prepared benzo $[d]$ thiazol-6-ol $\mathbf{H} L^{2 \mathrm{c} \prime}$ and copper(II) chloride produced $\left[\mathrm{Cu}\left(\mathrm{HL}^{2 \mathrm{Cl}^{\prime}}\right) \mathrm{Cl}_{2}\right]$ (6) under an inert atmosphere. The same reaction in air was accompanied by a further oxidation of $\mathbf{H} \mathbf{L}^{2 \mathrm{c} \prime}$ with the formation of benzo[d] thiazol-6-one $\left(\mathbf{H} L^{2 \mathrm{c} \prime \prime}\right)$ bound to copper(II). Complex 6 was characterized by the positive ion ESI mass spectrum with a peak at $\mathrm{m} / z 374.08$ attributed to $\left[\mathrm{Cu}\left(L^{2 \mathrm{c} \prime}\right)\right]^{+}$, whereas the product obtained by an oxidation in air revealed a peak at $\mathrm{m} / \mathrm{z} 373.06$ assigned to $\left[\mathrm{Cu}^{\mathrm{I}}\left(\mathrm{HL}^{2 \mathrm{c} \prime \prime}\right)\right]^{+}$. The peak at $m / z 373.06$ was also seen when the reaction mixture of $\mathrm{HL}^{2 \mathrm{c} \prime \prime}$ with $\mathrm{CuCl}_{2} \cdot 2 \mathrm{H}_{2} \mathrm{O}$ was subjected to an ESI MS measurement.

The reactions of copper(II) with the oxidized TSCs, namely, 1,3,4-thiadiazole-containing species $\mathbf{H} L^{\mathbf{1 a} \prime}$ and $\mathbf{H} L^{\mathbf{1 a} \prime \prime}$, were monitored by ESI-MS experiments. When $\mathrm{CuCl}_{2} \cdot 2 \mathrm{H}_{2} \mathrm{O}$ was allowed to react with $\mathrm{HL}^{1 \mathbf{a}^{\prime}}$ and $\mathrm{HL}^{1 \mathbf{1} \mathbf{a}^{\prime \prime}}$ in a 1:1 molar ratio, ESI mass spectra of the reaction mixtures indicated the formation of complexes with metal-to-ligand stoichiometry of 1:2, namely, $\left[\mathrm{Cu}\left(\mathrm{HL}^{1 \mathrm{a} \prime}\right)_{2}\right]^{+}$and $\left[\mathrm{Cu}\left(\mathrm{H} L^{1 \mathrm{a} \prime \prime}\right)_{2}\right]^{+}$, respectively. Interestingly, under varied reaction conditions (different solvents, air atmosphere, and varied temperature and reaction time, see details in Table S7) the synthesis of copper(II) complex of $\mathbf{H L}^{\mathbf{1 a} \mathbf{a}^{\prime}}$ resulted in a sequential oxidation of the two ligands, and several oxidized products could be identified based on ESI-MS peaks as $\left[\mathrm{Cu}\left(\mathrm{HL}^{1 \mathrm{a \prime} \prime}\right)_{2}\right]^{+}(m / z$ 659.16), $[\mathrm{Cu}-$ $\left.\left(\mathrm{H} L^{1 \mathrm{a} \prime}\right)\left(\mathrm{H} L^{1 \mathrm{a} \prime \prime}\right)\right]^{+}(m / z \quad 657.13), \quad\left[\mathrm{Cu}\left(\mathrm{HL}^{1 \mathrm{a} \prime \prime}\right){ }_{2}\right]^{+}(m / z$ 655.18), $\left[\mathrm{Cu}\left(\mathrm{HL}^{1 \mathrm{a} \prime}\right)\left(\mathrm{CH}_{3} \mathrm{CN}\right)\right]^{+}(m / z 402.10),\left[\mathrm{Cu}\left(\mathrm{H} L^{1 \mathrm{a} \prime \prime}\right)-\right.$ $\left.\left(\mathrm{CH}_{3} \mathrm{CN}\right)\right]^{+}(\mathrm{m} / z$ 400.10). Moreover, attempts of the chromatographic separation of the obtained compounds (on $\mathrm{SiO}_{2}$ with $\mathrm{MeOH}$ as eluent $)$ led to a new species $\left[\mathrm{Cu}\left(\mathrm{H} L^{1 \mathrm{a} \prime}\right)-\right.$ $\left.\left(\mathrm{H} L^{1 \mathrm{~d}}\right)\right]^{+}(m / z 537.15)$, in which one already oxidized ligand $\mathbf{H} L^{1 \mathbf{a} \prime}$ in $\left[\mathrm{Cu}\left(\mathrm{HL}^{1 \mathrm{a} \prime \prime}\right)_{2}\right]^{+}$lost the phenolic moiety. The complex formation of $\mathbf{H L}^{\mathbf{1 a}}$ in $\mathrm{MeOH}$ under heating at 50 ${ }^{\circ} \mathrm{C}$ resulted in two species $\left[\mathrm{Cu}\left(\mathrm{H} L^{1 \mathrm{a} \prime \prime}\right)\left(\mathrm{H} L^{1 \mathrm{~d}}\right)\right]^{+}(m / z 537.15)$ and $\left[\mathrm{Cu}\left(\mathrm{H} L^{1 \mathrm{~d}}\right)_{2}\right]^{+}(m / z 419.08)$, whereas under prolonged heating $(36 \mathrm{~h})$ only $\left[\mathrm{Cu}\left(\mathrm{H} L^{1 \mathrm{~d}}\right)_{2}\right]^{+}$was detected, and the formation of complex $\left[\mathbf{C u}\left(\mathbf{H L}^{\mathbf{1 d}}\right)_{2} \mathbf{C l}_{2}\right]$ (5) was confirmed by SC-XRD.

The potentially redox-active TSC ligands $\left(\mathbf{H L}^{\mathbf{1}},\left(\mathbf{L}^{2}\right)^{-}\right.$, and $\mathbf{H L}^{3}$ ) in $\mathbf{1}, \mathbf{2}^{\prime}$, and 3 proved to react slowly with oxygen in air. Indeed, ESI mass spectra of methanolic solutions of $1,2^{\prime}$, or 3 after a prolonged standing in air showed peaks with $\mathrm{m} / z$ shifted by 2 amu to lower masses in agreement with an oxidative dehydrogenation required for the formation of twoelectron oxidation products.

To finally determine the redox status of the 4-aminophenolic moiety, the configurations adopted by the metal-free ligands in the solid state and their protonation level in copper(II) complexes SC-XRD studies were performed.

X-ray Crystallography of the Metal-Free Ligands $\mathrm{HL}^{1}-\mathrm{HL}^{3}$ and Copper(II) Complexes $1^{\prime}-3^{\prime}$. The results of X-ray diffraction studies of TSCs $\mathrm{HL}^{1} \cdot \mathrm{C}_{2} \mathrm{H}_{5} \mathbf{O H}, \mathrm{HL}^{2}$ and $\mathbf{H L}^{3}$ are presented in Figure 3, while those of $\left[\mathbf{C u}\left(\mathbf{L}^{1}\right) \mathbf{C l}\right] \cdot$ $\mathrm{CH}_{3} \mathrm{OH}\left(1^{\prime} \cdot \mathrm{CH}_{3} \mathrm{OH}\right),\left[\mathrm{Cu}\left(\mathrm{L}^{2}\right) \mathrm{Cl}\right]\left(2^{\prime}\right)$, and $\left[\mathrm{Cu}\left(\mathrm{L}^{3}\right) \mathrm{Cl}\right] \cdot$ $\mathrm{CH}_{3} \mathrm{OH}\left(3^{\prime} \cdot \mathrm{CH}_{3} \mathrm{OH}\right)$ are in Figure 4 . The $\mathrm{HL}^{1} \cdot \mathrm{C}_{2} \mathrm{H}_{5} \mathbf{O H}$ crystallized in the triclinic centrosymmetric space group $P \overline{1}$, while $\mathbf{H L}^{2}$ and $\mathbf{H L}^{3}$ crystallized in the monoclinic space groups $P 2_{1} / c$ and $P 2_{1} / n$, respectively. All three metal-free ligands adopt an $E$ configuration in terms of the nomenclature used for the $\alpha-N$-heterocyclic thiosemicarbazones ${ }^{41}$ with the imine nitrogen in the s-trans position to the sulfur atom and the pyridine $\mathrm{N} 1$ atom. All TSCs crystallized in the thione form with the C7-S bond length of $1.6839(15), 1.683(4)$ and 
a)

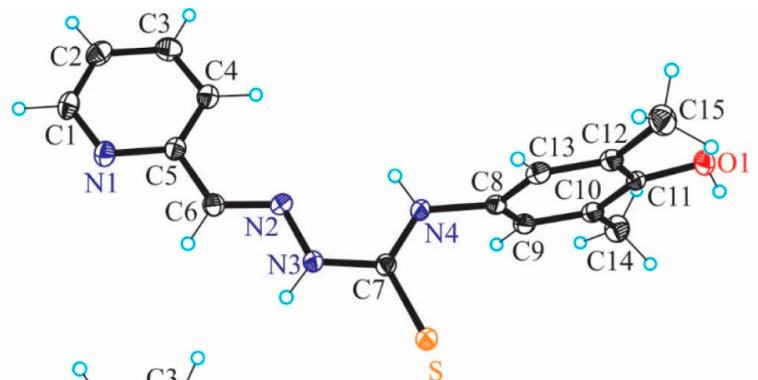

b)

c)
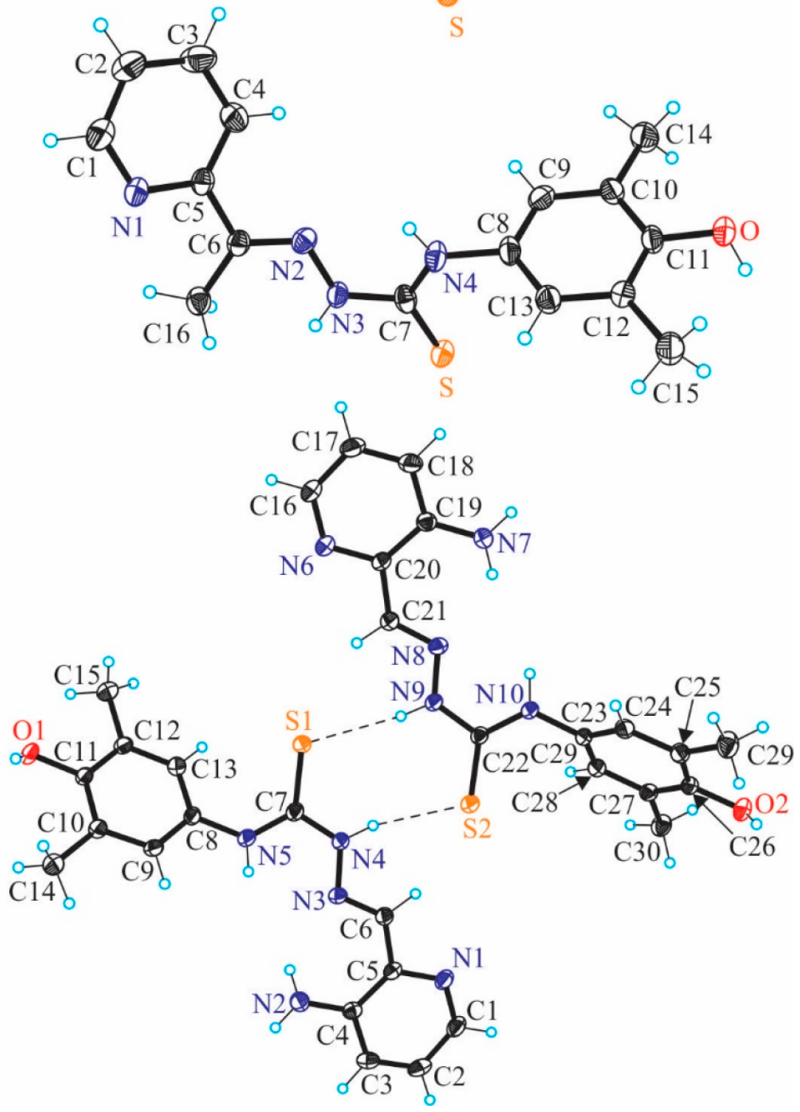

Figure 3. ORTEP views of $\mathbf{H L}^{1}-\mathbf{H L}^{3}$ with thermal ellipsoids at the $50 \%$ probability level. Selected bond distances $(\AA)$ and torsion angles (deg): (a) HL H $^{1}$ C6-N2 1.280(2), N2-N3 1.3701(18), N3-C7 1.357(2), C7-S 1.6839(15), C7-N4 1.331(2), N4-C8 1.442(2), C11-O1 1.3780(19); $\Theta_{\mathrm{C} 7-\mathrm{N} 4-\mathrm{C} 8-\mathrm{C} 13}-88.7(2)$; (b) $\mathrm{HL}^{2}$ : C6-N2 1.287(4), N2-N3 1.374(4), N3-C7 1.363(4), C7-S 1.683(4), C7$\mathrm{N} 4$ 1.326(4), N4-C8 1.446(4), C11-O 1.370(4); $\Theta_{\mathrm{C} 7-\mathrm{N} 4-\mathrm{C} 8-\mathrm{C} 13}-$ 78.4(4); (c) $\mathrm{HL}^{3}: \mathrm{C} 4-\mathrm{N} 21.361(3), \mathrm{C} 6-\mathrm{N} 31.288(2), \mathrm{N} 3-\mathrm{N} 4$ 1.385(2), N4-C7 1.343(2), C7-S1 1.695(2), C7-N5 1.342(3), N5-C8 1.430(2), C11-O1 1.380(2); $\Theta_{\mathrm{C} 7-\mathrm{N} 5-\mathrm{C} 8-\mathrm{C} 13} 52.5(3)$.

1.695(2) A, respectively. The distribution of electron density in the dimethylphenolic moiety is typical for aromatic systems. The C11-O bond length of $1.3780(19), 1.370(4)$, and $1.380(2) \AA$, respectively, is also characteristic for phenols. The molecules of the three proligands are not planar. The strong deviation of the phenolic unit from the mean plane of the thiosemicarbazone fragment can be estimated by a comparison of the torsion angle $\Theta_{\mathrm{C} 7-\mathrm{N} 4-\mathrm{C} 8-\mathrm{C} 13}$ of $88.7(2)$ and $78.4(4)^{\circ}$ in the first two structures (Figure $3 \mathrm{a}, \mathrm{b}$ ) and $\Theta_{\mathrm{C} 7-\mathrm{N} 5-\mathrm{C} 8-\mathrm{C} 13}$ and $\Theta_{\mathrm{C} 22-\mathrm{N} 10-\mathrm{C} 23-\mathrm{C} 28}$ of $52.5(3)$ and $54.2(3)^{\circ}$ in two crystallographically independent molecules of $\mathbf{H L}^{3}$ (Figure 3c).

In contrast to the structures of $\mathbf{H L}^{1}$ and $\mathbf{H L}^{2}$, the asymmetric unit of $\mathbf{H L}^{3}$ consists of two molecules associated a)

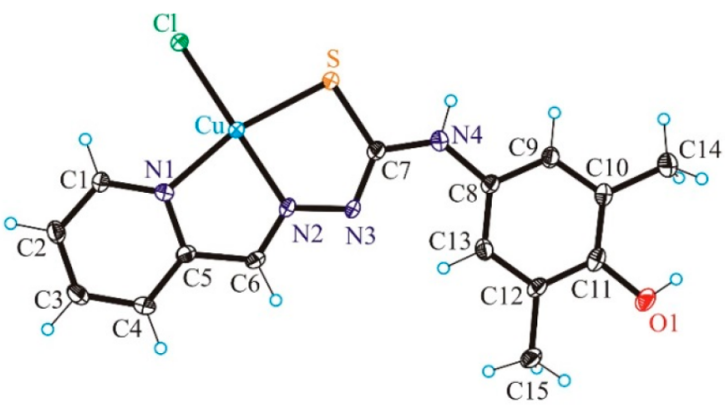

b)

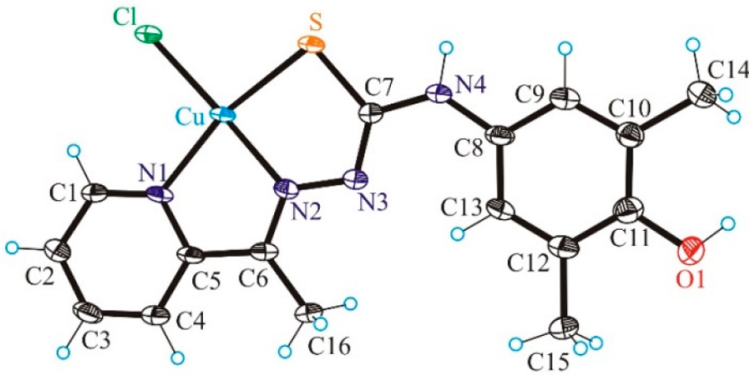

c)

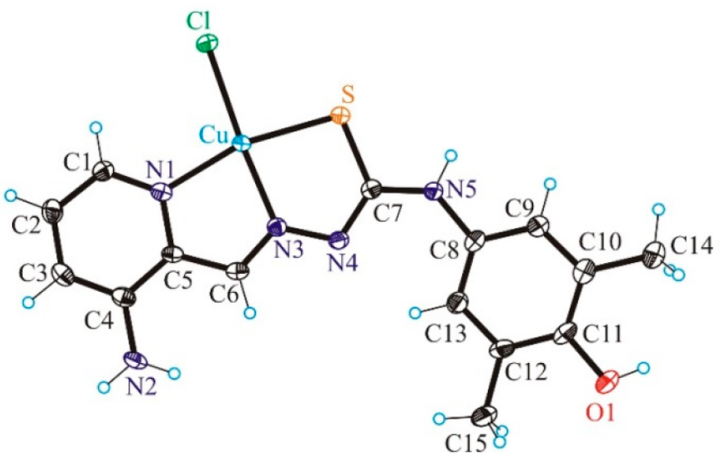

Figure 4. ORTEP views of $\mathbf{1}^{\prime}-\mathbf{3}^{\prime}$ with thermal ellipsoids at the $50 \%$ probability level. Selected bond distances $(\AA)$, bond angles (deg) and torsion angles (deg) in $\mathbf{1}^{\prime}$ : $\mathrm{Cu}-\mathrm{N} 12.005(2), \mathrm{Cu}-\mathrm{N} 21.962(2), \mathrm{Cu}-$ $\mathrm{S}$ 2.2325(7), $\mathrm{Cu}-\mathrm{Cl} 2.2507(7), \mathrm{C} 11-\mathrm{O} 1$ 1.370(4); N1-Cu-N2 81.77(9), N2-Cu-S 84.07(7), $\Theta_{\mathrm{C} 7-\mathrm{N} 4-\mathrm{C} 8-\mathrm{C} 13}-0.8(5)$; in $2^{\prime}: \mathrm{Cu}-$ $\mathrm{N} 12.022(4), \mathrm{Cu}-\mathrm{N} 2$ 1.952(4), $\mathrm{Cu}-\mathrm{S}$ 2.2636(16), $\mathrm{Cu}-\mathrm{Cl}$ 2.2215(15), C11-O1 1.370(6); N1-Cu-N2 80.76(17), N2-Cu-S 84.46(12), $\Theta_{\mathrm{C} 7-\mathrm{N} 4-\mathrm{C} 8-\mathrm{C} 13}-2.1(8)$; in $3^{\prime}: \mathrm{Cu}-\mathrm{N} 12.025(2), \mathrm{Cu}-\mathrm{N} 3$ 1.961(2), Cu-S 2.2432(8), Cu-Cl 2.2636(8), C11-O1 1.374(4); $\mathrm{N} 1-\mathrm{Cu}-\mathrm{N} 3$ 81.58(10), N3-Cu-S 83.40(7), $\Theta_{\mathrm{C} 7-\mathrm{N} 5-\mathrm{C} 8-\mathrm{C} 13} 9.4(5)$.

in a centrosymmetric dimer via hydrogen-bonding interactions, namely, N4-H..S2 [N4-H4 = $0.88 \AA, \mathrm{H} 4 \cdots \mathrm{S} 2=2.48 \AA$, $\mathrm{N} 4 \cdots \mathrm{S} 2=3.3243(17) \AA]$ and $\mathrm{N} 9-\mathrm{H} \cdots \mathrm{S} 1\left[\mathrm{~N} 9-\mathrm{H} 9=0.88^{\circ}\right.$, $\mathrm{H} 9 \cdots \mathrm{S} 1=2.47 \AA, \mathrm{N} 9 \cdots \mathrm{S} 1=3.3341(17) \AA]$. A similar centrosymmetric association was recently reported for acetylpyrazine $4-\mathrm{N}$-phenyl thiosemicarbazone. ${ }^{54}$

The copper(II) complexes $\mathbf{1}^{\prime} \cdot \mathrm{CH}_{3} \mathrm{OH}$ and $3^{\prime} \cdot \mathrm{CH}_{3} \mathrm{OH}$ crystallized in the monoclinic centrosymmetric space group $P 2_{1} / c$, while $2^{\prime}$ crystallized in the triclinic centrosymmetric space group $P \overline{1}$ without any cocrystallized solvent. The copper(II) adopts a square-planar coordination geometry in all three structures (Figure 4). The thiosemicarbazones act as tridentate monoanionic ligands binding to copper(II) via a pyridine nitrogen atom, an azomethine nitrogen atom, and a thiolate sulfur atom. The fourth coordination site in all complexes is occupied by the chlorido coligand. Pertinent bond distances and bond angles are quoted in the legend to 
Figure 4. The same coordination geometry of a copper(II) bound by a monoanionic thiosemicarbazone and a monodentate coligand was reported for $[\mathrm{CuCl}(\mathrm{mPip}-\mathrm{FTSC}-\mathrm{H})]$. $0.15 \mathrm{CH}_{3} \mathrm{OH},{ }^{55}\left[\mathrm{Cu}\left(\mathrm{L}_{1}\right)(\mu-\mathrm{Cl})\right] \mathrm{Cl}$, and $\left[\mathrm{Cu}\left(\mathrm{L}_{2}\right)(\mu-\mathrm{Cl})\right] \mathrm{Cl}$. $\mathrm{H}_{2} \mathrm{O}$, where ligands $\mathrm{L}_{1}$ and $\mathrm{L}_{2}$ represent 3-methyl-5-oxo-1phenyl-3-pyrazolin-4-carboxaldehyde and 5-oxo-3-phenyl-3pyrazolin-4-carboxaldehyde TSC, respectively. ${ }^{56}$

A comparison of the $\mathrm{Cu}(\mathrm{II})$ to TSC ligand bond lengths in $\mathbf{1}^{\prime}$ with those in the copper(II) complex with pyridine-2carboxaldehyde thiosemicarbazone $^{57}(\mathrm{Cu}-\mathrm{N1}=2.034(4)$, $\mathrm{Cu}-\mathrm{N} 2=1.975(3), \mathrm{Cu}-\mathrm{S}=2.278(1) \AA$ ) shows that these are statistically significantly shorter in $\mathbf{1}^{\prime}$. This difference is probably due to the formation of centrosymmetric associates via intermolecular interactions with the shortest contact $\mathrm{Cu} \cdots S^{\mathrm{i}}$ $=2.760$ (2) $\AA$ and not due to the presence of a phenolic moiety at N4. The interatomic repulsions in the copper(II) complex with a $4+1$ coordination geometry are expected to be stronger than those in $\mathbf{1}^{\prime}$, in which the $\mathrm{Cu}(\mathrm{II})$ is four-coordinate. In another complex $[\mathrm{CuLCl}]_{2}\left[\mathrm{Cu}(\text { pic })_{2}\right]$ (with $\mathrm{HL}=$ pyridine-2carboxaldehyde thiosemicarbazone and $\mathrm{pic}^{-}=$pyridine-2carboxylate), in which the intermolecular contacts are over $3 \AA$, the $\mathrm{Cu}(\mathrm{II})$ to TSC bond distances are shorter and very similar to those in $\mathbf{1}^{\prime}(\mathrm{Cu}-\mathrm{N} 1=2.005(8), \mathrm{Cu}-\mathrm{N} 2=1.942(9), \mathrm{Cu}-\mathrm{S}$ $=2.264(3) \AA) .{ }^{48}$ The metric parameters in the copper(II)ligand chromophore of $[\mathrm{Cu}($ triapine- $\mathrm{H}) \mathrm{Cl}]\left(\mathrm{H}_{3} \mathrm{O}\right) \mathrm{Cl}\left(\mathrm{Cu}-\mathrm{N}_{\text {py }}\right.$ $=2.031(8), \mathrm{Cu}-\mathrm{N}_{\text {hydrazine }}=1.937(9), \mathrm{Cu}-\mathrm{S}=2.281(3)$ and $\mathrm{Cu}-\mathrm{Cl}=2.2493(5) \AA$ ) are statistically the same as those in $3^{\prime}$, except $\mathrm{Cu}-\mathrm{S}$, which is by ca. $0.04 \AA(>12 \sigma)$ shorter in $3^{\prime}$ than in the copper(II) complex with triapine. This is likely due to different protonation states of the ligands in the two complexes, even though the authors described the triapine ligand in its copper(II) complex as a monoanion with an extra proton at a cocrystallized water molecule. ${ }^{58}$

Note that the organic ligands in all three complexes are almost planar in contrast to the situation described previously for the metal-free ligands. The value of the torsion angle $\Theta_{\mathrm{C} 7-\mathrm{N} 4-\mathrm{C} 8-\mathrm{C} 13}$ for $\mathbf{1}^{\prime} \cdot \mathbf{C H}_{3} \mathbf{O H}$ and $\mathbf{2}^{\prime}$ (Figure $4 \mathrm{a}, \mathrm{b}$ ) increased from $-88.7(2)$ and $-78.4(4)^{\circ}$ in $\mathrm{HL}^{1}$ and $\mathrm{HL}^{2}$ to $-0.8(5)$ and $-2.1(8)^{\circ}$, respectively. Analogously, the torsion angle $\Theta_{\mathrm{C} 7-\mathrm{N} 5-\mathrm{C} 8-\mathrm{C} 13}$ of $52.5(3)$ in $\mathrm{HL}^{3}$ becomes of $9.4(5)^{\circ}$ in $3^{\prime} \cdot$ $\mathrm{CH}_{3} \mathrm{OH}$ upon coordination to copper(II).

As for the metal-free TSCs, the phenolic moiety remained intact in all three complexes, namely, in its original oxidation state. The distribution of electron density over the aromatic phenolic ring is well-comparable to that in the TSCs.

X-ray Crystallography of Oxidized Products. The results of $\mathrm{X}$-ray diffraction studies of oxidized organic species $\mathbf{H} L^{1 \mathrm{a} \prime}, \mathbf{H} L^{1 \mathrm{a} \mathbf{a}^{\prime \prime}}, \mathbf{H} L^{2 \mathrm{~b}}, \mathbf{H} L^{2 \mathrm{e}}$, and $\mathbf{H} L^{2 \mathrm{c} "} \cdot 0.5 \mathrm{CHCl}_{3}$ are displayed in Figure 5 and Figure S6, while those of copper(II) complexes with oxidized ligands 4-6 are shown in Figure 6 and Figure S7. The oxidized species $\mathbf{H} L^{1 \mathbf{a} \prime}$ and $\mathbf{H} L^{1 \mathbf{a} \prime \prime}$ crystallize in the monoclinic space groups $P 2_{1} / n$ and $C c$, respectively. The molecule $\mathbf{H} L^{\text {la' }}$ is almost planar, while in $\mathbf{H} L^{\mathbf{1 a} \text { ” }}$ the moiety at N4 slightly deviates from planarity. The dihedral angle $\Theta_{\mathrm{C} 7-\mathrm{N} 4-\mathrm{C} 8-\mathrm{C} 13}$ is of $5.8(3)^{\circ}$. Both contain a thiadiazole fivemembered ring. The distribution of electron density in them is very similar. In contrast, the bond length distribution in the aryloxide moiety is quite different. In the two-electron oxidized product $\mathbf{H} L^{\mathbf{1 a} \prime}$ the distribution of electron density is in agreement with that of the 3,5-dimethyl-1,4-aminophenolic moiety, while in the four-electron oxidized species $\mathbf{H} \mathbf{L}^{\mathbf{1 a}}$ the electron density agrees with that of the 3,5-dimethyl-1,4benzoquinone imine unit (see legend to Figure 5a,b). In a)

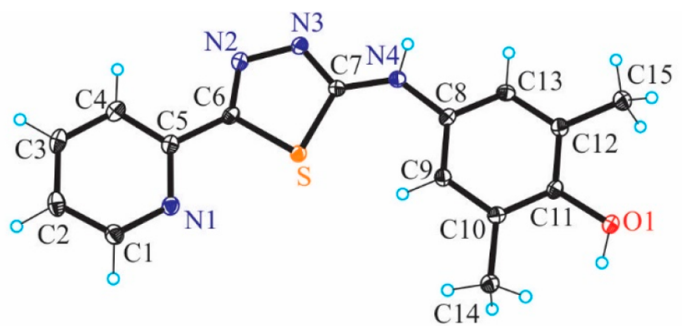

b)

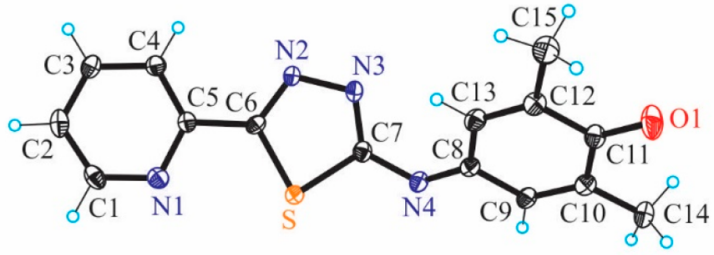

c)

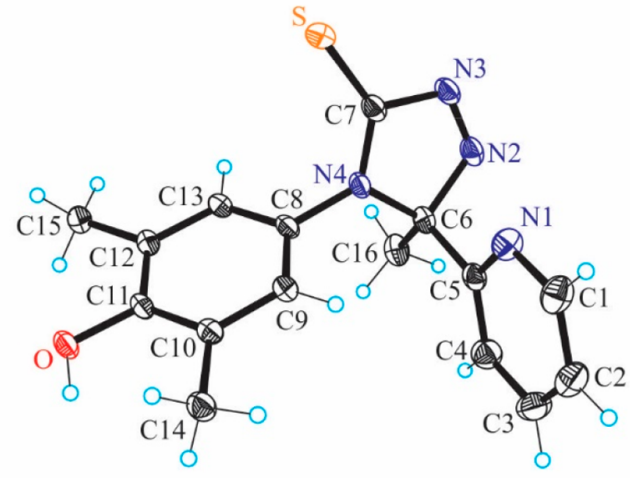

d)

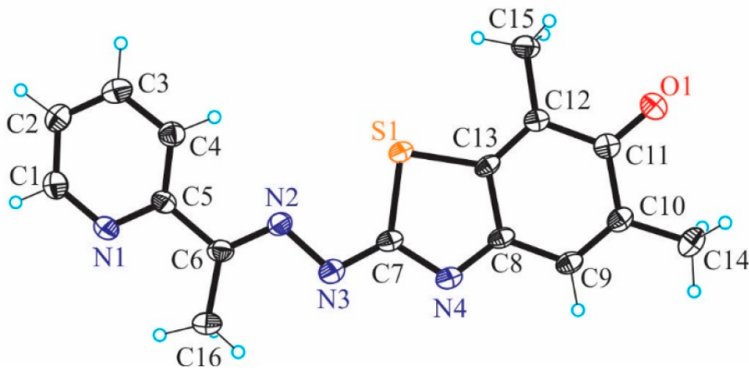

Figure 5. ORTEP views of two-electron and four-electron oxidized species of (a) $H L^{1 \mathbf{a} \prime}$ and (b) $H L^{1 \mathbf{a} \prime}$, as well as of products that resulted from an oxidation of $\mathbf{H L}^{2}$, namely, of (c) $\mathbf{H} L^{\mathbf{2 b}}$ and (d) $\mathbf{H L}^{2 \mathrm{c} "} \cdot \mathbf{0 . 5} \mathbf{C H C l}_{3}$. Selected bond distances $(\AA)$ and torsion angles (deg) in (a) $H L^{1 \mathbf{a}^{\prime}}$ : C6-N2 1.3029(17), N2-N3 1.3739(15), C6-S 1.7405(14), C7-S 1.7382(13), C8-C9 1.3878(19), C9-C10 1.4003(18), C10-C11 1.3927(19), C11-C12 1.4006(19), C12$\mathrm{C} 13$ 1.3922(19), $\mathrm{C} 11-\mathrm{O} 11.3820(16) ; \Theta_{\mathrm{C} 7-\mathrm{N} 4-\mathrm{C} 8-\mathrm{C} 9} 1.0(2)$; in (b) $\mathrm{HL}^{1 \mathrm{a}}{ }^{\prime \prime}: \mathrm{C} 6-\mathrm{N} 2$ 1.305(3), N2-N3 1.382(2), C6-S 1.727(2), C7-S 1.734(2), C8-C9 1.458(3), C9-C10 1.341(3), C10-C11 1.480(3), C11-C12 1.491(3), C12-C13 1.342(3), C11-O1 1.226(3); $\Theta_{\mathrm{C} 7-\mathrm{N} 4-\mathrm{C} 8-\mathrm{C} 13} 5.8(3)$; in (c) $\mathrm{HL}^{2 \mathbf{b}}: \mathrm{C} 6-\mathrm{N} 2 \quad 1.485(2), \mathrm{N} 2-\mathrm{N} 3$ 1.247(2), N3-C7 1.472(2), C7-S 1.6465(18), C7-N4 1.325(2), N4-C6 1.479(2), C11-O 1.3728(18), N4-C8 1.4409(19); in (d) $\mathrm{HL}^{2 \mathrm{c} "} \cdot \mathbf{0 . 5} \mathrm{CHCl}_{3}: \mathrm{C} 6-\mathrm{N} 2 \quad 1.306(4), \mathrm{N} 2-\mathrm{N} 3 \quad 1.394(4), \mathrm{N} 3-\mathrm{C} 7$ 1.296(4), C7-N4 1.388(4), N4-C8 1.311(4), C8-C9 1.444(4), C9-C10 1.340(4), C10-C11 1.488(5), C11-O1 1.234(4), C11C12 1.496(4), C12-C13 1.349(4), C13-C8 1.461(4), C13-S1 $1.745(3)$.

particular, the $\mathrm{C} 11-\mathrm{O} 1$ bond length in these two compounds is quite different at $1.3820(16)$ and $1.226(3) \AA$, respectively. The X-ray diffraction structure of $\mathbf{H L}^{\mathbf{2 b}}$ confirmed the twoelectron oxidation of the original ligand $\mathrm{HL}^{2}$ and the formation 
a)

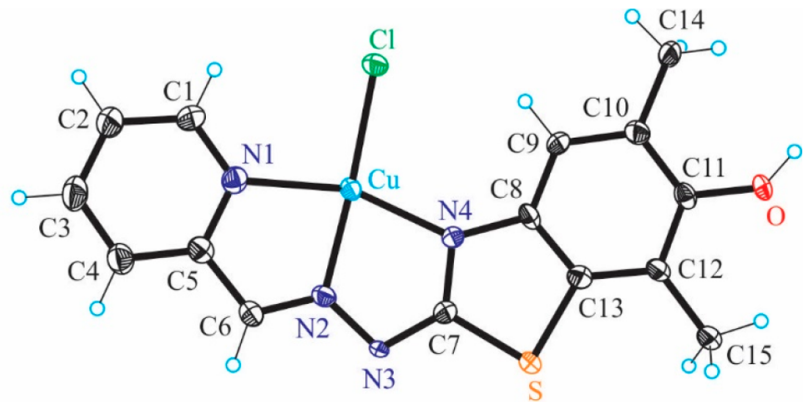

b)

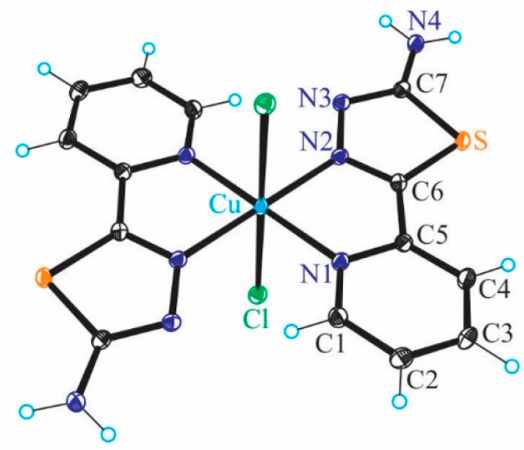

c)

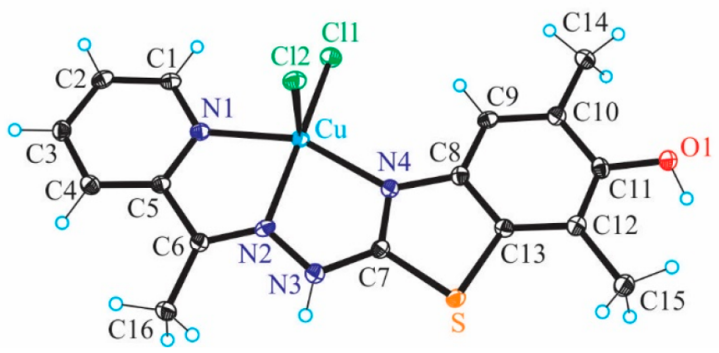

Figure 6. ORTEP views of $\left[\mathrm{Cu}\left(L^{1 c^{\prime}}\right) \mathrm{Cl}\right](4),\left[\mathrm{Cu}\left(\mathrm{HL}^{1 \mathrm{dd}}\right)_{2} \mathrm{Cl}_{2}\right](5)$, and $\left[\mathbf{C u}\left(\mathrm{HL}^{2 \mathrm{c}^{\prime}}\right) \mathrm{Cl}_{2}\right]$ (6) with thermal ellipsoids at the $50 \%$ probability level. Selected bond distances $(\AA)$ and bond angles (deg) in (a) 4: $\mathrm{Cu}-\mathrm{N} 1$ 2.054(4), $\mathrm{Cu}-\mathrm{N} 2$ 1.956(4), $\mathrm{Cu}-\mathrm{N} 4$ 2.001(3), $\mathrm{Cu}-\mathrm{Cl} 2.2575(12), \mathrm{C} 11-\mathrm{O} \quad 1.370(5) ; \mathrm{N} 2-\mathrm{Cu}-\mathrm{N} 1$ 80.02(15), $\mathrm{N} 2-\mathrm{Cu}-\mathrm{N} 4$ 78.59(14); in (b) 5: $\mathrm{Cu}-\mathrm{N} 1$ 2.0384(11), $\mathrm{Cu}-\mathrm{N} 2$ 2.0089(11), $\mathrm{Cu}-\mathrm{Cl} 2.8116(3), \mathrm{N} 2-\mathrm{Cu}-\mathrm{N} 1$ 99.32(4); in (c) 6: $\mathrm{Cu}-\mathrm{N} 1$ 2.0329(16), $\mathrm{Cu}-\mathrm{N} 2$ 1.9854(16), $\mathrm{Cu}-\mathrm{N} 4$ 2.0358(16), $\mathrm{Cu}-\mathrm{Cl1} 2.2100(5), \mathrm{C} 11-\mathrm{O} 1.374(2)$; N2-Cu-N1 78.00(16), N2$\mathrm{Cu}-\mathrm{N} 479.31(6)$.

of the TAT ring, while that of $\mathbf{H} L^{2 \mathbf{c} \prime}$ confirmed the further two-electron oxidation of $\mathbf{H} \mathbf{L}^{\mathbf{2 c} \prime}$. The bond-length distribution in the molecule of $\mathbf{H} L^{2 \mathrm{c} \prime \prime}$ indicates the presence of the benzo[d]thiazol-6-one moiety. The double-bond character of N3-C7 1.296(4) indicates the formation of this four-electron oxidation product from the two-electron oxidation product $\mathbf{H} \mathbf{L}^{2 \mathrm{c}^{\prime}}$ by the loss of two electrons and two protons.

The X-ray diffraction study of 4 (Figure 6a) revealed that the ligand underwent an oxidative dehydrogenation accompanied by the intramolecular cyclization via a $\mathrm{C}-\mathrm{S}$ coupling reaction between a phenolic carbon and a thione group into a five-membered thiazole ring instead of the expected oxidative dehydrogenation (two-electron oxidation accompanied by the loss of two protons) of the 3,5-dimethyl-1,4-aminophenol unit with formation of a 3,5-dimethyl-1,4-benzoquinone imine moiety (see Chart 2, Scheme 1). This intramolecular sulfur arylation resulted in the change of coordination mode, so that the thioether sulfur atom with diminished electron-donor properties is not involved in the coordination to copper(II). This is in agreement with the coordination chemistry of isothiosemicarbazones, ${ }^{59}$ which as a rule do not use a sulfur atom for coordination to first-row transition metals. In this context, it is worth mentioning that the binding of isothiosemicarbazones to zinc(II) and copper(II) via a thioether sulfur atom has been documented quite recently, ${ }^{60}$ when bulkier than chlorido coligands, for example, iodido and bromido, were involved in coordination to the metal. Complex 4 might be one of the products of the oxidation of copper(II) complexes over time in methanol by air oxygen. Some rare examples of a thiosemicarbazone cyclization with the thiazole ring formation due to the coordination to copper(II) were recently reported (iminodiacetate-thiosemicarbazones and $\mathrm{N}$ phenylthiosemicarbazones)..$^{52,53,61}$ The new ligand obtained by the intramolecular cyclization in $\mathbf{C u}\left(\mathbf{H L}^{1}\right) \mathbf{C l}_{2}$ belongs to the class of biologically active substituted 2-hydrazinylbenzothiazoles, which showed anticancer activity themselves as well as upon coordination to different metals. ${ }^{62-65}$ Two molecules of complex 4 are associated into a centrosymmetric dimer via two intermolecular $\mu$-chlorido bridges as shown in Figure S7.

The molecular structure of $\mathbf{5}$ shown in Figure $6 \mathrm{~b}$ indicates a strongly tetragonally distorted six-coordinate geometry of copper(II), in which two pyridine-thiadiazole ligands act as bidentate and occupy the equatorial sites in a trans mutual arrangement and two quite weakly bound chlorido coligands in axial positions. Taking into account the interatomic $\mathrm{Cu}-\mathrm{Cl}$ separation $(2.8116(3) \AA)$ the complex can also be described as square-planar.

As in 4, the coordinated ligand in 6 acts as tridentate and binds to copper(II) via atoms N1, N2, and N4. However, while 4 is square-planar, 6 is very close to square-pyramidal $\left(\tau_{5}=\right.$ $0.16) .{ }^{66}$ The organic ligand is monoanionic in 4 , while neutral in 6. An additional coordination of chlorido coligands counterbalances the $2+$ charge of the central atom.
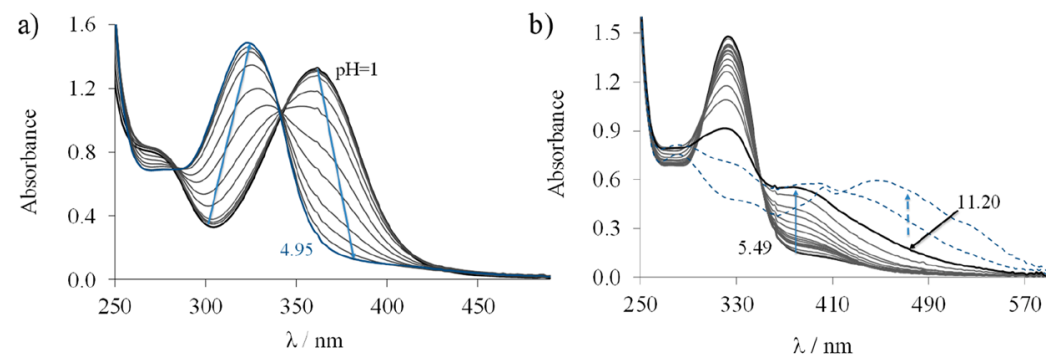

Figure 7. UV-vis absorption spectra recorded for proligand $\mathrm{HL}^{1}$ in the $\mathrm{pH}$ ranges of (a) $1.00-4.95$ and (b) $5.49-11.82 . c_{\mathrm{HL}}=50 \mu \mathrm{M} ; 30 \%(\mathrm{v} / \mathrm{v})$ $\mathrm{DMSO} / \mathrm{H}_{2} \mathrm{O} ; \mathrm{I}=0.1 \mathrm{M}(\mathrm{KCl}) ; \mathrm{T}=25^{\circ} \mathrm{C}$. 
Table 1. pK $K_{\mathrm{a}}$ Values Determined by UV-vis Titrations in $30 \%(\mathrm{v} / \mathrm{v}) \mathrm{DMSO} / \mathrm{H}_{2} \mathrm{O}$ and $\log D_{7.4}$ ( $n$-Octanol/Water) Values of the TSCs $\mathrm{HL}^{1}-\mathrm{HL}^{3}$ and Their Complexes ${ }^{a}$

\begin{tabular}{lllll} 
& \multicolumn{1}{c}{ method } & \multicolumn{1}{c}{$\mathrm{HL}^{1}$} & \multicolumn{1}{c}{$\mathrm{HL}^{2}$} & \multicolumn{1}{c}{$\mathrm{HL}^{3}$} \\
$\mathrm{p} K_{\mathrm{a}}\left(\mathrm{PyH}^{+}\right)$ & UV-vis & $3.01 \pm 0.01$ & $3.59 \pm 0.02$ & $3.95 \pm 0.04$ \\
$\mathrm{p} K_{\mathrm{a}}(\mathrm{NNH})$ & UV-vis & $10.55 \pm 0.01$ & $11.08 \pm 0.02$ & $\mathrm{nd}$ \\
$\log D_{7.4}$ (proligand) & partitioning & $+1.30 \pm 0.03$ & $+2.1 \pm 0.1$ & $+1.67 \pm 0.01$ \\
$\log K_{5.9}^{\prime}$ (complex) & EDTA displacement & $9.67 \pm 0.01$ & $\mathrm{nd}^{b}$ & $9.78 \pm 0.01$ \\
$\log D_{7.4}($ complex $)$ & partitioning & $-0.40 \pm 0.06$ & $\mathrm{nd}^{b}$ & $-0.42 \pm 0.03$ \\
$k_{\mathrm{obs}}\left(\mathrm{min}^{-1}\right)$ (complex) in 30\% DMSO & UV-vis (with GSH) & $0.033 \pm 0.004$ & $\mathrm{nd}^{b}$ & $0.035 \pm 0.004$ \\
$k_{\text {obs }}\left(\mathrm{min}^{-1}\right)$ (complex) in 60\% DMSO & UV-vis (with GSH) & $0.021 \pm 0.001$ & too slow $^{c}$ & $0.024 \pm 0.004$
\end{tabular}

${ }^{a}$ Conditional stability constants $\left(\log K^{\prime}{ }_{5.9}\right)$ of the complexes determined by UV-vis EDTA displacement studies in $30 \%(v / v) ~ D M S O / \mathrm{H}_{2} \mathrm{O}$ and rate constants $\left(k_{\mathrm{obs}}\right)$ obtained for the redox reaction of the complexes with GSH $\left(\mathrm{pH}=7.4(50 \mathrm{mM} \mathrm{HEPES}) ; c_{\mathrm{complex}}=25 \mu \mathrm{M} ; c_{\mathrm{GSH}}=1.25 \mathrm{mM}\right.$ in $\left.30 \%(\mathrm{v} / \mathrm{v}) \mathrm{DMSO} / \mathrm{H}_{2} \mathrm{O}\right) ; c_{\text {complex }}=12.5 \mu \mathrm{M} ; c_{\mathrm{GSH}}=600 \mu \mathrm{M}$ in $\left.60 \%(\mathrm{v} / \mathrm{v}) \mathrm{DMSO} / \mathrm{H}_{2} \mathrm{O}\right)\left\{\mathrm{T}=25^{\circ} \mathrm{C} ; I=0.1 \mathrm{M}(\mathrm{KCl})\right\} .{ }^{b} \mathrm{Not} \operatorname{determined}(\mathrm{nd})$ due to the bad solubility of the complex under the conditions. ${ }^{c}$ Rate constant could not be determined due to the very slow redox reaction.

To understand the difference in protonation states and reactivity of the originally prepared complexes and those isolated upon crystallization from diluted methanolic solutions equilibrium studies were performed on the ligands and their copper(II) complexes.

\section{SOLUTION EQUILIBRIUM STUDIES}

Proton Dissociation Processes and Lipophilicity of the Ligands. Proton dissociation constants $\left(\mathrm{p} K_{\mathrm{a}}\right)$ of drug molecules indicate the actual protonation state and the charge at a given $\mathrm{pH}$, and therefore $\mathrm{p} K_{\mathrm{a}}$ are important parameters that affect the pharmacokinetic properties as well. The $\mathrm{N}$-terminally monosubstituted TSCs $\mathbf{H L}^{1}-\mathbf{H L}^{3}$ belong to the family of $\alpha-N$ pyridyl TSCs; thus, they possess the pyridinium $(\mathrm{PyH})^{+}$and the hydrazinic-NNH as proton dissociable groups besides the phenolic moiety. Since these TSCs and their copper(II) complexes have a limited water solubility, the equilibrium studies were performed by UV-vis spectrophotometry in a $30 \%$ (v/v) DMSO $/ \mathrm{H}_{2} \mathrm{O}$ solvent mixture using relatively low concentrations $(50 \mu \mathrm{M})$. Representative UV-vis spectra recorded for $\mathbf{H L}^{1}$ at various $\mathrm{pH}$ values are shown in Figure $7 \mathrm{a}$.

On the basis of the spectral changes two well-separated deprotonation processes were observed between $\mathrm{pH} 2$ and 11 . The first proton dissociation step taking place at $\mathrm{pH}<5$ is accompanied by a blue shift, and the $\lambda_{\max }$ is shifted from 362 to $322 \mathrm{~nm}$. This deprotonation step is attributed to the proton on the pyridinium nitrogen $\left(\mathrm{PyH}^{+}\right)$. Upon an increase of the $\mathrm{pH}$ a new process occurred as evidenced by a new band in the range of $350-450 \mathrm{~nm}$ (Figure $7 \mathrm{~b}$ ) and an isosbestic point at $350 \mathrm{~nm}$, namely, the deprotonation of the hydrazinic nitrogen. In the strongly basic $\mathrm{pH}$ range $(\mathrm{pH}>11.2)$ new broad bands appear at 400-600 $\mathrm{nm}$ (Figure $7 \mathrm{~b}$ ) with irreversible spectral changes most likely due to an oxidation of the TSC by the air oxygen.

Therefore, only two $\mathrm{p} K_{\mathrm{a}}$ values could be determined (Table 1) based on the deconvolution of the UV-vis spectra recorded at $\mathrm{pH}<11.2$ for $\mathbf{H L}^{\mathbf{1}}$ (molar absorbance spectra are seen in Figure S8a) as the oxidation hindered the accurate determination of the $\mathrm{p} K_{\mathrm{a}}$ for the aromatic $\mathrm{OH}$ group. Two $\mathrm{p} K_{\mathrm{a}}$ values were computed for $\mathbf{H L}^{2}$ from the $\mathrm{UV}$-vis titration data (Figure S9) as well; however, only one $\mathrm{p} K_{\mathrm{a}}$ was obtained in the case of $\mathbf{H L}^{3}$ (Table 1), namely, that for the deprotonation of the $\mathrm{PyH}^{+}$, since the proton dissociation of the hydrazinic nitrogen and the oxidation of the TSC were partly overlapped. On the basis of the determined $\mathrm{p} K_{\mathrm{a}}$ values, it can be concluded that the presence of the electron-donating methyl group in $\mathbf{H L}^{2}$ results in a significant increase of both $\mathrm{p} K_{\mathrm{a}}$ values when compared to that of $\mathbf{H L}^{\mathbf{1}}$. A similar behavior was reported for the analogous 2-formylpyridine and 2acetylpyridine TSC in our previous work. ${ }^{67}$ The $\mathrm{p} K_{\mathrm{a}}$ of the $\mathrm{PyH}^{+}$group was also increased significantly by the addition of the electron-donating amine group at the pyridine ring, in agreement with data reported previously for the FTSC and triapine. ${ }^{68}$ All proligands are air-sensitive in the strongly basic $\mathrm{pH}$ range $(\mathrm{pH}>11)$. Concentration distribution curves were computed for them at $\mathrm{pH}<11$ (see Figure $\mathrm{S} 8 \mathrm{~b}$ for $\mathbf{H L}^{\mathbf{1}}$ ) revealing that their neutral forms predominate at a physiological $\mathrm{pH}$.

The solution stability of the proligands was monitored at $\mathrm{pH}$ 7.4 by spectrophotometry. The UV-vis spectra recorded over $4 \mathrm{~h}$ revealed no measurable spectral changes, suggesting that the oxidation of these proligands does not take place (or just very slowly) in an aqueous solution at a physiological $\mathrm{pH}$. However, $\mathbf{H L}^{2}$ showed a certain level of slow decomposition at $\mathrm{pH} 1.5$, namely, a $6 \%$ absorbance decrease at $354 \mathrm{~nm}$ in $\sim 3 \mathrm{~h}$ (Figure S10), which is most likely the consequence of the less extended conjugation in the molecule due to the cleavage of the $\mathrm{C}=\mathrm{N}$ Schiff base bond, as it was also reported for 2acetylpyridine TSC. ${ }^{67}$ Thus, the rate of this acid-catalyzed reaction is increased with the increasing number of methyl groups present in the $\alpha$-N-pyridyl TSC.

Besides $\mathrm{pK}_{\mathrm{a}}$ values, lipophilicity is also an important pharmacological property of a drug, as it strongly influences the ability of the compound to pass through biological membranes. Therefore, distribution coefficients $\left(\log D_{7.4}\right)$ were determined using the shake-flask method in an n-octanolbuffered aqueous solution at $\mathrm{pH} 7.4$ (Table 1 ). The $\log D_{7.4}$ values indicate the moderate lipophilic character of the proligands. The substitution at the end nitrogen atom of the thosemicarbazide moiety and the presence of a methyl group at the Schiff base bond induce a somewhat higher lipophilicity. The presence of the phenolic moiety undoubtedly increases the $\log D_{7.4}$ values compared to those of FTSC $\left.(+0.73)\right)^{67}$ AcTSC $(+1.02)^{67}$ and triapine $(+0.85) .^{69}$

In summary, these TSCs are stable in their neutral form in a quite broad $\mathrm{pH}$ range (including $\mathrm{pH}$ 7.4).

Solution Stability and Redox Properties of the Copper(II) Complexes. The metal complexes often undergo transformation processes upon dissolution, such as protonation, deprotonation, or dissociation to a metal-free ligand and metal ion depending on the $\mathrm{pH}$, their concentration, and the solution speciation. The knowledge of the actual chemical form of the biologically active metal complexes in solution close to physiologically relevant conditions is quite important to elucidate the mechanism of action. Therefore, the solution 
stability of the copper(II) complexes $\left(\mathbf{C u}\left(\mathbf{H L}^{1}\right) \mathbf{C l}_{2},\left[\mathbf{C u}\left(\mathbf{L}^{2}\right)\right.\right.$ $\mathrm{Cl}$ ], and $\mathrm{Cu}\left(\mathrm{HL}^{3}\right) \mathrm{Cl}_{2}$ ) was studied by $\mathrm{UV}-$ vis spectrophotometry. The simple $\alpha$-N-pyridyl TSCs (e.g., triapine, FTSC) generally form very stable monoligand copper(II) complexes, and the species in which the monoanionic ligand is coordinated via the $\left(\mathrm{N}_{\text {pyridine }}, \mathrm{N}, \mathrm{S}^{-}\right)$mode predominates in a wide $\mathrm{pH}$ range at a 1:1 metal-to-ligand ratio. ${ }^{68}$ At lower $\mathrm{pH}$ this type of complex is protonated, and thus the neutral ligand is bound via $\left(\mathrm{N}_{\text {pyridine, }}, \mathrm{N}, \mathrm{S}\right)$ donor atoms, while a mixed hydroxido complex with the $\left(\mathrm{N}_{\text {pyridine }}, \mathrm{N}, \mathrm{S}^{-}\right)(\mathrm{OH})$ coordination pattern is formed in the basic $\mathrm{pH}$ range. On the basis of the close structural similarities between $\mathbf{H L}^{\mathbf{1}}-\mathbf{H L}^{3}$ and the listed TSCs with a simpler scaffold, the formation of the same type of complexes is feasible. UV-vis titrations were performed with the complexes in a $30 \%(\mathrm{v} / \mathrm{v}) \mathrm{DMSO} / \mathrm{H}_{2} \mathrm{O}$ solvent mixture, and representative spectra are shown for $\mathbf{C u}\left(\mathbf{H L}^{1}\right) \mathbf{C l}_{2}$ in Figure 8. The spectra remain intact in a broad

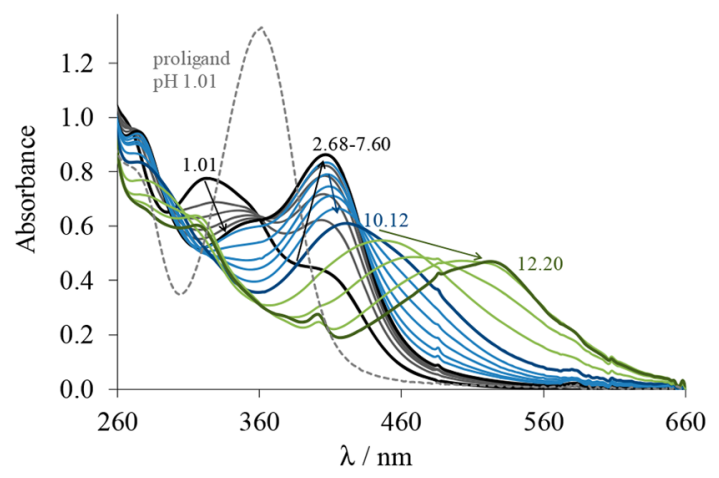

Figure 8. UV-vis absorption spectra recorded for complex $\mathbf{C u}$ $\left(\mathbf{H L}^{1}\right) \mathbf{C l}_{2}$ in the $\mathrm{pH}$ range of 1.01-12.20 (solid lines) and for $\mathbf{H L}^{1}$ at $\mathrm{pH} 1.01$ (dashed gray line). $c_{\text {complex } / \mathrm{HL}}=50 \mu \mathrm{M} ; 30 \%(\mathrm{v} / \mathrm{v}) \mathrm{DMSO} /$ $\mathrm{H}_{2} \mathrm{O} ; I=0.1 \mathrm{M}(\mathrm{KCl}) ; \mathrm{T}=25^{\circ} \mathrm{C}$.

$\mathrm{pH}$ range (2.7-7.6), and an absorption band is observed with $\lambda_{\max }$ at $406 \mathrm{~nm}$ being typical for a $\mathrm{S} \rightarrow \mathrm{Cu}$ charge transfer. This finding indicates the dominant presence of only one kind of complex, which is most probably the species with the $\left(\mathrm{N}_{\text {pyridine }}, \mathrm{N}, \mathrm{S}^{-}\right)$tridentate coordination mode. By decreasing the $\mathrm{pH}$ the $\lambda_{\max }$ is hypsochromically shifted to $322 \mathrm{~nm}$. The presence of the isosbestic point at $362 \mathrm{~nm}$ implies that only two species are involved in this equilibrium. As the spectrum recorded at $\mathrm{pH} 1.01$ significantly differs from that of the TSC, this equilibrium corresponds to the protonation of the complex at the noncoordinating hydrazinic nitrogen (Chart S1) rather than to its dissociation to the free metal ion and ligand. This process is not completed when the $\mathrm{pH}$ decreases to 1 , and a $\mathrm{p} K_{\mathrm{a}}$ value less than 1.5 could be estimated. When the $\mathrm{pH}$ is increased, two overlapping processes are suggested to take place at $\mathrm{pH}>8$ via the continuous bathochromic shift of the absorption maximum, and $\mathrm{p} K_{\mathrm{a}}$ values of $9.80 \pm 0.01$ and 11.02 \pm 0.01 were computed. In this $\mathrm{pH}$ range most probably the coordinated water molecule deprotonates, and a mixed hydroxido complex is formed along with the deprotonation of the phenolic group of the bound ligand. Similar spectral changes were monitored for $\mathbf{C u}\left(\mathbf{H L}^{3}\right) \mathbf{C l}_{2}$, and $\mathrm{p} K_{\mathrm{a}}<1.5$ was estimated for the process in the acidic $\mathrm{pH}$ range as well.

However, the formation of precipitate (significant baseline elevation and absorbance decrease in the whole wavelength range) at $\mathrm{pH}>8$ hindered the calculation of the proton dissociation constants of the complexes from spectra collected in this $\mathrm{pH}$ range. Unfortunately, during the titration of $\left[\mathbf{C u}\left(\mathbf{L}^{2}\right) \mathbf{C l}\right]$ the formation of a precipitate was observed already at the acidic $\mathrm{pH}$; thus, the deprotonation processes could not be evaluated.

The copper(II)-TSC complexes are often redox-active under physiological conditions, which has an impact on their cytotoxicity. To investigate whether complexes $\left[\mathbf{C u}\left(\mathbf{L}^{1}\right)\right]^{+}$, $\left[\mathbf{C u}\left(\mathbf{L}^{2}\right)\right]^{+}$, and $\left[\mathbf{C u}\left(\mathbf{L}^{3}\right)\right]^{+}$can be reduced by the most abundant low molecular mass cellular reductant, GSH, spectrophotometric measurements were performed on their direct reaction under strictly anaerobic conditions at $\mathrm{pH} 7.4$. First, the assay was performed in the presence of $30 \%$ DMSO using a $25 \mu \mathrm{M}$ complex concentration. However, the limited solubility of $\left[\mathbf{C u}\left(\mathbf{L}^{2}\right)\right]^{+}$did not allow the measurement. Therefore, the assay was also performed in the presence of $60 \%$ DMSO at a lower $(12.5 \mu \mathrm{M})$ concentration for all the three complexes. The spectral changes are shown in Figure 9 for $\left[\mathbf{C u}\left(\mathbf{L}^{1}\right)\right]^{+}$and $\left[\mathbf{C u}\left(\mathbf{L}^{3}\right)\right]^{+}$complexes in the presence of a large excess of $\mathrm{GSH}$ in $30 \%(\mathrm{v} / \mathrm{v}) \mathrm{DMSO} / \mathrm{H}_{2} \mathrm{O}$. After the complexes were mixed with GSH, a well-detectable change is observed due to the formation of ternary complexes via the coordination of GSH as it was reported for several TSC complexes. $^{70,71}$ Then the spectral changes show the absorbance decrease at the $\lambda_{\max }$ of the $S \rightarrow \mathrm{Cu}$ charge transfer band of the complexes. The final spectra show a strong similarity to those of $\mathrm{HL}^{1}$ and $\mathrm{HL}^{3}$ at $\lambda>310 \mathrm{~nm}$ suggesting the release of the TSCs. However, in this case the reduction is responsible for the liberation of the TSCs and copper(I), which forms complexes with GSH (that is in high excess in the sample). Copper(I) favors a tetrahedral coordination environment, while $\mathbf{H L}^{1}$ and $\mathbf{H L}^{3}$ as planar tridentate ligands cannot satisfy these requirements and accommodate the cation. This contradiction is a driving force for a complex destabilization, especially in the presence of GSH, which can efficiently bind copper(I). ${ }^{64}$ In addition, a one-electron reduction increases the
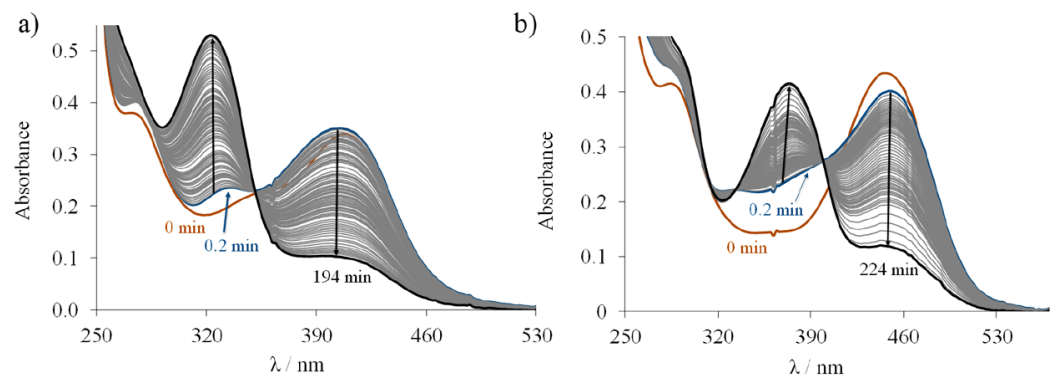

Figure 9. Time-dependent changes of the UV-vis spectra of (a) $\mathbf{C u}\left(\mathbf{H L}^{1}\right) \mathbf{C l}_{2}$ and (b) $\mathbf{C u}\left(\mathbf{H L}^{3}\right) \mathbf{C l}_{2}$ in the presence of 50 equiv of GSH at pH 7.4 under anaerobic conditions. $c_{\text {complex }}=25 \mu \mathrm{M} ; c_{\mathrm{GSH}}=1.25 \mathrm{mM} ; \mathrm{pH}=7.40 ; 30 \%(\mathrm{v} / \mathrm{v}) \mathrm{DMSO} / \mathrm{H}_{2} \mathrm{O} ; \mathrm{I}=0.1 \mathrm{M}(\mathrm{KCl}) ; \mathrm{T}=25^{\circ} \mathrm{C}$. 
a)

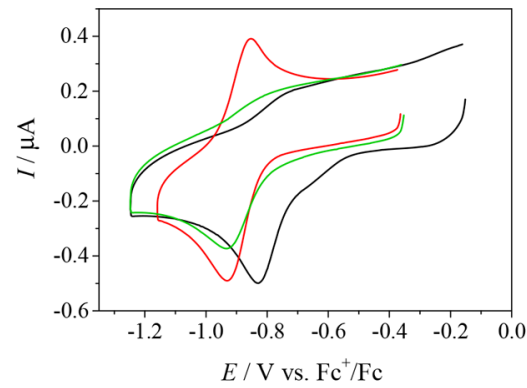

b)

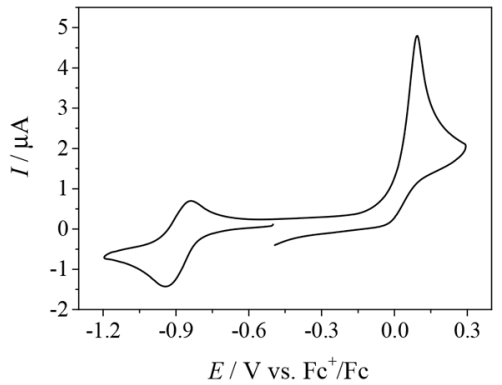

Figure 10. (a) Cyclic voltammograms of $0.5 \mathrm{mM} 1$ (black trace), $2^{\prime}$ (red trace), and 3 (green trace) in $\mathrm{DMSO} / n-\mathrm{Bu}_{4} \mathrm{NPF}_{6}$ at a GC working electrode at the scan rate of $100 \mathrm{mV} \mathrm{s}^{-1}$; (b) comparison of the reduction and the oxidation peak of $2^{\prime}$ (scan rate of $100 \mathrm{mV} \mathrm{s}$ ).

a)

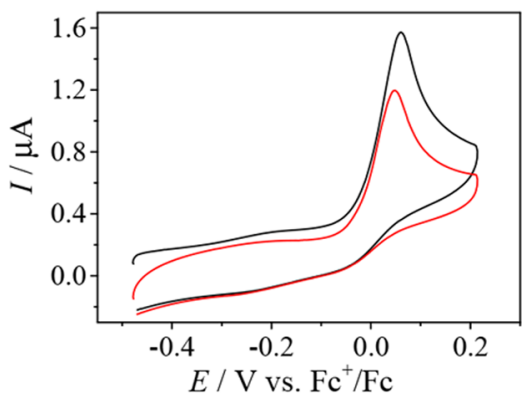

b)

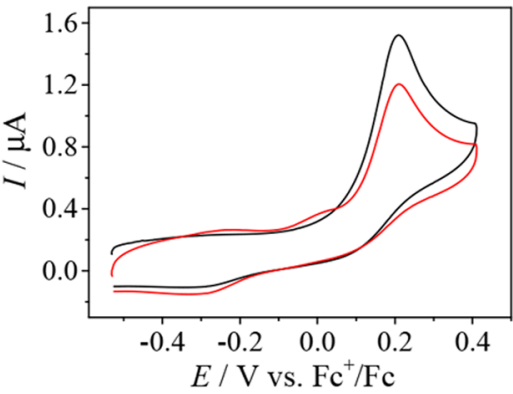

c)

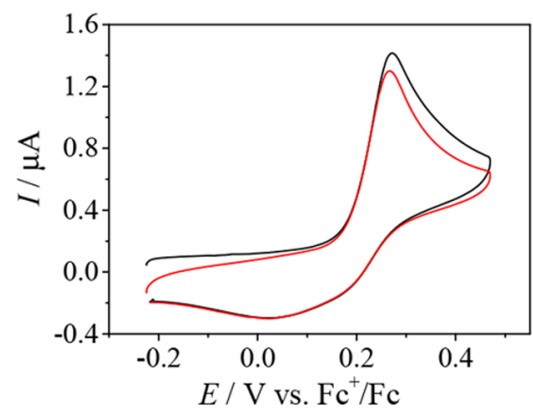

Figure 11. Cyclic voltammograms of $0.5 \mathrm{mM}$ of (a) 1 and (b) the corresponding ligand in $\mathrm{DMSO} / n-\mathrm{Bu}_{4} \mathrm{NPF}_{6}$ and of $(\mathrm{c}) \mathbf{1}$ in $\mathrm{MeOH} / \mathrm{LiClO}{ }_{4}$ at the GC working electrode, at scan rate of $100 \mathrm{mV} \mathrm{s}^{-1}$.

basicity of the coordinated TSCs facilitating their protonation and dissociation from the copper(I). ${ }^{72}$ Note, however, that the process was reversible, as bubbling oxygen into the samples regenerated the starting spectra. Complex $\left[\mathbf{C u}\left(\mathbf{L}^{2}\right)\right]^{+}$behaved differently, as only minor spectral changes were seen upon treatment with $\mathrm{GSH}$ in $60 \%(\mathrm{v} / \mathrm{v}) \mathrm{DMSO} / \mathrm{H}_{2} \mathrm{O}$ (Figure $\mathrm{S} 11 \mathrm{~b})$. From the measured absorbance-time curves rate constants $\left(k_{\text {obs }}\right)$ were calculated (Table 1$)$. Similar reduction rates for $\left[\mathbf{C u}\left(\mathbf{L}^{1}\right)\right]^{+}$and $\left[\mathbf{C u}\left(\mathbf{L}^{3}\right)\right]^{+}$complexes were obtained, and somewhat lower $k_{\text {obs }}$ values were found in the presence of the higher fraction of DMSO. Notably, ascorbate, which is a weaker reducing agent compared to GSH and is found in higher concentration in the extracellular fluids, was not able to reduce these complexes under the same conditions. On the contrary, the more powerful reducing agent DTT could reduce $\left[\mathbf{C u}\left(\mathbf{L}^{1}\right)\right]^{+},\left[\mathbf{C u}\left(\mathbf{L}^{2}\right)\right]^{+}$, and $\left[\mathbf{C u}\left(\mathbf{L}^{3}\right)\right]^{+}$in a very fast reaction. The reduction was complete within several seconds (at 12.5 $\mu \mathrm{M}$ complex and $600 \mu \mathrm{M}$ DTT concentrations in the presence of $60 \%$ DMSO, Figure S11c,d). In this case, the reaction was reversible upon exposure to $\mathrm{O}_{2}$ only for $\left[\mathrm{Cu}\left(\mathbf{L}^{2}\right)\right]^{+}$.

Overall, the solution equilibrium data provide further evidence that the complex $[\mathbf{C u}(\mathbf{L})]^{+}$with the coordinated monoanionic ligand predominates in a wide $\mathrm{pH}$ range. In order to obtain a deeper insight into the observed behavior of both metal-free ligands and their copper(II) complexes in the presence of oxidants (atmospheric oxygen) and reductants (GSH and ascorbate) spectroelectrochemical investigations were also performed.

Electrochemistry and Spectroelectrochemistry. Cyclic voltammograms of $\mathbf{1}, \mathbf{2}^{\prime}$, and 3 in $\mathrm{DMSO} / n-\mathrm{Bu}_{4} \mathrm{NPF}_{6}$ recorded with a glassy carbon (GC) working electrode at a scan rate of $100 \mathrm{mV} \mathrm{s}^{-1}$ showed a redox activity in both cathodic and anodic regions. Copper(II) undergoes an electrochemically irreversible or quasi-reversible reduction to copper(I) at $E_{\mathrm{pc}}=$ $-0.83 \mathrm{~V}$ for 1 and $-0.93 \mathrm{~V}$ versus $\mathrm{Fc}^{+} / \mathrm{Fc}$ for both $2^{\prime}$ and 3 (Figure 10a). Notably, the corresponding ligands are not redox-active in the cathodic region (data not shown). An irreversible oxidation was observed for these complexes, which was identified as a two-electron oxidation of the TSCs with a release of two protons. A two-electron oxidation was confirmed by a comparison of the reduction peak (one-electron $\mathrm{Cu}$ (II) $\rightarrow$ $\mathrm{Cu}(\mathrm{I})$ redox process) and the oxidation peak of $2^{\prime}$ taken in equivalent amounts as shown in Figure $10 \mathrm{~b}$. In addition, an electrolysis of $\mathbf{H L}^{1}$ at $1000 \mathrm{mV}$ versus $\mathrm{Ag} / \mathrm{AgCl}$ in $\mathrm{CH}_{3} \mathrm{CN}$ in the presence of $0.2 \mathrm{M} n-\mathrm{Bu}_{4} \mathrm{NPF}_{6}$ generated a mixture of several products from which $\mathbf{H} L^{\mathbf{1 a} \prime}$ and $\mathbf{H} L^{\mathbf{1 a} \prime}$ were separated on silica. ESI-MS and ${ }^{1} \mathrm{H}$ NMR spectra were identical with those of the products obtained by an oxidation of $\mathbf{H L}^{1}$ with DDQ as mentioned previously.

The oxidation peak of the TSC ligand was observed at $E_{\mathrm{pa}}=$ $+0.06 \mathrm{~V}$ for $\mathbf{1}$ and $\mathbf{2}^{\prime}$ and at $+0.04 \mathrm{~V}$ for 3 , and it is negatively shifted in comparison to the corresponding metal-free ligands $\left(E_{\mathrm{pa}}=+0.21 \mathrm{~V}\right.$ for $\mathbf{H L}^{1},+0.24 \mathrm{~V}$ for $\mathbf{H L}^{2}$, and $+0.18 \mathrm{~V}$ for $\mathbf{H L}^{3}$ (all vs $\mathrm{Fc}^{+} / \mathrm{Fc}$ at a scan rate of $100 \mathrm{mV} \mathrm{s}^{-1}$ )), as shown for $\mathbf{1}$ and its corresponding metal-free ligand $\mathbf{H L}^{1}$ in Figure $11 \mathrm{a}, \mathrm{b}$, respectively. There are also significant changes in the shape and intensity of cyclic voltammograms upon the second oxidation scan (see red traces in Figure 11a,b), which indicate a further oxidation of the products obtained after the first oxidation in DMSO, in line with the chemical oxidation of the compounds. Note that, in a proton-donating solvent, the potentials of both reduction and oxidation processes were shifted to the more positive values versus the internal potential standard $\mathrm{Fc}^{+} / \mathrm{Fc}$, and additionally, a broad reduction peak 
appeared during the reverse scan in the cyclic voltammogram at a strongly negatively shifted potential (Figure 11c). A distinct oxidation pattern of the corresponding voltammograms in protic media is caused by the involvement of protons in the process in accordance with chemical oxidations discussed previously and the well-known reaction mechanism proposed for the quinone-like systems. $^{70,71}$

Similar redox behavior was observed for the anodic oxidation of $\mathbf{H} L^{1 \mathbf{a} \prime}$ in DMSO with several new redox-active species, which appeared upon the first and the second voltametric scans (Figure S12a). However, the oxidized 1,4benzoquinone imine species $\mathbf{H} L^{1 \mathbf{a}}$ "can be reversibly reduced in the cathodic part (Figure S12b) with a voltammetric pattern characteristic for the electrochemistry of quinones in aprotic media. ${ }^{72}$ Moreover, EPR spectroelectrochemistry confirmed the formation of an anion radical at the first reduction peak (see inset in Figure S12b). A rich hyperfine splitting and a $g$ value of 2.0046 points to the spin delocalization and contribution of heteroatom (presumably nitrogen) to the $g$ value.

To support the assignment of the redox processes described previously, EPR/UV-vis spectroelectrochemical measurements were performed, and the results are shown for $\mathbf{1}$ in Figures 12 and 13. The UV-vis spectrum of 1 exhibits two absorption bands at 276 and $428 \mathrm{~nm}$, where the first one is due to the absorption of the TSC ligand, while the second one can be attributed to the ligand-to-metal $(\mathrm{S} \rightarrow \mathrm{Cu})$ charge transfer (LMCT) ${ }^{73,74}$ Upon the cathodic reduction of $\mathbf{1}$ in the region of the first reduction peak a new broad absorption band at 331

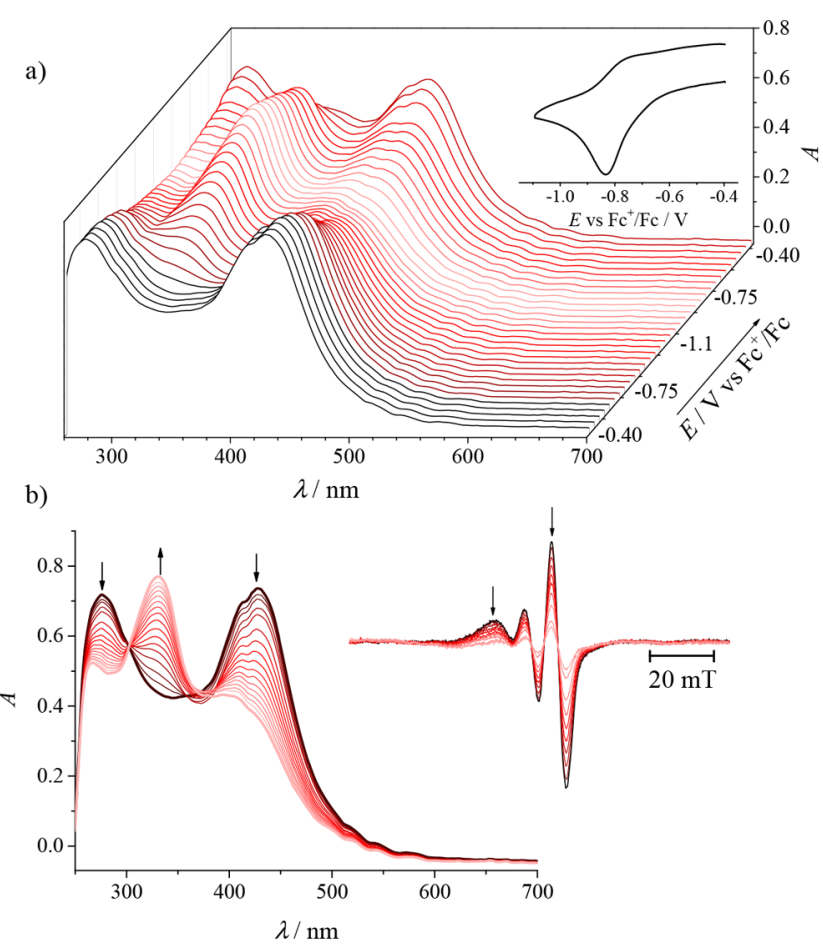

Figure 12. Spectroelectrochemistry of $\mathbf{1}$ in $n-\mathrm{Bu}_{4} \mathrm{NPF}_{6} / \mathrm{DMSO}$ in the region of the first cathodic peak: (a) potential dependence of UV-vis spectra with the corresponding in situ cyclic voltammogram (Ptmicrostructured honeycomb working electrode, scan rate of $5 \mathrm{mV}$ $\mathrm{s}^{-1}$ ); (b) evolution of UV-vis spectra in 2D projection upon forward scan. (inset) Evolution of EPR spectra measured at the first reduction peak using a Pt mesh working electrode. $\mathrm{nm}$ appears with a simultaneous decrease of the initial optical bands at 276 and $428 \mathrm{~nm}$ via an isosbestic point at $302 \mathrm{~nm}$ (Figure 12). An analogous spectroelectrochemical response was observed for $\mathbf{2}^{\prime}$ as shown in Figure S13. This observation is different from that encountered by the reduction of the copper(II)-TSC complexes by GSH (vide supra), which led to the liberation of the ligand and formation of the copper(I) complex with GSH. In the spectroelectrochemical experiment in the absence of strong $\mathrm{Cu}(\mathrm{I})$ complexing agents, such as $\mathrm{GSH}$, the TSC ligand may coordinate to $\mathrm{Cu}(\mathrm{I})$ and form a linear or tetrahedral complex. Upon the voltammetric reverse scan, a nearly full recovery of the initial optical bands was observed, which confirms the relatively good stability of cathodically generated $\mathrm{Cu}(\mathrm{I})$ complex with $\mathbf{H L}^{2}$ and, thus, the chemical reversibility of this redox process. Rare examples of four- and three-coordinate copper(I) complexes with potentially tridentate and bidentate thiosemicarbazones were reported previously. ${ }^{75,76}$ The room-temperature X-band EPR spectrum of 1 showed a typical signal for $d^{9} \mathrm{Cu}(\mathrm{II})$ species, which decreased stepwise upon a cathodic reduction at the first cathodic peak. This is in line with the metal-centered reduction and formation of EPR-silent $\mathrm{d}^{10} \mathrm{Cu}(\mathrm{I})$ species ${ }^{10}$ (see inset in Figure 12b). EPR spectra of 1, 2', and 3 measured in frozen $n$ $\mathrm{Bu}_{4} \mathrm{NPF}_{6} / \mathrm{DMSO}$ at $77 \mathrm{~K}$ show a characteristic axial symmetry $\left(g_{\|}>g_{\perp}>g_{\mathrm{e}}\right)$ implying a square-planar coordination and the presence of one dominating species in DMSO (Figure S14).

The in situ cyclic voltammogram and simultaneously recorded evolution of UV-vis spectra upon an anodic oxidation of $\mathbf{1}$ in DMSO provide further evidence for the ligand-based irreversible oxidation. Spectral changes accompanying the oxidation of $\mathbf{1}$ are shown in Figure 13. These changes are characteristic for the other two complexes $2^{\prime}$ and 3 as well. Note that, in the region of the first oxidation peak, new optical bands at 295 and $356 \mathrm{~nm}$ appear with a simultaneous decrease of the initial absorption with a maximum at $428 \mathrm{~nm}$ (Figure 13a). However, the product formed upon oxidation is not reduced back during the reverse voltammetric scan (Figure $13 \mathrm{~b})$, indicating the chemical irreversibility of the redox process. In the EPR spectroelectrochemistry of 1 in DMSO/n$\mathrm{Bu}_{4} \mathrm{NPF}_{6}$, no changes of the EPR signal were detected upon the oxidation at the first anodic peak, providing evidence of the two-electron oxidation process taking place on the TSC ligand.

The remarkable stability of copper(II) complexes 1, $\mathbf{2}^{\prime}$, and 3 at a physiological $\mathrm{pH}$, their moderate lipophilic character $\left(\log D_{7.4}=-0.4\right.$ to -0.42$)$ and copper(II)/copper(I) redox activity $\left(E_{\text {red }}=-0.83\right.$ to $-0.93 \mathrm{~V}$ vs $\left.\mathrm{Fc}^{+} / \mathrm{Fc}\right)$ in a biologically relevant window of redox potentials $(-0.4$ to $+0.8 \mathrm{~V}$ vs NHE or -1.04 to $0.16 \mathrm{~V}$ vs $\mathrm{Fc} / \mathrm{Fc}^{+}$) prompted the investigation of their antiproliferative activity in cancer cell lines.

\section{INHIBITION OF CELL VIABILITY AND APOPTOSIS ASSAY}

Cytotoxicity of the TSCs, Their Oxidized Products and Copper(II) Complexes. The in vitro cytotoxicity of the TSCs $\mathbf{H L}^{1}-\mathbf{H L}^{3}$, copper(II) complexes $\mathbf{C u}\left(\mathbf{H L}^{1}\right) \mathbf{C l}_{2},[\mathbf{C u}-$ $\left(\mathbf{L}^{2}\right) \mathbf{C l}$, and $\mathbf{C u}\left(\mathbf{H L}^{3}\right) \mathbf{C l}_{2}$, and oxidized TSCs $\mathbf{H} L^{1 \mathbf{a} \prime}, \mathbf{H} L^{1 \mathbf{a} \prime}$, and $\mathrm{HL}^{2 \mathrm{c}^{\prime}} \cdot \mathrm{CH}_{3} \mathbf{C O O H}$ was tested in the doxorubicin-sensitive Colo205 and the multidrug-resistant Colo320 human colonic adenocarcinoma cell lines as well as in normal human embryonal lung fibroblast cells (MRC-5) by the colorimetric MTT assay. The data that resulted (expressed as the halfmaximal inhibitory concentration $\left(\mathrm{IC}_{50}\right)$ ) are collected in 

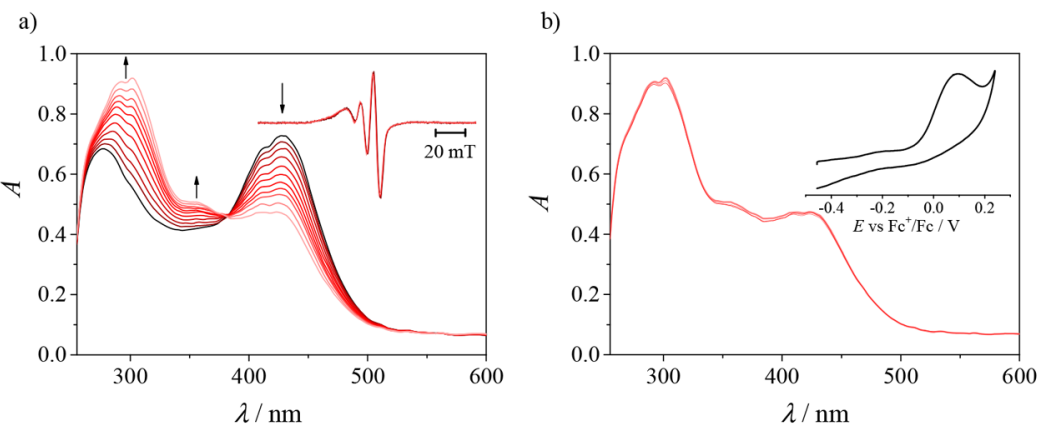

Figure 13. UV-vis spectra measured simultaneously (a) upon anodic oxidation of $\mathbf{1}$ in the region of the first anodic peak (inset: time evolution of EPR spectra acquired at the first anodic peak) and (b) upon the back scan (inset: the corresponding in situ cyclic voltammogram).

Table 2 and compared with those for triapine, doxorubicin, and $\mathrm{CuCl}_{2}$.

Table 2. In Vitro Cytotoxicity $\left(\mathrm{IC}_{50}\right.$ Values in $\left.\mu \mathrm{M}\right)$ of MetalFree Ligands $\mathrm{HL}^{1}-\mathrm{HL}^{3}$, Copper(II) Complexes $\mathrm{Cu}\left(\mathrm{HL}^{1}\right) \mathrm{Cl}_{2},\left[\mathrm{Cu}\left(\mathrm{L}^{2}\right) \mathrm{Cl}\right]$, and $\mathrm{Cu}\left(\mathrm{HL}^{3}\right) \mathrm{Cl}_{2}$, and, of the Oxidized Species $\mathrm{HL}^{1 \mathrm{a} \prime}, \mathrm{HL}^{1 \mathrm{a} \prime \prime}$, and $\mathrm{HL}^{2 \mathrm{c}^{\prime}} \cdot \mathrm{CH}_{3} \mathrm{COOH}$ in Colo205, Colo320, and MRC-5 Cell Lines after $72 \mathrm{~h}$ of Exposure

\begin{tabular}{|c|c|c|c|}
\hline $\mathrm{IC}_{50}(\mu \mathrm{M})$ & Colo205 & Colo320 & MRC-5 \\
\hline $\mathrm{HL}^{1}$ & $>100$ & $6.32 \pm 0.49$ & $>100$ \\
\hline $\mathrm{HL}^{2}$ & $>100$ & $>100$ & $>100$ \\
\hline $\mathrm{HL}^{3}$ & $48.2 \pm 6.8$ & $>100$ & $>100$ \\
\hline $\mathrm{Cu}\left(\mathrm{HL}^{1}\right) \mathrm{Cl}_{2}$ & $2.08 \pm 0.12$ & $2.21 \pm 0.18$ & $3.13 \pm 0.17$ \\
\hline$\left[\mathrm{Cu}\left(\mathrm{L}^{2}\right) \mathrm{Cl}\right]$ & $0.181 \pm 0.039$ & $0.159 \pm 0.009$ & $0.276 \pm 0.049$ \\
\hline $\mathrm{Cu}\left(\mathrm{HL}^{3}\right) \mathrm{Cl}_{2}$ & $26.6 \pm 1.6$ & $27.6 \pm 1.6$ & $>100$ \\
\hline$H L^{1 a^{\prime}}$ & $>25$ & $>25$ & $>25$ \\
\hline$H L^{1 \mathbf{a} \prime \prime}$ & $>25$ & $>25$ & $>25$ \\
\hline $\mathrm{HL}^{2 \mathrm{c}^{\prime}} \cdot \mathrm{CH}_{3} \mathrm{COOH}$ & $2.733 \pm 0.059$ & $0.188 \pm 0.041$ & $2.15 \pm 0.10$ \\
\hline $\mathrm{CuCl}_{2}$ & $19.7^{a}$ & $20.0^{a}$ & $24.5^{a}$ \\
\hline triapine & $3.34 \pm 0.12$ & $4.21 \pm 0.46$ & $10.2 \pm 1.3$ \\
\hline doxorubicin & $3.28^{a}$ & $3.12^{a}$ & $5.19^{a}$ \\
\hline
\end{tabular}

The metal-free ligands were either devoid of cytotoxicity or showed a weak response; only $\mathbf{H L}^{1}$ and $\mathbf{H L}^{3}$ revealed a somewhat higher activity against Colo320 and Colo205 cells, respectively, even though it was inferior to that of triapine. Notably, the copper(II) complexes are quite cytotoxic. So the effect of the copper(II) coordination is obvious in all cases. Low $\mathrm{IC}_{50}$ values $(0.16-2.2 \mu \mathrm{M})$ were obtained for $\mathbf{C u}\left(\mathbf{H L}^{1}\right)$ $\mathbf{C l}_{2}$ and $\left[\mathbf{C u}\left(\mathbf{L}^{2}\right) \mathbf{C l}\right]$ in both cancer cell lines (Colo205 and Colo320). To gain further insights into the cytotoxic behavior of the compounds, apoptosis induction by lead compounds $\mathrm{HL}^{1}$ and $\left[\mathbf{C u}\left(\mathrm{L}^{2}\right) \mathbf{C l}\right]$ was investigated by a flow cytometry analysis of multidrug-resistant Colo320 cells stained with Annexin-V-FITC and propidium iodide (PI). The two compounds that displayed the highest cytotoxicity against this cell line were tested at two concentrations in the range of their IC $_{50}$ values. 12H-Benzophenothiazine (M627) and cisplatin were used as positive controls. The fluorescence of PI (FL3) was plotted versus Annexin-V fluorescence (FL1) as shown in Figure 14 for the positive controls and for the tested compounds at a chosen concentration. The percentage of the gated events regarding the early apoptosis, the late apoptosis and necrosis, and cell death is quoted in Table S8. According to these data, both compounds studied, $\mathbf{H L}^{1}$ and $\left[\mathbf{C u}\left(\mathbf{L}^{2}\right) \mathbf{C l}\right]$, can be considered as efficient apoptosis inducers.

The antiproliferative activity of $\mathbf{1}$ and $\mathbf{2}^{\prime}$ in the normal cells (MRC-5) was only slightly lower than in Colo205 and Colo320 cells, indicating a quite moderate selectivity for cancer cells. Complex $\mathbf{C u}\left(\mathbf{H L}^{3}\right) \mathbf{C l}_{2}$ was found to be less cytotoxic compared to the other two complexes tested, and the $\mathrm{IC}_{50}$ values are similar to those of the copper(II) chloride, while the selectivity for cancer cells is obvious in this case (SI > 3). It is worth mentioning that the analogous $\alpha$-N-pyridyl thiosemicarbazones, that is, FTSC, AcTSC, and triapine, were reported to be cytotoxic in the low micromolar concentration range against several human cancer cells, the latter being the most potent among them $\left(\mathrm{IC}_{50}\right.$ values reported for triapine: 0.4-2.6 $\mu \mathrm{M}$ (in good agreements with the data quoted in Table 5), for FTSC: $1.9-10.6 \mu \mathrm{M}$, for AcFTSC: $2.5-3.6 \mu \mathrm{M}$ in SW480, ${ }^{36}$ MES-SA, ${ }^{36}$ MES-SA/Dx5, ${ }^{36}$ HL60, $^{58} 41 \mathrm{M},{ }^{80}$ SK-BR-3 $\left.{ }^{80}\right)$.

Their $\mathrm{Cu}(\mathrm{II})$ complexes were reported to possess a similar or even weaker cytotoxicity compared to the metal-free ligands, in contrast to complexes studied in the present work, which might indicate a distinct mode of action. It is also of note that the two-electron oxidized product $\mathbf{H L}^{2 \mathrm{c} \prime}$ revealed a superior antitumor activity in the two cancer cell lines over that of $\mathbf{H} L^{1 \mathbf{a} \prime}$ and $\mathbf{H} \mathbf{L}^{\mathbf{1 a \prime \prime}}$. In agreement with this, closely related 2formyl- and 2-acetylpyridine 2-benzothiazolyl hydrazones were shown to be potent cytotoxic drugs against a series of 17 murine (e.g., L1210 lymphoid leukemia, P388 lymphocytic leukemia) and human cancer cells (e.g., HeLa cervix carcinoma, bone SOS, lung MB9812, lung A549). In addition, these compounds showed selectivity for the multidrug-resistant doxorubicin-selected uterine sarcoma cell line MES-SA/Dx5 over parental or sensitive MES-SA cells. ${ }^{78,79}$

Tyrosyl Radical Reduction in mR2 RNR. The TSCs $\mathbf{H L}^{1}-\mathbf{H L}^{3}$ and their copper(II) complexes $\mathbf{1}, \mathbf{2}^{\prime}$, and 3 were found to effectively quench the tyrosyl radical in $\mathrm{mR} 2 \mathrm{RNR}$ in the presence of an external reductant (DTT). The timedependent tyrosyl radical reduction in $\mathrm{mR} 2 \mathrm{RNR}$ by equimolar concentrations of TSCs and their respective copper(II) complexes, under reducing conditions, is shown in Figure 15. The $\mathrm{mR} 2$ inhibition potency follows the order $\mathrm{HL}^{1} \approx$ triapine $>\mathbf{H L}^{3}>\mathbf{H L}^{2}$. The coordination to copper(II) was found to increase the tyrosyl radical quenching potential for all TSCs, which is in agreement with the observed lowering of $\mathrm{IC}_{50}$ values in all cancer cell lines (Table 2). Complex $\mathbf{1}$ was shown to be as efficient as triapine, ${ }^{17}$ reducing $100 \%$ of the tyrosyl radical in $3 \mathrm{~min}$. Complexes $\mathbf{2}^{\prime}$ and $\mathbf{3}$ exhibited comparable reduction kinetics despite the fact that, among the investigated TSCs, $\mathbf{H L}^{2}$ was found to be most inefficient. The favorable 


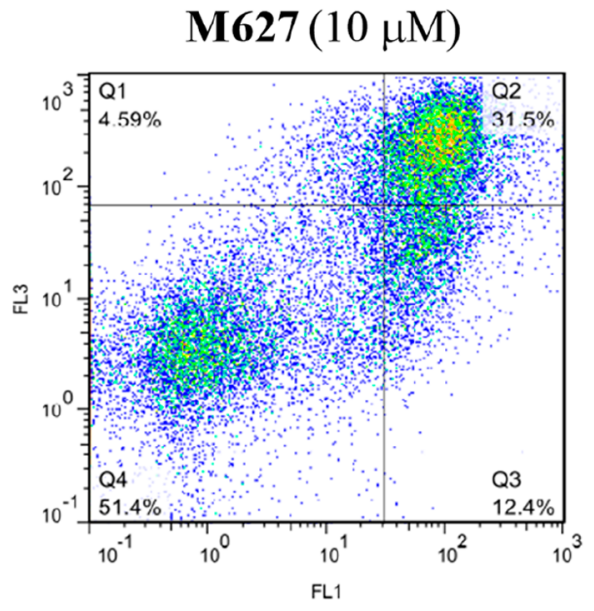

$\mathbf{H L}^{1}(4 \mu \mathrm{M})$

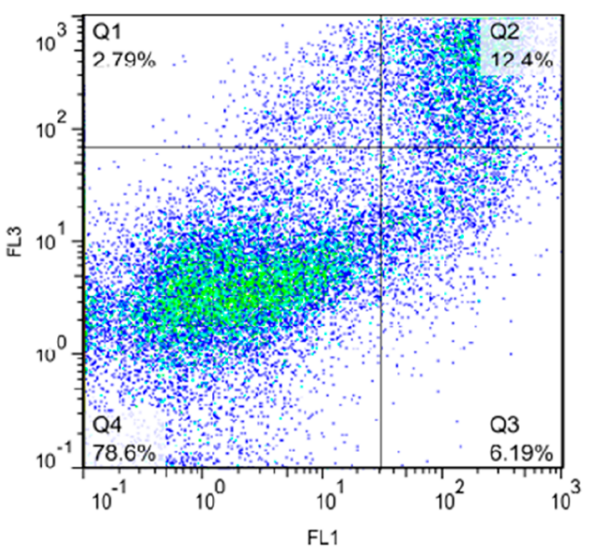

cisplatin $(15 \mu \mathrm{M})$

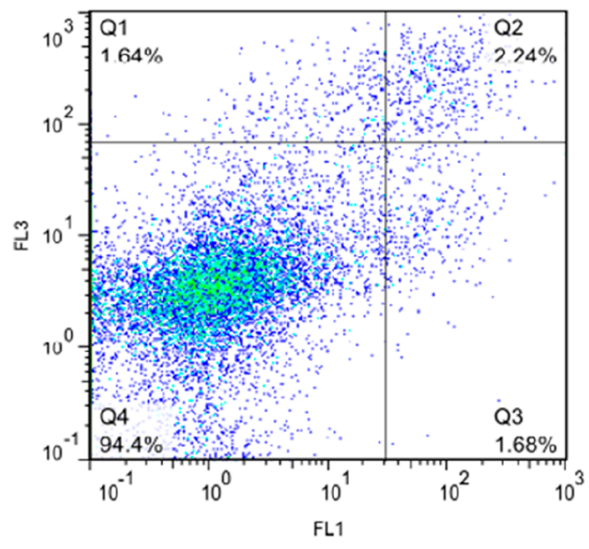

2' $(0.25 \mu \mathrm{M})$

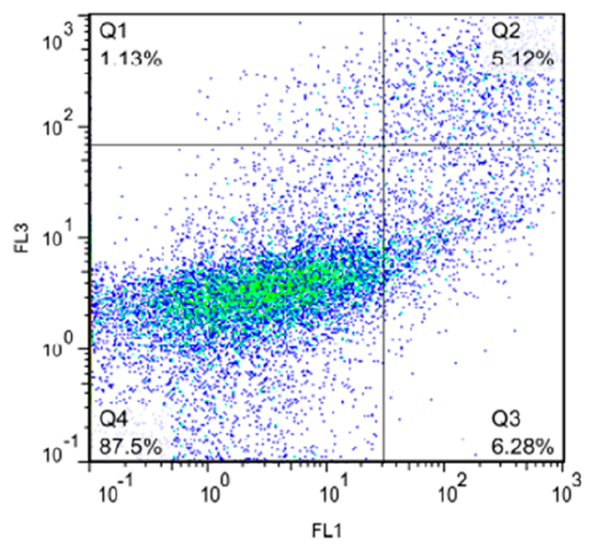

Figure 14. Quantification of apoptosis in Colo320 cells treated with $\mathbf{H L}^{1}$ and $\mathbf{2}^{\prime}$ and M627 and cisplatin (as positive controls) using the AnnexinV/PI double staining assay. Colo320 cells were treated at the indicated concentration of the drugs. The dual parametric dot plots that combine the Annexin-V (FL1) and PI (FL3) fluorescence show the viable cell population in the lower-left quadrant Annexin-V-/PI- (Q4), the early apoptotic cells in the lower-right quadrant Annexin-V+/PI- (Q3), and the late apoptotic and necrotic cells in the upper-right quadrant Annexin-V+/PI+ (Q2). (Number of cells counted: 23193 (M627), 20262 (cisplatin), $33193\left(\mathbf{H L}^{\mathbf{1}}\right)$, and $19312\left(\mathbf{2}^{\prime}\right)$ ).

impact of the copper(II) coordination on the $\mathrm{HL}^{2}$ inhibitory activity is quite obvious, when the ability to quench the tyrosyl radical by $\mathbf{H L}^{2}$ is compared to that of $\mathbf{2}^{\prime}$. Interestingly, the twoelectron oxidized product of $\mathrm{HL}^{2}$, namely, $\mathrm{HL}^{2 \mathrm{c}^{\prime}} \cdot \mathrm{CH}_{3} \mathrm{COOH}$, is as potent as $\mathrm{HL}^{3}$ in tyrosyl radical reduction.

The ability of $\mathbf{H L}^{\mathbf{1}}-\mathbf{H L}^{3}$ and $\mathbf{1}, \mathbf{2}^{\prime}$, and 3 to quench the tyrosyl radical correlates well with their first anodic redox potentials (0.82-0.88 V vs NHE) and (0.68-0.70 V vs NHE), respectively, which are well-compared with redox potential of hydroxyurea $(+0.724 \mathrm{~V}){ }^{83}$ which reduced the tyrosyl radical in the $\mathrm{R} 2$ protein with an estimated redox potential of $1.0 \pm 0.1 \mathrm{~V}$ vs NHE. $^{36}$ Note, however, that hydroxyurea, a well-known inhibitor of RNR and an anticancer drug, ${ }^{84}$ is a small molecule able to enter the hydrophobic R2 protein pocket, where the tyrosyl radical is buried. Finally, the two- and four-electron oxidized products of $\mathbf{H L}^{1}$, namely, $\mathbf{H} L^{1 \mathbf{a} \prime}$ and $\mathbf{H} L^{1 \mathbf{a} \prime \prime}$, do not have an effect on the tyrosyl radical in the absence of DTT and, interestingly, cause an increase in the radical content in the presence of DTT (Figure S15).

Previously it has been shown that the radical content in $\mathrm{mR} 2$ may be slightly increased in the presence of DTT, as the result of the so-called radical reconstitution reaction, ${ }^{17,85}$ in which the DTT-reduced diiron center in the reaction with molecular oxygen is spontaneously oxidized through a series of intermediate states, generating the active $\mathrm{Fe}(\mathrm{III})-\mathrm{O}^{2-}-\mathrm{Fe}$ (III)/Tyr - cofactor. However, the radical increase caused by $\mathrm{HL}^{1 \mathbf{a} \prime}$ and $\mathrm{HL}^{\mathbf{1 a} \prime}$ (in reducing conditions) is much greater than that observed for DTT, providing evidence that the formation of the active iron/radical site in $\mathrm{mR} 2$ is more efficient when the DTT-reduced form of $\mathrm{mR} 2$ is oxidized by $\mathbf{H} L^{1 \mathbf{a} \prime}$ or $\mathbf{H} L^{\mathbf{1 a} \prime}$, than by molecular oxygen only.

Consistent with enzyme inhibition studies, which revealed a potent inhibition of $\mathrm{mR} 2 \mathrm{RNR}$, compounds $\mathrm{HL}^{\mathbf{1}}, \mathbf{1}$, and $\mathbf{2}^{\prime}$ were found to increase the population of the S-phase in SW480 cells.

Cell Cycle Arrest. The perturbation effects of $10 \mu \mathrm{M} \mathrm{HL}^{1}$, 1 , and $2^{\prime}$ on the cell cycle progression of SW480 cells when compared to negative control are shown in Figure 16 and Table S9, while the effects of $0,1.0$, and $10 \mu \mathrm{M}$ are presented in Figure S16. It can be noted that the population of S-phase cells increased after an incubation with $\mathrm{HL}^{1}$ (37.1\%), complex 1 (44.0), and $2^{\prime}$ (46.5) compared with the negative control (29.8\%). Gemcitabine (GC), a positive control, showed a canonical G1/S-phase arrest at the concentration of $0.01 \mu \mathrm{M}$ with $26.8 \%$ of cells in the G1 phase and $62.3 \%$ of cells in the S phase compared to the negative control with $49.1 \%$ of cells in the G1 phase and $29.8 \%$ of cells in the S phase (Figure S17). An increase in the population of the S-phase cells by ca. $20 \%$ 


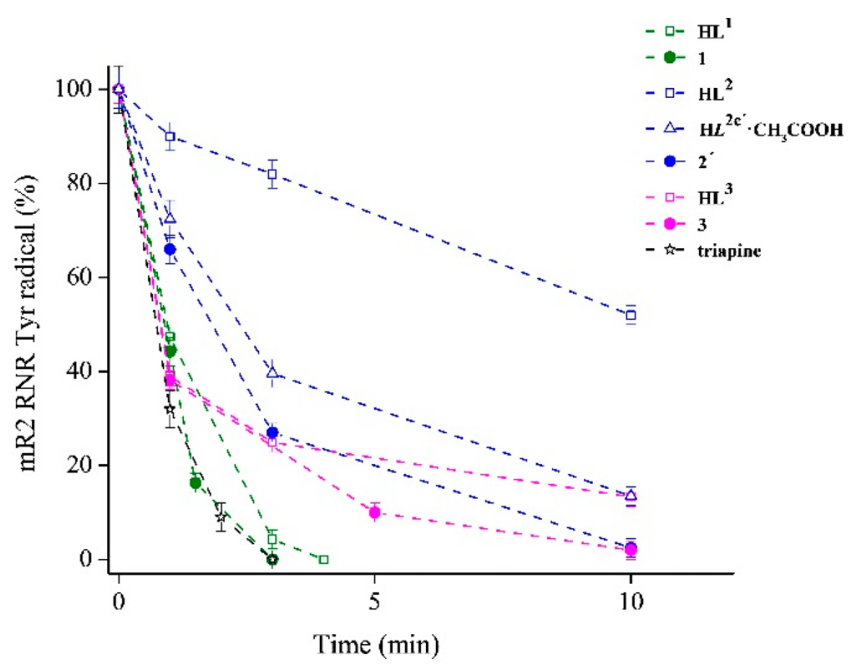

Figure 15. Tyrosyl radical reduction kinetics in mouse R2 RNR protein by TSCs $\mathbf{H L}^{1}, \mathbf{H L}^{2}, \mathbf{H L}^{3}$, and their corresponding copper complexes $1,2^{\prime}$, and 3 as well as by the two-electron oxidized product of $\mathrm{HL}^{2}\left(\mathrm{HL}^{2 \mathrm{c}^{\prime}} \cdot \mathrm{CH}_{3} \mathbf{C O O H}\right)$, in the presence of an external reductant, measured at $30 \mathrm{~K}$ by EPR spectroscopy and compared to triapine. The samples contained $20 \mu \mathrm{M} \mathrm{mR2}$ in $50 \mathrm{mM}$ HEPES buffer, $\mathrm{pH}$ $7.60 / 100 \mathrm{mM} \mathrm{KCl}, 20 \mu \mathrm{M}$ compound in $1 \%(\mathrm{v} / \mathrm{v}) \mathrm{DMSO} / \mathrm{H}_{2} \mathrm{O}$, and 2 mM DTT.

has been reported for a series of triapine analogues at concentrations from 0.25 to $5.0 \mu \mathrm{M}^{80}$ The $\mathrm{S}$-phase arrest is characteristic for cells treated with triapine. ${ }^{81}$

These data indicate that there is a correlation between the ability of the compounds tested to inhibit R2 RNR and their ability to induce an S-phase arrest. Nevertheless, the inhibition of RNR does not appear to be the main mechanism underlying the antiproliferative activity of both TSCs studied herein and their copper(II) complexes.

ROS Generation. Since metal-free TSCs that enter the cells or are released from copper(I) complexes generated by a reduction of their copper(II) counterparts can react in the cells with iron(II), the redox activity of the $\left[\mathrm{Fe}^{\mathrm{II}}\left(\mathrm{L}^{1}\right)_{2}\right]$ complex, prepared by the reaction of an anoxic aqueous solution of $\mathrm{FeSO}_{4} \cdot 7 \mathrm{H}_{2} \mathrm{O}$ with a DMSO solution of $\mathrm{HL}^{1}$ at a $1: 2$ molar ratio, was investigated by EPR spin-trapping experiments. To investigate whether this ferrous complex is able to generate ROS in the aqueous environment by a Fenton reaction, which is supposed to quench the tyrosyl radical of the $\mathrm{mR} 2$ enzyme, hydrogen peroxide was added into the system in the presence of 5,5-dimethyl-1-pyrroline $N$-oxide (DMPO) as the spintrapping agent. A four-line EPR signal characteristic for the . OH-DMPO spin adduct was observed (Figure 17, black trace, EPR signal marked with circles).

Additionally a $\cdot \mathrm{DMPO}-\mathrm{OCH}_{3}$ spin adduct can be seen in the corresponding EPR spectrum as a consequence of the reaction of hydroxyl radicals with the DMSO solvent forming methyl radicals, which react with molecular oxygen resulting in the generation of peroxomethyl radicals serving as a source of -DMPO- $\mathrm{OCH}_{3}$ spin adducts (Figure 17, black trace, EPR signal marked with squares). ${ }^{82}$ Only a trace amount of carboncentered radicals was detected for $\mathrm{Fe}(\mathrm{II}) / \mathrm{HL}^{\mathbf{1}} / \mathrm{DMPO}$ in $\mathrm{H}_{2} \mathrm{O}-\mathrm{DMSO}$ in the absence of $\mathrm{H}_{2} \mathrm{O}_{2}$ (Figure 17, blue and red traces, EPR signal marked with stars). In this case DMSO acts as a $\mathrm{HO}$. scavenger, generating reactive carbon-centered radicals, which are trapped by DMPO. It is important to mention that no radicals were formed in the system of $\mathbf{H L}^{1}$ /
$\mathrm{H}_{2} \mathrm{O}_{2} / \mathrm{DMPO} / \mathrm{H}_{2} \mathrm{O}-\mathrm{DMSO}$ (not shown), which indicates the crucial role of the $\mathrm{Fe}(\mathrm{II})$ complex for ROS generation. Consequently complex $\left[\mathrm{Fe}^{\mathrm{II}}\left(\mathrm{L}^{1}\right)_{2}\right]$ is redox-active in the Fenton reaction indicating the important role of the $\mathrm{HL}^{1}$ ligand for the observed antiproliferative activity against cancer cell lines and its ability to quench the tyrosyl radical in the $\mathrm{mR} 2$ protein. A direct reduction of the tyrosyl radical by iron(II) complexes with reported TSCs can also not be excluded. $^{16}$

\section{CONCLUSIONS}

New triapine analogues bearing a redox-active $p$-aminophenolic moiety and their copper(II) complexes have been synthesized and characterized by spectroelectrochemical and analytical techniques, which confirmed the noninnocent identity of the latter. The crystal structures of TSCs $\mathrm{HL}^{1}$ $\mathbf{H L}^{3}$ and complexes $\left[\mathbf{C u}\left(\mathrm{L}^{1-3}\right) \mathbf{C l}\right]$ were studied by SC-XRD revealing the tridentate $(\mathrm{N}, \mathrm{N}, \mathrm{S})$ coordination mode of the ligands. The presence of $E$ and $Z$ isomers of $\mathbf{H L}^{1}-\mathbf{H L}^{3}$ with a predominance of the first one in DMSO has been disclosed by $1 \mathrm{D}$ and 2D NMR spectroscopy. These data along with DFT calculations on the model compound 2-formylpyridine TSC indicate that the $Z / E$ isomerization involves an inversion at the aldimine nitrogen atom, rather than a tautomeric shift of the thioamide $\mathrm{N} 2 \mathrm{H}$ proton to the pyridine nitrogen, followed by a rotation around the $\mathrm{C}-\mathrm{N} 1$ bond as suggested previously. ${ }^{44}$ The relatively high Gibbs free energy barrier $(\sim 35.3 \mathrm{kcal} / \mathrm{mol})$ for the $Z / E$ conversion rules out the possibility of an isomerization at room temperature, in agreement with timedependent NMR data.

A two-electron oxidative dehydrogenation of $\mathbf{H L}^{1}$ by a reaction with 1 equiv of DDQ afforded the new species $\mathbf{H} \mathbf{L}^{\mathbf{1 a}}$ containing a thiadiazole five-membered ring formed via a nucleophilic attack of a thione sulfur atom on an aldimine carbon atom. This is supported by frontier molecular orbitals (MOs) with the HOMO and LUMO located at opposite parts of the molecule of $\mathbf{H L}^{1}$. When 2 equiv of DDQ were used, a further two-electron oxidation coupled with a two-proton loss occurred at the 3,5-dimethyl-4-aminophenolic moiety to give the 3,5-dimethyl-1,4-benzoquinone imine unit in $\mathbf{H} L^{1 \mathbf{a} \prime}$. Also note that the coordinated ligand $\mathbf{H L}^{1}$ is able to form a thiazole five-membered ring in $\mathbf{4}$ via a sulfur attack on the carbon atom in position 2 or 6 of the 3,5-dimethyl-4-aminophenolic moiety. The arylated sulfur atom has lost the competition in binding to copper(II) for an end nitrogen atom due to the reduction of the electron-donating ability of the sulfur atom. The oxidation of $\mathrm{HL}^{2}$ with $\mathrm{PBQ}$ in a 1:1 molar ratio furnished the twoelectron oxidative cyclization product $\mathbf{H} \mathbf{L}^{2 \mathbf{b}}$ and the diphenolic species $\mathbf{H} L^{2 \mathrm{e}}$. A tentative mechanism of their formation is proposed. The pathway to $H L^{2 \mathrm{e}}$ implies the formation of the 4isothiocyanato-2,6-dimethylphenol intermediate. Treatments of $\mathbf{H L}^{2}$ with 1 and 2 equiv of PIDA afforded the two-electron oxidation product $\mathrm{HL}^{2 \mathrm{c} \prime}$ and the four-electron oxidation product $\mathbf{H} \mathbf{L}^{2 \mathrm{c} \prime \prime}$, respectively. In contrast to $\mathbf{H L}^{1}-\mathbf{H L}^{3}$, the $Z$ / $E$ isomerization was observed at room temperature for $\mathbf{H L}^{2 \mathrm{c}^{\prime}}$. The isolation and investigation of oxidation products of new TSCs was of interest also from the point of view of collecting spectroscopic data that might be useful for an eventual analysis of metabolites, which can be generated in vivo from the corresponding TSCs and their copper(II) complexes.

Solution equilibrium studies performed by UV-vis spectrophotometry revealed the acidic $\mathrm{p} K_{\mathrm{a}}$ values $(3.01-3.95)$ of the pyridinium nitrogen and $\mathrm{p} K_{\mathrm{a}}$ values greater than or equal 

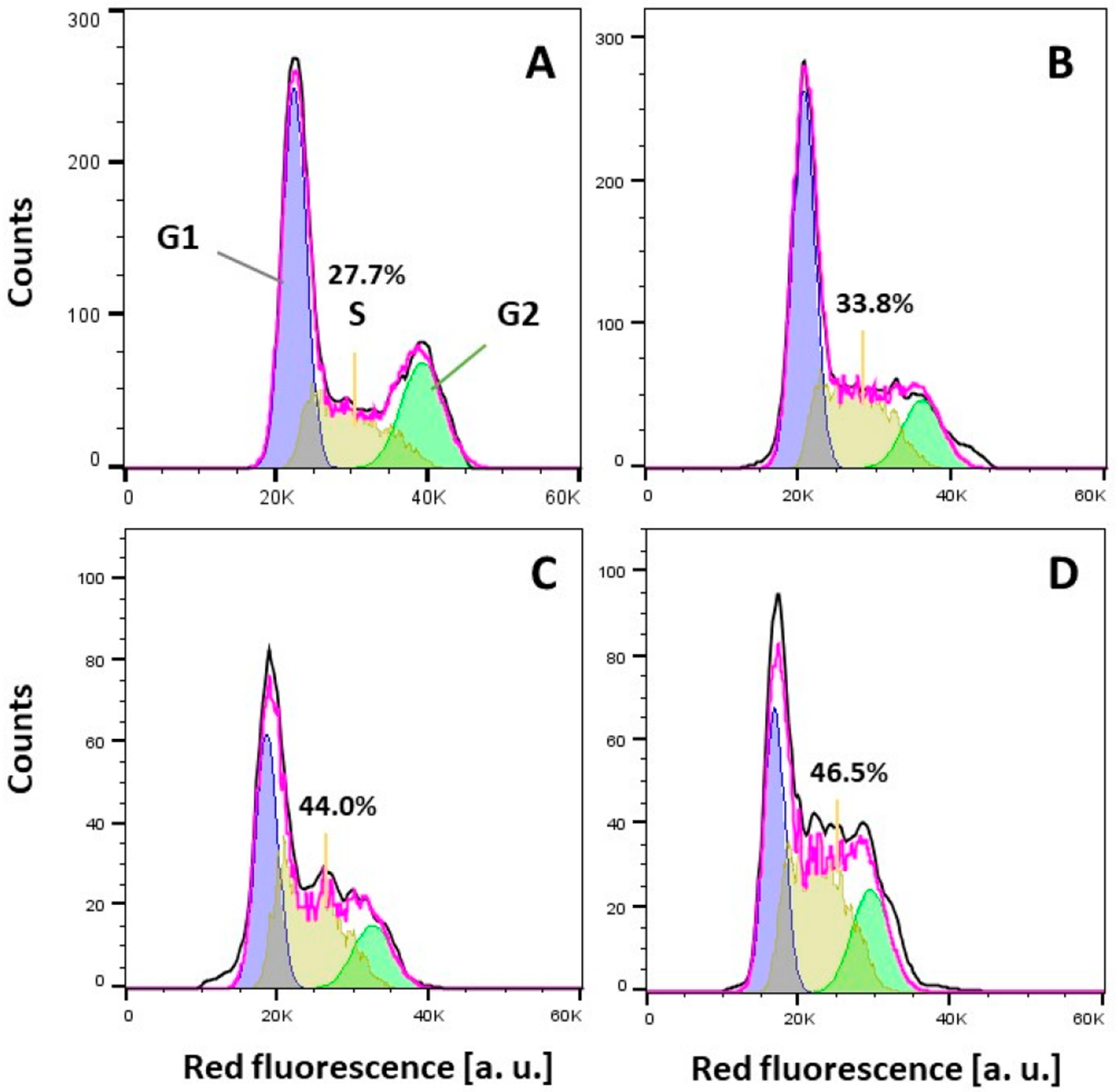

Figure 16. Flow cytometry analysis for a cell cycle distribution of SW480 cells induced by TSC $\mathbf{H L}^{\mathbf{1}}$ (B) and complexes $\mathbf{1}$ (C) and $\mathbf{2}^{\prime}$ (D) at the concentration of $10 \mu \mathrm{M}$ for $24 \mathrm{~h}$ compared to the negative control (DMSO) (A).

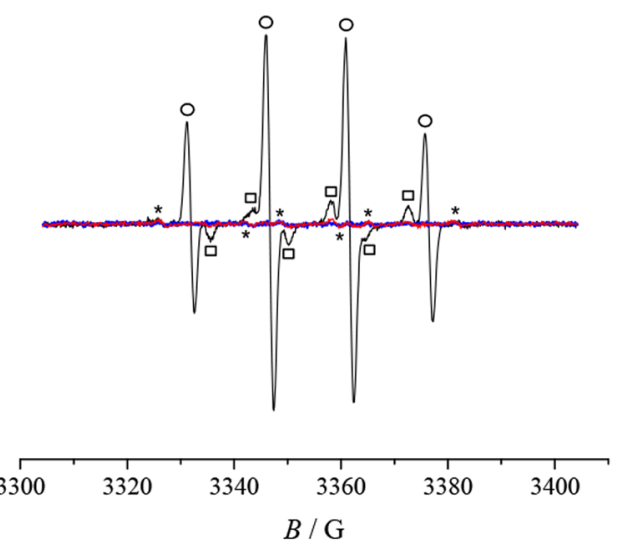

Figure 17. Experimental EPR spectra of $\mathrm{Fe}(\mathrm{II}) / \mathrm{HL}^{1} / \mathrm{DMPO} / \mathrm{H}_{2} \mathrm{O}_{2}$ in $5 \%(\mathrm{v} / \mathrm{v}) \mathrm{H}_{2} \mathrm{O}-\mathrm{DMSO}$ (black line), in the system of $\mathrm{Fe}(\mathrm{II}) / \mathbf{H L}^{1} /$ DMPO in $5 \%(\mathrm{v} / \mathrm{v}) \mathrm{H}_{2} \mathrm{O}-\mathrm{DMSO}$ (blue line), and in $30 \%(\mathrm{v} / \mathrm{v})$ $\mathrm{H}_{2} \mathrm{O}-\mathrm{DMSO}$ (red line). Initial concentrations: $c\left(\mathrm{HL}^{1}\right)=0.2 \mathrm{mM}$, $c\left(\mathrm{FeSO}_{4} \cdot 7 \mathrm{H}_{2} \mathrm{O}\right)=0.1 \mathrm{mM}, c(\mathrm{DMPO})=20 \mathrm{mM}, c\left(\mathrm{H}_{2} \mathrm{O}_{2}\right)=10 \mathrm{mM}$. to 10.55 for the hydrazinic-NNH and phenolic $(\mathrm{PhOH})$ moiety of the metal-free ligands. The latter are neutral and stable at a physiological $\mathrm{pH}$. However, they become airsensitive upon deprotonation of the $\mathrm{OH}$ group in the basic $\mathrm{pH}$ range. The formation of high-stability monoligand copper(II) complexes was found in different protonation states in solution; namely, coordination via $\left(\mathrm{N}_{\text {pyridine }}, \mathrm{N}, \mathrm{S}\right)\left(\mathrm{H}_{2} \mathrm{O}\right)$, $\left(\mathrm{N}_{\text {pyridine, }} \mathrm{N}, \mathrm{S}^{-}\right)\left(\mathrm{H}_{2} \mathrm{O}\right)$, and $\left(\mathrm{N}_{\text {pyridine, }}, \mathrm{N}, \mathrm{S}^{-}\right)\left(\mathrm{OH}^{-}\right)$donor sets are probable. The complexes with a $\left(\mathrm{N}_{\text {pyridine }}, \mathrm{N}, \mathrm{S}^{-}\right)\left(\mathrm{H}_{2} \mathrm{O}\right)$ coordination predominate in a wide $\mathrm{pH}$ range including $\mathrm{pH}$ 7.4. Conditional stability constants determined for the $\left[\mathbf{C u}\left(\mathbf{L}^{1}\right)\right]^{+}$and $\left[\mathbf{C u}\left(\mathbf{L}^{3}\right)\right]^{+}$complexes by an EDTA UV-vis spectrophotometric competition experiment show the somewhat higher stability of the $\left[\mathbf{C u}\left(\mathbf{L}^{3}\right)\right]^{+}$complex. The attachment of a phenolic moiety undoubtedly increases the lipophilicity of new Schiff bases and copper(II) complexes when compared to triapine and its copper(II) complex. The new complexes can be reduced by glutathione, the most abundant low molecular mass reducing agent in a cell, in a reversible redox reaction. According to the electrochemical studies complexes $1,2^{\prime}$, and 3 can undergo a redox process in a 
biologically accessible window $\left(-0.4\right.$ to $+0.8 \mathrm{~V}$ vs $\left.\mathrm{Fc}^{+} / \mathrm{Fc}\right)$. These findings suggest a possible role of the redox properties of the copper(II) complexes in their biological activity.

The metal-free ligands and several oxidized products showed no or only a moderate cytotoxicity against doxorubicinsensitive Colo205 and the multidrug-resistant Colo320 human colonic adenocarcinoma cell lines. Their copper(II) complexes revealed a high cytotoxic potency when compared to that of the corresponding metal-free ligands. $\left[\mathbf{C u}\left(\mathbf{L}^{2}\right) \mathbf{C l}\right]$ showed the highest cytotoxic activity with $\mathrm{IC}_{50}$ values in the low micromolar concentration range and induced apoptosis, while $\mathbf{C u}\left(\mathbf{H L}^{3}\right) \mathbf{C l}_{2}$ has the highest selectivity for cancer cells over the normal fibroblast MRC-5 cells. The highest antiproliferative activity of $\left[\mathbf{C u}\left(\mathbf{L}^{2}\right) \mathbf{C l}\right]$ is likely due to the more negative reduction potential when compared to those of 1 and 3 and low reduction rate in reaction with GSH. ${ }^{36}$ In addition, $\mathbf{H L}^{1}-\mathbf{H L}^{3}$ and their copper(II) complexes were found to efficiently quench the tyrosyl radical in mR2 RNR in the presence of DTT as an external reductant and increase the population of S-phase cells. The capacity of $\mathbf{H L}^{1}$ to destroy the tyrosyl radical is almost identical with that of triapine, which is by the factor of 1000 a more potent R2 RNR inhibitor than hydroxyurea, a known clinical drug. ${ }^{17}$ Thus, the copper(II) complexes reported herein deserve further investigation as potential anticancer drugs.

\section{ASSOCIATED CONTENT}

\section{SI Supporting Information}

The Supporting Information is available free of charge at https://pubs.acs.org/doi/10.1021/acs.inorgchem.1c01275.

Synthesis of oxidized thiosemicarbazones and their copper(II) complexes, methods used for characterization of the compounds, atom labeling schemes used in the NMR resonances assignment, NMR and UV-vis spectra showing $E / Z$ isomerization of TSCs in solution, 2D NMR spectra, UV-vis spectra of TSCs at different $\mathrm{pH}$ values and measured over time, tyrosyl radical kinetic behavior in absence and presence of DTT, crystal data and details of data collection, collected multinuclear NMR data, summarized ESI mass spectra, computational details (PDF)

\section{Accession Codes}

CCDC 2074017-2074030 and 2074341 contain the supplementary crystallographic data for this paper. These data can be obtained free of charge via www.ccdc.cam.ac.uk/data_request/ cif, or by emailing data_request@ccdc.cam.ac.uk, or by contacting The Cambridge Crystallographic Data Centre, 12 Union Road, Cambridge CB2 1EZ, UK; fax: +44 1223336033.

\section{AUTHOR INFORMATION}

\section{Corresponding Authors}

Vladimir B. Arion - Institute of Inorganic Chemistry, University of Vienna, A-1090 Vienna, Austria; (1) orcid.org/ 0000-0002-1895-6460; Email: vladimir.arion@univie.ac.at

Anatoly D. Shutalev - N. D. Zelinsky Institute of Organic Chemistry, Russian Academy of Sciences, 119991 Moscow, Russian Federation; (1) orcid.org/0000-0002-8038-8230; Email: anatshu@gmail.com

Peter Rapta - Institute of Physical Chemistry and Chemical Physics, Faculty of Chemical and Food Technology, Slovak University of Technology in Bratislava, SK-81237 Bratislava, Slovak Republic; Email: peter.rapta@stuba.sk
Eva A. Enyedy - Department of Inorganic and Analytical Chemistry, Interdisciplinary Excellence Centre and MTASZTE Lendület Functional Metal Complexes Research Group, University of Szeged, H-6720 Szeged, Hungary; 이이.org/0000-0002-8058-8128; Email: enyedy@ chem.u-szeged.hu

\section{Authors}

Iuliana Besleaga - Institute of Inorganic Chemistry, University of Vienna, A-1090 Vienna, Austria

Iryna Stepanenko - Institute of Inorganic Chemistry, University of Vienna, A-1090 Vienna, Austria

Tatsiana V. Petrasheuskaya - Department of Inorganic and Analytical Chemistry, Interdisciplinary Excellence Centre and MTA-SZTE Lendület Functional Metal Complexes Research Group, University of Szeged, H-6720 Szeged, Hungary

Denisa Darvasiova - Institute of Physical Chemistry and Chemical Physics, Faculty of Chemical and Food Technology, Slovak University of Technology in Bratislava, SK-81237 Bratislava, Slovak Republic

Martin Breza - Institute of Physical Chemistry and Chemical Physics, Faculty of Chemical and Food Technology, Slovak University of Technology in Bratislava, SK-81237 Bratislava, Slovak Republic; 이이.org/0000-0001-5995-0279

Marta Hammerstad - Section for Biochemistry and Molecular Biology, Department of Biosciences, University of Oslo, NO0316 Oslo, Norway

Małgorzata A. Maŕ́ - Department of Inorganic and Analytical Chemistry, Interdisciplinary Excellence Centre, University of Szeged, H-6720 Szeged, Hungary; Department of Medical Microbiology, Albert Szent-Györgyi Health Center and Faculty of Medicine, University of Szeged, 6725 Szeged, Hungary

Alexander Prado-Roller - Institute of Inorganic Chemistry, University of Vienna, A-1090 Vienna, Austria

Gabriella Spengler - Department of Medical Microbiology, Albert Szent-Györgyi Health Center and Faculty of Medicine, University of Szeged, 6725 Szeged, Hungary; MTA-SZTE Lendület Functional Metal Complexes Research Group, University of Szeged, H-6720 Szeged, Hungary

Ana Popovic-Bijelić - Faculty of Physical Chemistry, University of Belgrade, 11158 Belgrade, Serbia; 이이.org/ 0000-0003-3121-2391

Complete contact information is available at:

https://pubs.acs.org/10.1021/acs.inorgchem.1c01275

\section{Notes}

The authors declare no competing financial interest.

\section{ACKNOWLEDGMENTS}

The financial support of the Austrian Science Fund (Grant No. I4729) and of the Russian Foundation for Basic Research (Grant No. 20-53-14002) is gratefully acknowledged. This work was also supported by the Lendület program of the Hungarian Academy of Sciences (LP2019-6/2019), the National Research, Development and Innovation OfficeNKFIA through Project Nos. GINOP-2.3.2-15-2016-00038 and FK 124240 and the Ministry of Human Capacities, Hungary, Grant No. TKP-2020. T.V.P. is thankful for the support of Scholarship Foundation of the Republic of Austria (ICM-2019-14969). We are thankful to Dr. D. Dumitrescu for the collection of X-ray diffraction data for complex $2^{\prime}$ at the XRD2 structural biology beamline, Elettra synchrotron. P.R. 
and D.D. acknowledge the support of Slovak Research and Development Agency (contract Nos. APVV-15-0053, APVV19-0024 and DS-FR-19-0035) and Slovak Scientific Grant Agency VEGA (1/0504/20). This work was also supported by COST Action CA18202, NECTAR-Network for Equilibria and Chemical Thermodynamics Advanced Research.

\section{REFERENCES}

(1) Matesanz, A.; Souza, P. $\alpha$-N-Heterocyclic Thiosemicarbazone Derivatives as Potential Antitumor Agents: A Structure-Activity Relationships Approach. Mini-Rev. Med. Chem. 2009, 9, 1389-1396.

(2) Garcia-Tojal, J.; Gil-Garcia, R.; Gomez-Saiz, P.; Ugalde, M. Pyridine-2-Carbaldehyde Thiosemicarbazonecopper System: Extending Some Findings to Other Thiosemicarbazone and Coordination Compounds. Curr. Inorg. Chem. 2011, 1, 189-210.

(3) Kalinowski, D. S.; Quach, P.; Richardson, D. R. Thiosemicarbazones: The New Wave in Cancer Treatment. Future Med. Chem. 2009, $1,1143-1151$

(4) Heloisa, B.; Gambino, D. The Wide Pharmacological Versatility of Semicarbazones, Thiosemicarbazones and Their Metal Complexes. Mini-Rev. Med. Chem. 2004, 4, 31-39.

(5) Shimada, K.; Reznik, E.; Stokes, M. E.; Krishnamoorthy, L.; Bos, P. H.; Song, Y.; Quartararo, C. E.; Pagano, N. C.; Carpizo, D. R.; deCarvalho, A. C.; Lo, D. C.; Stockwell, B. R. Copper-Binding Small Molecule Induces Oxidative Stress and Cell-Cycle Arrest in Glioblastoma-Patient-Derived Cells. Cell Chem. Biol. 2018, 25, 585594.

(6) Zeglis, B. M.; Divilov, V.; Lewis, J. S. Role of Metalation in the Topoisomerase II $\alpha$ Inhibition and Antiproliferation Activity of a Series of $\alpha$-Heterocyclic- $\mathrm{N}^{4}$-Substituted Thiosemicarbazones and Their Cu(II) Complexes. J. Med. Chem. 2011, 54, 2391-2398.

(7) Ishiguro, K.; Lin, Z. P.; Penketh, P. G.; Shyam, K.; Zhu, R.; Baumann, R. P.; Zhu, Y.-L.; Sartorelli, A. C.; Rutherford, T. J.; Ratner, E. S. Distinct Mechanisms of Cell-Kill by Triapine and Its Terminally Dimethylated Derivative Dp44mT Due to a Loss or Gain of Activity of Their Copper(II) Complexes. Biochem. Pharmacol. 2014, 91, 312322.

(8) Jansson, P. J.; Kalinowski, D. S.; Lane, D. J. R.; Kovacevic, Z.; Seebacher, N. A.; Fouani, L.; Sahni, S.; Merlot, A. M.; Richardson, D. $\mathrm{R}$. The Renaissance of Polypharmacology in the Development of Anti-Cancer Therapeutics: Inhibition of the "Triad of Death" in Cancer by Di-2-Pyridylketone Thiosemicarbazones. Pharmacol. Res. 2015, 100, 255-260.

(9) Kowol, C. R.; Miklos, W.; Pfaff, S.; Hager, S.; Kallus, S.; Pelivan, K.; Kubanik, M.; Enyedy, E. A.; Berger, W.; Heffeter, P.; Keppler, B. $\mathrm{K}$. Impact of Stepwise $\mathrm{NH}_{2}$-Methylation of Triapine on the Physicochemical Properties, Anticancer Activity, and Resistance Circumvention. J. Med. Chem. 2016, 59, 6739-6752.

(10) Ohui, K.; Afanasenko, E.; Bacher, F.; Ting, R. L. X.; Zafar, A.; Blanco-Cabra, N.; Torrents, E.; Dömötör, O.; May, N. V.; Darvasiova, D.; Enyedy, É. A.; Popović-Bijelić, A.; Reynisson, J.; Rapta, P.; Babak, M. V.; Pastorin, G.; Arion, V. B. New Water-Soluble Copper(II) Complexes with Morpholine-Thiosemicarbazone Hybrids: Insights into the Anticancer and Antibacterial Mode of Action. J. Med. Chem. 2019, 62, 512-530.

(11) Richardson, D. R. Iron Chelators as Therapeutic Agents for the Treatment of Cancer. Crit. Rev. Oncol./Hematol. 2002, 42, 267-281.

(12) Krakoff, I. H.; Etcubanas, E.; Tan, C.; Mayer, K.; Bethune, V.; Burchenal, J. H. Clinical Trial of 5-Hydroxypicolinaldehyde Thiosemicarbazone (5-HP; NSC-107392), with Special Reference to Its Iron-Chelating Properties. Cancer Chemother. Rep. 1974, 58, 207-212.

(13) Merlot, A. M.; Kalinowski, D. S.; Richardson, D. R. Novel Chelators for Cancer Treatment: Where Are We Now? Antioxid. Redox Signaling 2013, 18, 973-1006.

(14) Nutting, C. M.; van Herpen, C. M. L.; Miah, A. B.; Bhide, S. A.; Machiels, J.-P.; Buter, J.; Kelly, C.; de Raucourt, D.; Harrington, K. J. Phase II Study of 3-AP Triapine in Patients with Recurrent or
Metastatic Head and Neck Squamous Cell Carcinoma. Ann. Oncol. 2009, 20, 1275-1279.

(15) Salim, K. Y.; Maleki Vareki, S.; Danter, W. R.; San-Marina, S.; Koropatnick, J. COTI-2, a Novel Small Molecule That Is Active against Multiple Human Cancer Cell Lines in Vitro and in Vivo. Oncotarget 2106, 7, 41363-41379.

(16) Aye, Y.; Long, M. J. C.; Stubbe, J. Mechanistic Studies of Semicarbazone Triapine Targeting Human Ribonucleotide Reductase in Vitro and in Mammalian Cells: Tyrosyl Radical Quenching not Involving Reactive Oxygen Species. J. Biol. Chem. 2012, 287, 3576835778.

(17) Popović-Bijelić, A.; Kowol, C. R.; Lind, M. E. S.; Luo, J.; Himo, F.; Enyedy, E. A.; Arion, V. B.; Gräslund, A. Ribonucleotide Reductase Inhibition by Metal Complexes of Triapine (3-Aminopyridine-2-Carboxaldehyde Thiosemicarbazone): A Combined Experimental and Theoretical Study. J. Inorg. Biochem. 2011, 105, 14221431.

(18) Yu, Y.; Wong, J.; Lovejoy, D. B.; Kalinowski, D. S.; Richardson, D. R. Chelators at the Cancer Coalface: Desferrioxamine to Triapine and Beyond. Clin. Cancer Res. 2006, 12, 6876-6883.

(19) Shao, J.; Zhou, B.; Di Bilio, A. J.; Zhu, L.; Wang, T.; Qi, C.; Shih, J.; Yen, Y. A Ferrous-Triapine Complex Mediates Formation of Reactive Oxygen Species That Inactivate Human Ribonucleotide Reductase. Mol. Cancer Ther. 2006, 5, 586-592.

(20) Benharroch, D.; Osyntsov, L. Infectious Diseases Are Analogous With Cancer. Hypothesis And Implications. J. Cancer 2012, 3, 117-121.

(21) Aye, Y.; Li, M.; Long, M. J. C.; Weiss, R. S. Ribonucleotide Reductase and Cancer: Biological Mechanisms and Targeted Therapies. Oncogene 2015, 34, 2011-2021.

(22) Elledge, S. J.; Zhou, Z.; Allen, J. B. Ribonucleotide Reductase: Regulation, Regulation, Regulation. Trends Biochem. Sci. 1992, 17, 119-123.

(23) Mulliez, E.; Fontecave, M. Ribonucleotide Reductases: Metal and Free Radical Interplay. Coord. Chem. Rev. 1999, 185-186, 775793.

(24) Nordlund, P.; Reichard, P. Ribonucleotide Reductases. Annu. Rev. Biochem. 2006, 75, 681-706.

(25) Shao, J.; Zhou, B.; Chu, B.; Yen, Y. Ribonucleotide Reductase Inhibitors and Future Drug Design. Curr. Cancer Drug Targets 2006, 6, 409-431.

(26) Mannargudi, M. B.; Deb, S. Clinical Pharmacology and Clinical Trials of Ribonucleotide Reductase Inhibitors: Is It a Viable Cancer Therapy? J. Cancer Res. Clin. Oncol. 2017, 143, 1499-1529.

(27) Luo, J.; Gräslund, A. Ribonucleotide Reductase Inhibition by $p$ Alkoxyphenols Studied by Molecular Docking and Molecular Dynamics Simulations. Arch. Biochem. Biophys. 2011, 516, 29-34.

(28) Lassmann, G.; Pötsch, S. Structure of Transient Radicals from Cytostatic-Active p-Alkoxyphenols by Continuous-Flow EPR. Free Radical Biol. Med. 1995, 19, 533-539.

(29) Liermann, B.; Lassmann, G.; Langen, P. Quenching of Tyrosine Radicals of M2 Subunit from Ribonucleotide Reductase in Tumor Cells by Different Antitumor Agents: An EPR Study. Free Radical Biol. Med. 1990, 9, 1-4.

(30) Vad, N. M.; Yount, G.; Moore, D.; Weidanz, J.; Moridani, M. Y. Biochemical Mechanism of Acetaminophen (APAP) Induced Toxicity in Melanoma Cell Lines. J. Pharm. Sci. 2009, 98, 1409-1425.

(31) Takahashi, N.; Ohba, T.; Yamauchi, T.; Higashiyama, K. Antioxidant and Anticancer Activities of Novel $p$-Alkylaminophenols and p-Acylaminophenols (Aminophenol Analogues). Bioorg. Med. Chem. 2006, 14, 6089-6096.

(32) Jungwirth, U.; Kowol, C. R.; Keppler, B. K.; Hartinger, C. G.; Berger, W.; Heffeter, P. Anticancer Activity of Metal Complexes: Involvement of Redox Processes. Antioxid. Redox Signaling 2011, 15, $1085-1127$

(33) Santini, C.; Pellei, M.; Gandin, V.; Porchia, M.; Tisato, F.; Marzano, C. Advances in Copper Complexes as Anticancer Agents. Chem. Rev. 2014, 114, 815-862. 
(34) Serda, M.; Kalinowski, D. S.; Rasko, N.; Potǔčková, E.; MrozekWilczkiewicz, A.; Musiol, R.; Małecki, J. G.; Sajewicz, M.; Ratuszna, A.; Muchowicz, A.; Gołąb, J.; Šmůnek, T.; Richardson, D. R.; Polanski, J. Exploring the Anti-Cancer Activity of Novel Thiosemicarbazones Generated through the Combination of Retro-Fragments: Dissection of Critical Structure-Activity Relationships. PLoS One 2014, 9, e110291.

(35) Li, Y.; Trush, M. A. Reactive Oxygen-Dependent DNA Damage Resulting from the Oxidation of Phenolic Compounds by a CopperRedox Cycle Mechanism. Cancer Res. 1994, 54, 1895s-1898s.

(36) Hager, S.; Pape, V. F. S.; Pósa, V.; Montsch, B.; Uhlik, L.; Szakács, G.; Tóth, S.; Jabronka, N.; Keppler, B. K.; Kowol, C. R.; Enyedy, E. A.; Heffeter, P. High Copper Complex Stability and Slow Reduction Kinetics as Key Parameters for Improved Activity, Paraptosis Induction and Impact on Drug-Resistant Cells of Anticancer Thiosemicarbazones. Antioxid. Redox Signaling 2020, 33, 395-414.

(37) Santoro, A.; Calvo, J. S.; Peris-Díaz, M. D.; Krężel, A.; Meloni, G.; Faller, P. The Glutathione/Metallothionein System Challenges the Design of Efficient $\mathrm{O}_{2}$-Activating Copper Complexes. Angew. Chem., Int. Ed. 2020, 59, 7830-7835.

(38) Silva, K. E.; Elgren, T. E.; Que, L.; Stankovich, M. T. Electron Transfer Properties of the R2 Protein of Ribonucleotide Reductase from Escherichia Coli. Biochemistry 1995, 34, 14093-14103.

(39) Venuti, M. C.; Stephenson, R. A.; Alvarez, R.; Bruno, J. J.; Strosberg, A. M. Inhibitors of Cyclic AMP Phosphodiesterase. 3. Synthesis and Biological Evaluation of Pyrido and Imidazolyl Analogs of 1,2,3,5-Tetrahydro-2-Oxoimidazo[2,1-b] Quinazoline. J. Med. Chem. 1988, 31, 2136-2145.

(40) Lungu, L.; Ciocarlan, A.; Barba, A.; Shova, S.; Pogrebnoi, S.; Mangalagiu, I.; Moldoveanu, C.; Vornicu, N.; D’Ambrosio, M.; Babak, M. V.; Arion, V. B.; Aricu, A. Synthesis and Evaluation of Biological Activity of Homodrimane Sesquiterpenoids Bearing Hydrazinecarbothioamide or 1,2,4-Triazole Unit. Chem. Heterocycl. Compd. 2019, 55, $716-724$.

(41) West, D. X.; Bain, G. A.; Butcher, R. J.; Jasinski, J. P.; Li, Y.; Pozdniakiv, R. Y.; Valdés-Martínez, J.; Toscano, R. A.; HernándezOrtega, S. Structural Studies of Three Isomeric Forms of Heterocyclic N(4)-Substituted Thiosemicarbazones and Two Nickel(II) Complexes. Polyhedron 1996, 15, 665-674.

(42) Pessôa, M. M. B.; Andrade, G. F. S.; Paoli Monteiro, V. R.; Temperini, M. L. A. 2-Formylpyridinethiosemicarbazone and Methyl Derivatives: Spectroscopic Studies. Polyhedron 2001, 20, 3133-3141.

(43) Kowol, C. R.; Eichinger, R.; Jakupec, M. A.; Galanski, M.; Arion, V. B.; Keppler, B. K. Effect of Metal Ion Complexation and Chalcogen Donor Identity on the Antiproliferative Activity of 2Acetylpyridine N,N-Dimethyl(Chalcogen)Semicarbazones. J. Inorg. Biochem. 2007, 101, 1946-1957.

(44) Venkatachalam, T. K.; Pierens, G. K.; Reutens, D. C. Synthesis, NMR Structural Characterization and Molecular Modeling of Substituted Thiosemicarbazones and Semicarbazones Using DFT Calculations to Prove the Syn/Anti Isomer Formation. Magn. Reson. Chem. 2014, 52, 98-105.

(45) Kessler, H. Detection of Hindered Rotation and Inversion by NMR Spectroscopy. Angew. Chem., Int. Ed. Engl. 1970, 9, 219-235.

(46) Walker, D.; Hiebert, J. D. 2,3-Dichloro-5,6-Dicyanobenzoquinone and Its Reactions. Chem. Rev. 1967, 67, 153-195.

(47) Huynh, M. T.; Anson, C. W.; Cavell, A. C.; Stahl, S. S.; Hammes-Schiffer, S. Quinone $1 \mathrm{e}^{-}$and $2 \mathrm{e}^{-} / 2 \mathrm{H}^{+}$Reduction Potentials: Identification and Analysis of Deviations from Systematic Scaling Relationships. J. Am. Chem. Soc. 2016, 138, 15903-15910.

(48) Gil-García, R.; Fraile, R.; Donnadieu, B.; Madariaga, G.; Januskaitis, V.; Rovira, J.; González, L.; Borrás, J.; Arnáiz, F. J.; GarcíaTojal, J. Desulfurization Processes of Thiosemicarbazonecopper(II) Derivatives in Acidic and Basic Aqueous Media. New J. Chem. 2013, $37,3568-3580$.

(49) Tokuyama, H.; Yamashita, T.; Reding, M. T.; Kaburagi, Y.; Fukuyama, T. Radical Cyclization of 2-Alkenylthioanilides: A Novel
Synthesis of 2,3-Disubstituted Indoles. J. Am. Chem. Soc. 1999, 121, 3791-3792.

(50) Budnikova, Y.; Dudkina, Y.; Khrizanforov, M. Redox-Induced Aromatic $\mathrm{C}-\mathrm{H}$ Bond Functionalization in Metal Complex Catalysis from the Electrochemical Point of View. Inorganics 2017, 5, 70.

(51) Avdeenko, A. P.; Konovalova, S. A.; Sergeeva, A. G.; Zubatyuk, R. I.; Palamarchuk, G. V.; Shishkin, O. V. Synthesis and Structure of N-Alkyl(Aryl)Aminocarbonyl-1,4-Benzoquinone Imines. Russ. J. Org. Chem. 2008, 44, 1765-1772.

(52) Zaltariov, M. F.; Hammerstad, M.; Arabshahi, H. J.; Jovanović, K.; Richter, K. W.; Cazacu, M.; Shova, S.; Balan, M.; Andersen, N. H.; Radulović, S.; Reynisson, J.; Andersson, K. K.; Arion, V. B. New Iminodiacetate-Thiosemicarbazone Hybrids and Their Copper(II) Complexes Are Potential Ribonucleotide Reductase R2 Inhibitors with High Antiproliferative Activity. Inorg. Chem. 2017, 56, 35323549 .

(53) Hosseini-Yazdi, S. A.; Mirzaahmadi, A.; Khandar, A. A.; Eigner, V.; Dušek, M.; Mahdavi, M.; Soltani, S.; Lotfipour, F.; White, J. Reactions of Copper(II), Nickel(II), and Zinc(II) Acetates with a New Water-Soluble 4-Phenylthiosemicarbazone Schiff Base Ligand: Synthesis, Characterization, Unexpected Cyclization, Antimicrobial, Antioxidant, and Anticancer Activities. Polyhedron 2017, 124, 156165.

(54) Kowol, C. R.; Reisner, E.; Chiorescu, I.; Arion, V. B.; Galanski, M.; Deubel, D. V.; Keppler, B. K. An Electrochemical Study of Antineoplastic Gallium, Iron and Ruthenium Complexes with Redox Noninnocent $\alpha$-N-Heterocyclic Chalcogensemicarbazones. Inorg. Chem. 2008, 47, 11032-11047.

(55) Bacher, F.; Dömötör, O.; Chugunova, A.; Nagy, N. V.; Filipović, L.; Radulović, S.; Enyedy, É. A.; Arion, V. B. Strong Effect of Copper(II) Coordination on Antiproliferative Activity of Thiosemicarbazone-Piperazine and Thiosemicarbazone-Morpholine Hybrids. Dalton Trans. 2015, 44, 9071-9090.

(56) Leovac, V. M.; Bogdanović, G. A.; Jovanović, L. S.; Joksović, L.; Marković, V.; Joksović, M. D.; Denčić, S. M.; Isaković, A.; Marković, I.; Heinemann, F. W.; Trifunović, S.; Đalović, I. Synthesis, Characterization and Antitumor Activity of Polymeric Copper(II) Complexes with Thiosemicarbazones of 3-Methyl-5-Oxo-1-Phenyl-3Pyrazolin-4-Carboxaldehyde and 5-Oxo-3-Phenyl-3-Pyrazolin-4-Carboxaldehyde. J. Inorg. Biochem. 2011, 105, 1413-1421.

(57) García-Tojal, J.; Urtiaga, M. K.; Cortés, R.; Lezama, L.; Arriortua, M. I.; Rojo, T. Synthesis, Structure, Spectroscopic and Magnetic Properties of Two Copper(II) Dimers Containing Pyridine2-Carbaldehyde Thiosemicarbazonate $(\mathrm{L}),\left[\{\mathrm{CuL}(\mathrm{X})\}_{2}\right](\mathrm{X}=\mathrm{Cl}$ or Br). J. Chem. Soc., Dalton Trans. 1994, 2233-2238.

(58) Kowol, C. R.; Heffeter, P.; Miklos, W.; Gille, L.; Trondl, R.; Cappellacci, L.; Berger, W.; Keppler, B. K. Mechanisms Underlying Reductant-Induced Reactive Oxygen Species Formation by Anticancer Copper(II) Compounds. J. Biol. Inorg. Chem. 2012, 17, 409423.

(59) Arion, V. B. Coordination Chemistry of S-Substituted Isothiosemicarbazides and Isothiosemicarbazones. Coord. Chem. Rev. 2019, 387, 348-397.

(60) Graur, V.; Usataia, I.; Bourosh, P.; Kravtsov, V.; Garbuz, O.; Hureau, C.; Gulea, A. Synthesis, Characterization, and Biological Activity of Novel $3 d$ Metal Coordination Compounds with 2Acetylpyridine $\mathrm{N}^{4}$-Allyl-S-methylisothiosemicarbazone. Appl. Organomet. Chem. 2021, 35, e6172.

(61) Mahmoudi, G.; Castiñeiras, A.; Garczarek, P.; Bauzá, A.; Rheingold, A. L.; Kinzhybalo, V.; Frontera, A. Synthesis, X-ray Characterization, DFT Calculations and Hirshfeld Surface Analysis of Thiosemicarbazone Complexes of $\mathrm{M}^{\mathrm{n}+}$ Ions $(\mathrm{n}=2,3 ; \mathrm{M}=\mathrm{Ni}, \mathrm{Cd}$, $\mathrm{Mn}, \mathrm{Co}$ and $\mathrm{Cu}$ ). CrystEngComm 2016, 18, 1009-1023.

(62) Lawrence, H. R.; Li, Z.; Richard Yip, M. L.; Sung, S.-S.; Lawrence, N. J.; McLaughlin, M. L.; McManus, G. J.; Zaworotko, M. J.; Sebti, S. M.; Chen, J.; Guida, W. C. Identification of a Disruptor of the MDM2-P53 Protein-Protein Interaction Facilitated by HighThroughput in Silico Docking. Bioorg. Med. Chem. Lett. 2009, 19, $3756-3759$ 
(63) Pape, V. F. S.; Tóth, S.; Füredi, A.; Szebényi, K.; Lovrics, A.; Szabó, P.; Wiese, M.; Szakács, G. Design, Synthesis and Biological Evaluation of Thiosemicarbazones, Hydrazinobenzothiazoles and Arylhydrazones as Anticancer Agents with a Potential to Overcome Multidrug Resistance. Eur. J. Med. Chem. 2016, 117, 335-354.

(64) Chen, G.; Niu, C.; Yi, J.; Sun, L.; Cao, H.; Fang, Y.; Jin, T.; Li, Y.; Lou, C.; Kang, J.; Wei, W.; Zhu, J. Novel Triapine Derivative Induces Copper-Dependent Cell Death in Hematopoietic Cancers. J. Med. Chem. 2019, 62, 3107-3121.

(65) Dneprovskaya, E. V.; Holzwarth, M. S. Compounds and Methods for Treating Cancer. WO2018/081612 A1, 2018.

(66) Addison, A. W.; Rao, T. N.; Reedijk, J.; van Rijn, J.; Verschoor, G. C. Synthesis, Structure, and Spectroscopic Properties of Copper(II) Compounds Containing Nitrogen-Sulphur Donor Ligands; the Crystal and Molecular Structure of Aqua[1,7-Bis(N-Methylbenzimidazol-2'-Yl)-2,6-Dithiaheptane]Copper(II) Perchlorate. J. Chem. Soc., Dalton Trans. 1984, 1349-1356.

(67) Dömötör, O.; May, N. V.; Pelivan, K.; Kiss, T.; Keppler, B. K.; Kowol, C. R.; Enyedy, E. A. A Comparative Study of $\alpha$-N-Pyridyl Thiosemicarbazones: Spectroscopic Properties, Solution Stability and Copper(II) Complexation. Inorg. Chim. Acta 2018, 472, 264-275.

(68) Enyedy, E. A.; Primik, M. F.; Kowol, C. R.; Arion, V. B.; Kiss, T.; Keppler, B. K. Interaction of Triapine and Related Thiosemicarbazones with Iron(III)/(II) and Gallium(III): A Comparative Solution Equilibrium Study. Dalton Trans. 2011, 40, 5895-5905.

(69) Enyedy, É. A.; Zsigó, É.; Nagy, N. V.; Kowol, C. R.; Roller, A.; Keppler, B. K.; Kiss, T. Complex-Formation Ability of Salicylaldehyde Thiosemicarbazone towards $\mathrm{Zn}^{\mathrm{II}}, \mathrm{Cu}^{\mathrm{II}}, \mathrm{Fe}^{\mathrm{II}}, \mathrm{Fe}^{\mathrm{III}}$ and $\mathrm{Ga}^{\mathrm{III}}$ Ions. Eur. J. Inorg. Chem. 2012, 4036-4047.

(70) Cyclic Voltammetry: Simulation and Analysis of Reaction Mechanisms; Gosser, D. K., Ed.; VCH: New York, 1993.

(71) Dvoranová, D.; Barbieriková, Z.; Dorotíková, S.; Malček, M.; Brincko, A.; Rišpanová, L.; Bučinský, L.; Staško, A.; Brezová, V.; Rapta, P. Redox Processes of 2,6-Dichlorophenolindophenolate in Different Solvents. A Combined Electrochemical, Spectroelectrochemical, Photochemical, and Theoretical Study. J. Solid State Electrochem. 2015, 19, 2633-2642.

(72) Quan, M.; Sanchez, D.; Wasylkiw, M. F.; Smith, D. K. Voltammetry of Quinones in Unbuffered Aqueous Solution: Reassessing the Roles of Proton Transfer and Hydrogen Bonding in the Aqueous Electrochemistry of Quinones. J. Am. Chem. Soc. 2007, 129, 12847-12856.

(73) Hickey, J. L.; Lim, S.; Hayne, D. J.; Paterson, B. M.; White, J. M.; Villemagne, V. L.; Roselt, P.; Binns, D.; Cullinane, C.; Jeffery, C. M.; Price, R. I.; Barnham, K. J.; Donnelly, P. S. Diagnostic Imaging Agents for Alzheimer's Disease: Copper Radiopharmaceuticals That Target A $\beta$ Plaques. J. Am. Chem. Soc. 2013, 135, 16120-16132.

(74) Fedorova, O. A.; Shepel, N. E.; Tokarev, S. D.; Lukovskaya, E. V.; Sotnikova, Y. A.; Moiseeva, A. A.; D’Aléo, A.; Fages, F.; Maurel, F.; Fedorov, Y. V. Intramolecular Electron Transfer in $\mathrm{Cu}(\mathrm{II})$ Complexes with Aryl-Imidazo-1,10-Phenanthroline Derivatives: Experimental and Quantum Chemical Calculation Studies. New J. Chem. 2019, 43, 2817-2827.

(75) Ashfield, L. J.; Cowley, A. R.; Dilworth, J. R.; Donnelly, P. S. Functionalized Thiosemicarbazone Clusters of Copper(I) and Silver(I). Inorg. Chem. 2004, 43, 4121-4123.

(76) Lhuachan, S.; Siripaisarnpipat, S.; Chaichit, N. Synthesis, Spectra and Crystal Structure of Two Copper(I) Complexes of Acetonethiosemicarbazone. Eur. J. Inorg. Chem. 2003, 263-267.

(77) Petrasheuskaya, T. V.; Kiss, M. A.; Dömötör, O.; Holczbauer, T.; May, N. V.; Spengler, G.; Kincses, A.; Čipak Gašparović, A.; Frank, E.; Enyedy, E. A. Salicylaldehyde Thiosemicarbazone Copper Complexes: Impact of Hybridization with Estrone on Cytotoxicity, Solution Stability and Redox Activity. New J. Chem. 2020, 44, 1215412168.

(78) Hall, I. H.; Peaty, N. J.; Henry, J. R.; Easmon, J.; Heinisch, G.; Pürstinger, G. Investigations on the Mechanism of Action of the Novel Antitumor Agents 2-Benzothiazolyl, 2-Benzoxazolyl, and 2-
Benzimidazolyl Hydrazones Derived from 2-Acetylpyridine. Arch. Pharm. 1999, 332, 115-123.

(79) Pape, V. F. S.; Tóth, S.; Füredi, A.; Szebényi, K.; Lovrics, A.; Szabó, P.; Wiese, M.; Szakács, G. Design, Synthesis and Biological Evaluation of Thiosemicarbazones, Hydrazinobenzothiazoles and Arylhydrazones as Anticancer Agents with a Potential to Overcome Multidrug Resistance. Eur. J. Med. Chem. 2016, 117, 335-354.

(80) Plamthottam, S.; Sun, D.; Van Valkenburgh, J.; Valenzuela, J.; Ruehle, B.; Steele, D.; Poddar, S.; Marshalik, M.; Hernandez, S.; Radu, C. G.; Zink, J. I. Activity and Electrochemical Properties: Iron Complexes of the Anticancer Drug Triapine and Its Analogs. J. Biol. Inorg. Chem. 2019, 24, 621-632.

(81) Le, T. M.; Poddar, S.; Capri, J. R.; Abt, E. R.; Kim, W.; Wei, L.; Uong, N. T.; Cheng, C. M.; Braas, D.; Nikanjam, M.; Rix, P.; Merkurjev, D.; Zaretsky, J.; Kornblum, H. I.; Ribas, A.; Herschman, H. R.; Whitelegge, J.; Faull, K. F.; Donahue, T. R.; Czernin, J.; Radu, C. G. ATR Inhibition Facilitates Targeting of Leukemia Dependence on Convergent Nucleotide Biosynthetic Pathways. Nat. Commun. 2017, 8, 241.

(82) Dvoranová, D.; Barbieriková, Z.; Brezová, V. Radical Intermediates in Photoinduced Reactions on TiO2 (An EPR Spin Trapping Study). Molecules 2014, 19, 17279-17304. 